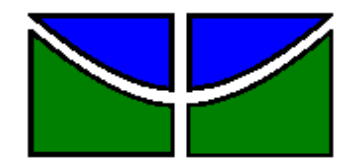

UNIVERSIDADE DE BRASÍLIA

FACULDADE DE MEDICINA

PROGRAMA DE PÓS-GRADUAÇÃO EM MEDICINA TROPICAL

Fernanda Dockhorn Costa Johansen

FATORES ASSOCIADOS AO ÓBITO POR COINFECÇÃO TUBERCULOSE E HIV NO BRASIL EM 2011

BRASÍLIA 


\title{
FATORES ASSOCIADOS AO ÓBITO POR COINFECÇÃO TUBERCULOSE E HIV NO BRASIL
}

\author{
Fernanda Dockhorn Costa Johansen
}

\begin{abstract}
Dissertação de Mestrado apresentada ao Programa de Pós-Graduação em Medicina Tropical da Faculdade de Medicina da Universidade de Brasília para a obtenção do título de mestre em Medicina Tropical, na área de concentração: Clínica das Doenças Infecciosas e Parasitárias.
\end{abstract}

Orientador: Dr. Wildo Navegantes de Araújo Co-orientador: Dr. Mauro Niskier Sanchez

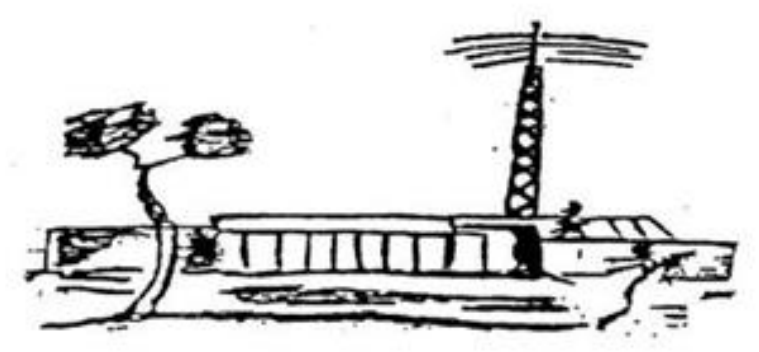

Brasília 
Ficha catalográfica elaborada automaticamente, com os dados fornecidos pelo(a) autor(a)

Johansen, Fernanda Dockhorn
FJ65foRES ASSOCIADOS AO OBITO POR CoINFECÇão
TUBERCULOSE E HIV NO BRASIL EM 2011 / Fernanda
Dockhorn Johansen; orientador Wildo Navegantes
Araújo; co-orientador Mauro Niskier Sanchez. --
Brasilia, 2015.
$128 \mathrm{p.}$
Dissertação (Mestrado - Mestrado em Medicina
Tropical) -- Universidade de Brasilia, 2015.
1. Tuberculose. 2. HIV. 3. Obito. 4. Fatores
associados. 5. Caso-controle. I. Araújo, Wildo
Navegantes, orient. II. Sanchez, Mauro Niskier, co
orient. III. Titulo.




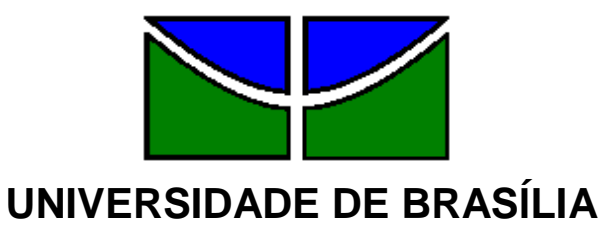

FACULDADE DE MEDICINA

PROGRAMA DE PÓS-GRADUAÇÃO EM MEDICINA TROPICAL

\title{
FATORES ASSOCIADOS AO ÓBITO POR COINFECÇÃO TUBERCULOSE E HIV NO BRASIL EM 2011
}

\author{
DATA DA DEFESA
}

05 de agosto de 2015

COMPOSIÇÃO DA BANCA EXAMINADORA

Josué Nazareno de Lima - Secretaria Municipal de Saúde de Campinas

Rossana Coimbra Brito - Hospital Federal dos Servidores do Estado

Daniel Roberto Coradi de Freitas - Agência Nacional de Vigilância

Sanitária/ANVISA (Suplente)

Wildo Navegantes de Araújo - Universidade de Brasília (orientador) 


\section{DEDICATÓRIA}

In memorian de Horário Johansen, que tão recentemente nos deixou. Me ensinou o valor da família e de se estar junto daqueles que amamos. Aprendi a valorizar ainda mais o próximo, na força do trabalho e na dedicação para o crescimento pessoal e profissional. Faz muita falta para a família e amigos. 


\section{AGRADECIMENTOS}

Depois de dois anos de correria, angustias e muito estudo finalmente esse momento chegou. Gostaria de agradecer ao Faber pelo intenso incentivo, parceria e compreensão, obrigada pela ajuda e companheirismo em todos os momentos da nossa vida juntos.

À minha família que apesar da distância sempre estiveram presentes em todos os momentos da minha vida com apoio e segurança. Sempre valorizaram a minha formação pessoal e profissional, com incentivo e amor incondicional.

Ao meu orientador Prof. Wildo Navegantes, pelos ensinamentos, apoio e por me dar a oportunidade de crescimento e força para continuar sempre em frente. A você muita admiração e respeito. Ao meu co-orientador e amigo Prof. Mauro Sanchez, pela paciência e apoio nos momentos de tensão e pelas horas de discussão na construção desse trabalho.

Á colega de trabalho e amiga Prof ${ }^{a}$ Maria do Socorro Evangelista, que contribuiu significativamente para essa dissertação, obrigada pela ajuda quando eu mais precisava. À amiga Denise Arakaki-Sanchez, pelo apoio, aprendizados e por compartilhar o prazer e a alegria de trabalhar. Aos amigos Lucas e Lourdinha, que tão bem me acolheram em Brasília e que me incluíram na sua família, sempre muito obrigada pelo apoio.

Não podia deixar de agradecer à Paty Bartholomay, Ana Torrens, Daniela Pelissari e Cintia Dantas pela paciência nos momentos mais inesperados, pelo importante aprendizado e apoio nos momentos de angústia. Ao Draurio, coordenador do PNCT, que me possibilitou cursar e defender esse mestrado, pela flexibilidade e visão na construção de um mundo melhor. Aos meus amigos do PNCT, principalmente da área de atenção, pela possibilidade desse crescimento e apoio nesses dois anos de estudo, sei que foram dias de muita correria, ansiedades e momentos de ausência, meu muito obrigada!

Aos meus colegas da UnB, foi muito bom compartilhar esse momento com vocês. 


\section{LISTA DE FIGURAS}

Figura 1: Algoritmo de inclusão na população de estudo.

Figura 2: Representação do relacionamento dos bancos de dados do estudo 


\section{LISTA DE GRÁFICOS}

Gráfico 1: Taxa de incidência de TB (100.000 habitantes), por Unidade Federada, 2013.

Gráfico 2: Taxa de mortalidade por TB (100.000 habitantes), por Unidade Federada, 2013.

Gráfico 3: Percentual de casos novos de TB que realizaram exame anti-HIV. Brasil, 2001-2013. 


\section{LISTAS DE TABELAS}

Artigo: Fatores associados ao óbito por coinfecção Tuberculose e HIV no Brasil.

Tabela 1: Distribuição das características sociodemográficas entre os casos (óbitos com coinfecção TB-HIV) e os controles (coinfecção TB-

HIV com cura da TB) no Brasil, 2011

Tabela 2: Distribuição das características clínicas entre os casos (óbitos com coinfecção TB-HIV) e dos controles (coinfecção TB-HIV com cura da TB) no Brasil, 2011

Tabela 3: Fatores associados ao óbito em pacientes com coinfecção tuberculose e HIV no Brasil, 2011 


\section{LISTAS DE ABREVIATURAS E SIGLAS}

\begin{tabular}{|c|c|}
\hline 3TC & Lamivudina \\
\hline$A B C$ & Abacavir \\
\hline ADA & Adenosina Deaminase \\
\hline AIDS & Síndrome da Imunodeficiência Adquirida \\
\hline antiTB & AntiTuberculose \\
\hline ARV & Antirretroviral \\
\hline AZT & Zidovudina \\
\hline BAAR & Bacilo Álcool-Ácido Resistente \\
\hline DNA & Ácidos Desoxirribonucléicos \\
\hline DO & Declaração de Óbito \\
\hline DOTS & Directly Observed Treatment Short-Course \\
\hline DST & Doenças Sexualmente Transmissíveis \\
\hline E & Etambutol \\
\hline et. $A /$ & et. Al Et alter (e outro) \\
\hline $\mathrm{H}$ & Isoniazida \\
\hline HIV & Vírus da Imunodeficiência Humana \\
\hline ID & Variável Identificadora \\
\hline ILTB & Infecção Latente da Tuberculose \\
\hline IP & Inibidores da Protease \\
\hline ITRN & Transcriptase Reversa Análogos de Nucleosídeos \\
\hline ITRNN & $\begin{array}{l}\text { Inibidores da Transcriptase Reversa não } \\
\text { Nucleosídeos }\end{array}$ \\
\hline LT & Células Linfócito T \\
\hline LT-CD4+ & Linfócitos T CD4+ \\
\hline MS & Ministério da Saúde \\
\hline ODM & Objetivos de Desenvolvimento do Milênio \\
\hline OMS & Organização Mundial de Saúde \\
\hline ONU & Organização das Nações Unidas \\
\hline PCR & $\begin{array}{l}\text { Polimerase chain reaction - Reação da Polimerase } \\
\text { em Cadeia }\end{array}$ \\
\hline PNI & Programa Nacional de Imunizações \\
\hline $\mathrm{PO}_{2}$ & Pressão Parcial de Oxigênio \\
\hline PPD & Derivado Proteico Purificado \\
\hline PT & Prova Tuberculínica \\
\hline PVHA & Pessoas Vivendo com HIV/aids \\
\hline $\mathrm{R}$ & Rifampicina \\
\hline $\mathrm{RH}$ & Rifampicina, Isoniazida \\
\hline $\mathrm{RHZE}$ & Rifampicina, Isoniazida, Pirazinamida e Etambutol \\
\hline RNA & Ácidos Ribonucléicos \\
\hline RTR-TB & Rede de Teste Rápido para Tuberculose \\
\hline SAE & $\begin{array}{l}\text { Serviços de Atenção Especializada a Pessoas } \\
\text { Vivendo com HIV/aids }\end{array}$ \\
\hline Siclom & Sistema de Controle Logístico de Medicamentos \\
\hline
\end{tabular}




$\begin{array}{ll}\text { SIM } & \text { Sistema de Informações de Mortalidade } \\ \text { Sinan } & \text { Sistema de Informação de Agravos de Notificação } \\ \text { SIRI } & \text { Síndrome Inflamatória da Reconstituição Imune } \\ \text { Siscel } & \text { Sistema de Controle de Exames Laboratoriais } \\ \text { SITETB } & \text { Sistema de Informação de Tratamentos Especiais de } \\ \text { SUS } & \text { Tuberculose } \\ \text { TARV } & \text { Sistema Único de Saúde } \\ \text { TE } & \text { Terapia Antirretroviral } \\ \text { TB } & \text { Tuberculose } \\ \text { TB DR } & \text { Tuberculose Drogarresistente } \\ \text { TB MDR } & \text { Tuberculose Multidrogarresistente } \\ \text { TB XDR } & \text { Tuberculose com Resistência Extensiva } \\ \text { TDF } & \text { Tenofovir } \\ \text { TDO } & \text { Tratamento Diretamente Observado } \\ \text { TRM-TB } & \text { Teste Rápido Molecular para Tuberculose } \\ \text { TS } & \text { Teste de Sensibilidade } \\ \text { WHO } & \text { World Health Organization } \\ \text { Z } & \text { Pirazinamida }\end{array}$




\section{FINANCIAMENTO}

Apoio financeiro com bolsa de mestrado da Coordenação de Aperfeiçoamento de Pessoal de Nível Superior (CAPES). 


\section{INDICE}

LISTA DE FIGURAS

LISTA DE GRÁFICOS

LISTA DE TABELAS $\mathbf{9}$

LISTA DE ABREVIATURAS E SIGLAS 10

FINANCIAMENTO 12

RESUMO 15

$\begin{array}{ll}\text { ABSTRACT } & 16\end{array}$

1. INTRODUÇÃO 17

2. JUSTIFICATIVA 46

3. OBJETIVOS 47

3.1 Objetivo geral $\quad \mathbf{4 7}$

3.2 Objetivos específicos $\quad \mathbf{4 7}$

4. MÉTODOS 48

4.1 Tipo de estudo $\quad 48$

4.2 Fontes de dados $\quad \mathbf{4 8}$

4.3 População do estudo $\quad 48$

4.4 Critérios de inclusão e exclusão $\quad 49$

4.4.1 Critério de inclusão $\quad 49$

4.4.2 Critério de exclusão $\quad 49$

4.5 Relacionamento das bases de dados $\quad \mathbf{5 0}$

4.5.1 Linkage com o SIM $\mathbf{5 1}$

4.6 Análise dos dados e definições das variáveis $\mathbf{5 2}$

4.7 Aspectos éticos $\quad \mathbf{5 4}$

5. RESULTADOS 56

6. CONSIDERAÇÕES FINAIS 95

7. REFERÊNCIAS BIBLIOGRÁFICAS 97

8. ANEXOS 111

Anexo I: Ficha de Notificação e Investigação da Tuberculose. 111 
Anexo II: Boletim de Acompanhamento da Tuberculose

Anexo III: Nova Ficha de Notificação e Investigação da Tuberculose (a partir de 2015).

113

Anexo IV: Boletim de Acompanhamento da Tuberculose (versão 2015).

Anexo V: Tabela com as Atividades colaborativas TB-HIV por objetivo. OMS 2012.

Anexo VI: Ficha de notificação e investigação da AIDS.

Anexo VII: Fichas de solicitação de exames do SISCEL.

118

Anexo VIII: Formulário de Solicitação de Medicamentos -

SICLOM (modelo utilizado em 2011).

Anexo X: Liberação de base de dados da Secretaria de Vigilância em Saúde.

Anexo XI- Termo de Responsabilidade e Compromisso do Pesquisador. 


\section{RESUMO}

Johansen, Fernanda. Fatores associados ao óbito por coinfecção Tuberculose e HIV no Brasil em 2011. Dissertação (Mestrado em Clínica das Doenças Infecciosas e Parasitárias) - Programa de Pós-Graduação em Medicina Tropical, Universidade de Brasília. Brasília, 2015.

Ainda que com o advento da terapia antorretroviral a tuberculose continua como a principal causa de óbito por doença infecciosa definida entre as pessoas que vivem com HIV/aids. O objetivo desse trabalho foi verificar os fatores associados ao óbito na coinfecção TB-HIV no Brasil no ano de 2011. Foi realizado um estudo do tipo caso controle, com análise por regressão logística multivariada. A fonte de dados para os casos de tuberculose foi 0 Sinan TB. Com o objetivo de qualificar os dados, o Sinan TB foi relacionado com o Sinan Aids, Siscel e Siclom. Para verificação dos óbitos foi realizado o relacionamento com o SIM. Nos resultados, demonstrou-se que os fatores de risco para o óbito foram: idade $>50$ anos (OR=2,48; IC95\% 1,01 a 6,08), uso de álcool (OR=1,84; IC95\% 1,45 a 2,34) e forma clínica da TB (pulmonar e extrapulmonar) (OR=1,85; IC95\% 1,36 a 2,52). Os fatores observados como proteção foram: a realização do LT-CD4+ (OR=0,68; IC95\% 0,54 a 0,86), estar em TARV (OR=0,50; IC95\%0,39 a 063) e estar em TDO (OR=0,69; IC95\% 0,39 a 0,63$)$. Os resultados demonstram uma situação de alerta em relação a coinfecção TB-HIV no Brasil, apesar dos avanços na estruturação da assistência à saúde no país, o acesso a um seguimento da coinfecção TB-HIV integral ainda é limitado, o que favorece a alta mortalidade nessa população. Há necessidade de revisão das estratégias nacionais, com priorização da coinfecção TB-HIV pelos programas de tuberculose e de HIV/Aids, matriciamento da assistência de tal modo que profissionais capacitados façam o diagnóstico oportuno da tuberculose e do HIV, além do início em tempo adequado do tratamento antirretroviral. 


\begin{abstract}
Johansen, Fernanda. Risk factors for death in tuberculosis and HIV co-infection in Brazil in 2011. Brasília, 2015
\end{abstract}

Even with the advent of antiretroviral therapy, tuberculosis still remains the main cause of death from infectious disease among people living with HIV / AIDS. The purpose of this study was to verify the associated factors with TB and HIV co-infection deaths in Brazil in 2011. A case-control study was conducted through multivariate logistic regression analysis. The Information System for Notifiable Diseases (Sinan) was the data source for TB cases, and for data qualification other databases from the Ministry of Health were used, such as: laboratory (Siscel), antiretroviral (Siclom) and Sinan AIDS databases, and from the Mortality Information System (SIM). The results were considered risk factors for mortality: age> 50 years (OR=2.48; IC95\% 1.01 to 6.08$)$, alcohol use $(\mathrm{OR}=1.84 ; \mathrm{IC} 95 \% 1.45$ to 2.34$)$ and clinical form of pulmonary and extrapulmonary TB $(\mathrm{OR}=1.85 ; \mathrm{IC} 95 \% 1.36$ to 2.52$)$. Factors considered protection were the LT-CD4+ conducted ( $\mathrm{OR}=0.68$; IC95\% 0.54 to 0.86 ), being on ART (OR=0.50; IC95\%0.39 a 0.63) and be in DOT (OR=0.69; IC95\% 0.39 a 0.63). The results describe an alarm situation related to TB/HIV co-infection in Brazil. Despite the progresses related to the structure reform in the health care services in the country, access to TB/HIV integral follow up is still limited, which favors high mortality rates among this population. There is an evident need for national strategies updates regarding recognizing the importance of TB/HIV coinfection to both diseases programmes (TB and HIV/AIDS). The organization of assistance so that trained providers are able to early diagnose TB and HIV, in addition to timely starting antiretroviral treatment. 


\section{INTRODUÇÃO}

A tuberculose (TB), causada pelo Mycobacterium tuberculosis teve seu bacilo identificado por Robert Koch em 1882. Somente nessa época que foi descrito seu caráter infecto-contagioso. Após esse período foram décadas de avanços no diagnóstico e tratamento, com a descoberta do raio $X$, da estreptomicina e da vacinação, esses dois últimos já no século XX (Farga et al., 2011). Existe muita especulação sobre a origem da tuberculose na espécie humana, sabe-se que é uma das mais antigas enfermidades que acometem a humanidade. Estima-se que o Mycobacterium tenha origem na antiguidade há cerca de 15 mil a 20 mil anos, a bactéria foi evoluindo e se adaptando ao meio ambiente ao longo dos anos até o surgimento do Mycobacterium bovis, primeira espécie a acometer a espécie humana. Uma das teorias mais aceitas indica que o Mycobacterium tuberculosis teve origem do M. bovis (Caminero, 2003).

A TB se mantém como um grave problema de saúde pública de relevância mundial, apesar de todos os esforços das últimas décadas para seu controle (Caminero, 2003, Kritski et al., 2007) e continua a obedecer a todos os critérios de priorização de um agravo em saúde pública, pois apresenta grande magnitude, transcendência e vulnerabilidade (Barreira et al., 2007, Brasil, 2014g).

No Brasil, desde o século XIX, a tuberculose vem apresentando importante queda na sua incidência com a melhoria da condição de vida da população. Ainda em 1927 foi instituída nacionalmente a vacinação pela BCG, tornando-se possível a prevenção das formas graves da doença. A descoberta da estreptomicina na década de 40 foi um importante aspecto para a possibilidade terapêutica da doença, assim como influenciou na queda da incidência (Hijjar et al., 2007).

A manutenção da TB como um grave problema de saúde pública no Brasil e no mundo deve-se entre outros fatores, ao empobrecimento de grande parte da população, ao uso de drogas ilícitas, aumento dos índices de migrações internas e externas, envelhecimento da população, má nutrição, 
aumento da taxa de abandono ao tratamento da tuberculose, ao aparecimento da resistência a múltiplos medicamentos antituberculose (antiTB) e em grande parte ao advento da pandemia do Vírus da Imunodeficiência Humana (HIV) na década de 80 (Kritski et al., 2007; Brasil, 2007;Guimarães et al., 2010).

A infecção pelo HIV é considerada um dos fatores mais importantes relacionados ao risco de adoecer por TB acarretando alterações na história natural de ambas as doenças (Antonucci et al., 1995; Lourdes et al., 2009).

\section{Definição da TB}

A tuberculose é uma doença infecciosa e transmissível, que tem como agente causador o bacilo denominado Mycobacterium tuberculosis. Afeta prioritariamente os pulmões, porém pode acometer outros órgãos e sistemas (Fiuza de Melo, 1993; Farga et al., 2011).

\section{Agente etiológico da tuberculose}

O Mycobacterium tuberculosis, também conhecido como bacilo de Koch é um bacilo álcool-ácido resistente (BAAR), fino, levemente encurvado e possui de 1 a 4 micra de comprimento. É considerado um parasita aeróbio intracelular, que não produz toxinas, e apresenta multiplicação lenta. Possui parede celular rica em lipídios, o que the garante baixa permeabilidade, facilita a sua sobrevivência nos macrófagos e reduz a ação da maioria dos antibióticos (Mandell, 2010).

A TB pode ser causada por qualquer uma das sete espécies que integram o Complexo Mycobacterium tuberculosis: M. tuberculosis, M. bovis, $M$. africanum, M. canetti, M. microti, $M$. pinnipedi e $M$. caprae, sendo a espécie considerada mais importante a M. tuberculosis (Brasil, 2008a).

Outras espécies de micobactérias podem produzir quadro clínico semelhante à tuberculose, sendo necessária a realização de exames mais específicos para seu diagnóstico diferencial (Farga et al., 2011). 


\section{Agente etiológico do HIV/Aids}

A infecção pelo HIV é causada pelos retrovírus HIV-1 e HIV-2, da família Lentiviridae. São retrovírus citopáticos (apresentam preferência por células e causam lesão celular) necessitando para replicação de uma enzima denominada transcriptase reversa, responsável pela transcrição do ácidos ribonucleicos (RNA) virais para uma cópia do ácido desoxirribonucléico (DNA), permitindo que o vírus se integre ao genoma do ser humano (Clavel et al., 1986, Santos et al., 2009).

\section{Coinfecção tuberculose e HIV/aids}

A coinfecção TB-HIV se estabelece quando o paciente apresenta TB ativa e infecção pelo HIV/aids simultaneamente. $O$ indivíduo pode ter 0 diagnóstico de TB ativa, sendo o diagnóstico do HIV realizado posteriormente, ou já conhecer o seu "status sorológico" para o HIV e apresentar TB ativa ao longo do seu seguimento (Brasil, 2013c).

A pessoa com HIV/aids tem risco de apresentar tuberculose, por reinfecção ou reativação da doença, por uma disfunção do seu sistema imunológico, com queda dos linfócitos T CD4+ (LT-CD4+). A infecção por TB pode se apresentar em qualquer fase da vida da PVHA, independentemente da contagem dos LT-CD4+ (Antonucci et al., 1995). Dependendo do nível de imunodepressão, há um maior risco de infecção, a depender da epidemiologia local, e de formas clínicas disseminadas. Além disso, o M. tuberculosis ativa a replicação viral do HIV, o que favorece ao avanço da imunossupressão (da Silva Santos et al., 2009). Quando a PVHA está com imunodrepressão grave ele apresenta a síndrome da imunodeficiência adquirida (AIDS) (Yang et al. 2004).

Quando o indivíduo apresenta uma imunodepressão avançada com várias infecções oportunistas (IO), causadas por microrganismos não considerados usualmente patogênicos, evidenciando um sistema imune anormal, caracteriza-se a AIDS (Brasil, 2013c). 
A coinfecção da TB com o HIV elevou os coeficientes de incidência, prevalência e mortalidade da TB em todo o mundo, principalmente no continente africano, onde ocorrem cerca de um terço dos casos da TB do mundo (Charisson \& Martinson 2008;Mugusi et al. 2009).

A estratégia para o manejo da coinfecção TB-HIV no Brasil vem sendo construída conjuntamente pelo Ministério da Saúde por meio do Programa Nacional de Controle da Tuberculose e o Departamento de DST, Aids e Hepatites Virais, responsáveis por estabelecer recomendações técnicas e operacionais a serem implementadas por programas estaduais e municipais, promovendo as relações interfederativas para execução das atividades conjuntas planejadas (Brasil 2014c).

Para o controle da coinfecção o Ministério da Saúde elencou estratégias prioritárias, dentre elas (Brasil 2011a):

\section{a) Garantir aos pacientes com tuberculose}

- Acesso precoce ao diagnóstico da infecção pelo HIV por meio da oferta do teste, preferencialmente o teste rápido;

- Acesso ao tratamento antirretroviral oportuno;

\section{b) Garantir as pessoas vivendo com HIV}

- Realização da prova tuberculínica e acesso ao tratamento da infecção latente da tuberculose, quando indicado;

- Diagnóstico precoce da tuberculose ativa nos pacientes com manifestações clínicas sugestivas.

Algumas informações importantes como o início da terapia antirretroviral (TARV) para pessoas com coinfecção TB-HIV e a profilaxia da TB em pessoas que vivem com HIV/aids (PVHA) com isoniazida, ainda não estão disponíveis nos sistemas de informação nacionais. Não raramente o diagnóstico do HIV ocorre após o diagnóstico da TB ativa, mostrando a importância da oferta do teste de HIV oportunamente a todas as pessoas com TB (Brasil, 2011a). 
No SUS, a rede de atenção é composta por unidades da atenção básica, referências secundárias e terciárias, além da rede laboratorial e os hospitais de diferentes níveis. Os Serviços de Atenção Especializada a Pessoas Vivendo com HIV/aids (SAE) são incorporados nessa rede como referência secundária para PVHA. Como importante estratégia para queda da morbimortlidade recomenda-se o atendimento integral do coinfectado TB-HIV nos SAE. Os SAE apresentam estrutura e equipe multiprofissional preparada para o seguimento desse grupo (Brasil 2014c).

\section{Modo de transmissão e reservatório}

O ser humano é o principal reservatório do $M$. tuberculosis, havendo outros possíveis reservatórios, tais como os primatas, aves, gado bovino e outros mamíferos (Fiuza de Melo, 1993).

A TB é uma doença infecciosa de transmissão aérea que ocorre a partir da inalação de aerossóis produzidos pela tosse, fala ou espirro de doentes com tuberculose pulmonar ou laríngea (Fiuza de Melo, 1993, Brasil, 2011a). As gotículas menores exaladas ( $<5-10 \mu \mathrm{m}$ de diâmetro) mantém-se em suspensão no ar por muitas horas, mantendo-se infectantes nesse período. As partículas em forma de aerossóis contêm uma grande quantidade de bacilos, podem alcançar os alvéolos e ao se multiplicarem, podem levar a doença ativa (Rieder, 1999).

As pessoas que eliminam o bacilo da tuberculose pelas vias aéreas superiores são as principais responsáveis pela manutenção da cadeia de transmissão da doença. Quanto maior o número de bacilos eliminados, maior o risco de transmissão da doença (Fiuza de Melo, 1993).

Há algumas regiões do mundo em que o gado bovino pode ser importante fonte de infecção, sendo o $M$. bovis um dos principais agentes identificados. Assume um importante papel na transmissão desses casos o consumo de grande quantidade de leite e derivados não pasteurizados ou não fervidos de gado bovino infectado (Cosivi et al., 1998).

Outras formas raras de transmissão da doença podem ocorrer pela inoculação direta do bacilo ou pela via transplacentária (Farga et al., 2011) 
A identificação e o diagnóstico precoce da pessoa com tuberculose e o seu tratamento são as principais estratégias para o controle da transmissão da doença. Quanto mais oportuno o diagnóstico e o início do tratamento, menos pessoas irão se infectar pelo bacilo da TB. Com o tratamento adequado, a transmissão tende a diminuir gradativamente. Em geral em 15 dias de tratamento, grande parte das pessoas infectadas já não elimina o bacilo (Fiuza de Melo, 1993, Farga et al., 2011, Brasil, 2014b).

\section{Período de latência}

Dependendo das condições imunológicas do hospedeiro e também do ambiente para multiplicação do bacilo, o M. tuberculosis pode permanecer em estado de latência por dias a anos. Condições como diminuição da pressão parcial de oxigênio $\left(\mathrm{PO}_{2}\right)$ ou do $\mathrm{pH}$ ácido $(<6,5)$ no órgão em que esteja alojado são desfavoráveis para seu desenvolvimento, podendo levar o bacilo a um estado de latência (Bauer et al., 2008; Farga et al., 2011).

O risco para adoecimento por TB é maior nos primeiros dois anos após a infecção, porém o desenvolvimento da doença ativa pode ocorrer em qualquer momento da vida do infectado. Fatores sociais, ambientais e principalmente imunológicos favorecem o adoecimento (Bauer et al., 2008, Brasil, 2011a).

\section{Risco de adoecimento}

A suscetibilidade à infecção por TB é universal, porém nem todas as pessoas expostas ao bacilo se infectam, e também nem todos os infectados ficam doentes (Brasil, 2011a). Caso a quantidade de bacilos inalados seja pequena, serão destruídos pelo sistema imunológico sem sequer infectar esse organismo. Caso a pessoa tenha contato com o bacilo e se infecte, na maioria dos casos o infectado resiste ao adoecimento, nesses casos o bacilo permanece de forma latente no organismo (bacilos encapsulados em pequenos focos quiescentes), levando a infecção latente da TB (ILTB) (Comstock et al., 1974). 
Após esse primeiro contato com o bacilo, dentre aqueles que se infectaram, aproximadamente $5 \%$ não consegue controlar a multiplicação do bacilo e ficam doentes, outros $5 \%$, controlam em um primeiro momento a multiplicação do bacilo, mas adoecem posteriormente, nesse caso é denominada tuberculose secundária (Brasil, 2011a).

O risco para adoecimento depende de fatores endógenos, principalmente da resposta imunológica do organismo, de fatores relacionados ao bacilo, como a virulência e a patogenicidade e de fatores ambientais, como a prevalência da doença no ambiente (Pawlowski et al., 2012).

A prova tuberculínica (PT) reatora é um marcador de risco conhecido para desenvolvimento da TB doença (Caminero, 2003). A PT consiste na inoculação intradérmica de um derivado protéico purificado (PPD, do inglês, purified protein derivative) do M. tuberculosis, por esse meio estima-se a resposta imune celular a esses antígenos (Brasil 2011a). Pessoas HIV negativas com PT considerada reatora, apresentam 5\% de risco de desenvolvimento de TB doença nos dois primeiros anos de contato e cerca de $5 \%$ de risco ao longo da vida, sendo então total de $10 \%$ de risco de ter tuberculose. Já as PVHA apresentam de 5 a 10\% de risco de apresentarem TB ativa ao ano, e isso se mantém pelo resto da vida, representando a infecção pelo HIV o maior risco conhecido de se ter TB após uma exposição (Comstock et al., 1974, Caminero, 2003). Fato diretamente relacionado ao tratamento antirretroviral, estudos mais recentes revelaram uma diminuição do risco de ter tuberculose com o TARV precoce (Temprano ANRS 12136 Study Group et al, 2015).

Outras populações sob risco são pessoas recebendo tratamentos imunossupressores, como os transplantados ou portadores de outras doenças imunossupressoras e o próprio diabetes mellitus que ao logo da última década vem ganhando destaque, principalmente pela grande quantidade de pessoas acometidas no mundo (WHO, 2011a).

Outro fator também conhecido é a idade em que a pessoa foi infectada, pessoas menores de dois anos de idade e os maiores de sessenta anos apresentam maior risco de adoecimento (Brasil, 2011a). 


\section{Apresentação clínica da doença}

A TB pulmonar é a apresentação clínica mais frequente e apresenta importante papel na perpetuação da cadeia de transmissão da doença. $O$ diagnóstico bacteriológico das formas pulmonares é fundamental para 0 adequado controle da doença (Brasil, 2011a).

Apesar de menos frequentes, outras formas de TB também são relevantes e apresentavam diferentes manifestações clínicas, a depender do órgão acometido (Brasil, 2012). Nesses casos outros sintomas como a febre e o emagrecimento devem ser valorizados (Sharma et al., 2005).

A tuberculose pulmonar do adulto é também conhecida como TB pósprimária, secundária ou por reinfecção, sendo a forma mais prevalente da TB, mais infecciosa e a maior causadora de mortes pela doença (Farga et al., 2011).

Classifica-se a tuberculose em pulmonar e extrapulmonar. A TB extrapulmonar ocorre quando, por disseminação hematogênica, outro órgão é acometido além do pulmão (Pestana et al., 1993, Fanning, 1999, Brasil, 2011a, WHO, 2013b). A forma mista (pulmonar mais extrapulmonar), na grande maioria das vezes é classificada juntamente com a forma extrapulmonar.

Mesmo na apresentação pulmonar os sintomas da TB são muito inespecíficos, sendo o diagnóstico diferencial de grande parte das doenças infecciosas. Os sintomas podem variar de intensidade, assim como a gravidade da doença, havendo casos que levam rapidamente ao óbito (Caminero, 2003, Farga et al., 2011).

\section{Tuberculose pulmonar}

A TB pulmonar primária é a forma clínica mais frequente nas crianças e em grande parte das vezes a apresentação clínica é insidiosa e de difícil diagnóstico. A TB é comum após a infecção, por isso é chamada de primária. As crianças geralmente apresentam sudorese noturna, febre baixa, irritabilidade, falta de apetite, tosse por quinze dias ou mais, o exame físico pode não revelar alterações (Sant'Anna, 2002). 
Em crianças menores de dez anos, o diagnóstico é difícil, o exame inexpressivo, agravado pela dificuldade de expectoração, ou quando presente, é negativa ao exame da baciloscopia (Brasil, 2011a).

A tuberculose secundária pode acontecer em qualquer idade, mas é mais frequente nos adolescentes e adultos jovens (Brasil, 2011a). O sintoma mais frequente e importante é a tosse, esta pode ser seca ou produtiva, com expectoração purulenta ou mucoide, podendo apresentar ou não sangue. Outros sinais e sintomas comuns são a febre vespertina, anorexia e emagrecimento.

A TB miliar é classificada como pulmonar devido ao aspecto radiológico pulmonar da doença, porém sabe-se que ocorre disseminação hematogênica e outros órgãos geralmente são acometidos. É considerada uma forma grave da doença e é mais frequente em imunodeprimidos, como nas pessoas infectadas pelo HIV. Ao exame físico pode apresentar hepatomegalia, alterações cutâneas e alterações do sistema nervoso central (Sharma et al., 2005).

\section{Tuberculose extrapulmonar}

Os sinais e sintomas das manifestações clínicas da TB extrapulmonar são dependentes do órgão acometido, mais de um órgão podem ser acometido ao mesmo tempo. A ocorrência de TB extrapulmonar aumenta em pessoas com doenças que levam a imunodepressão, especialmente aqueles com imunocomprometimento grave como em pessoas com aids (Yang et al., 2004).

A TB pleural é a forma mais comum de TB extrapulmonar em pessoas HIV negativas, geralmente acomete mais jovens, cursa com quadro de tosse seca, emagrecimento e astenia. Muitas vezes há o acometimento associado do pulmão. A TB meningoencefálica acomete geralmente crianças e imunodeprimidos. Em crianças abaixo de seis anos a meningite basal exsudativa é mais comum, pode se apresentar de forma subaguda ou crônica (Sant'Anna, 2002). Na apresentação crônica pode evoluir com várias semanas de cefaleia holocraniana com acometimento dos pares cranianos, muitas vezes levando a sequelas e comprometimento do sistema nervoso central. Em grande 
parte dos casos ocorre acometimento pulmonar concomitante (Sant'Anna, 1998, Brasil 2011a, Udani et al., 2015).

A TB óssea é mais comum em crianças ou em pessoas entre as quarta e quinta décadas de vida, atinge geralmente a coluna vertebral e as articulações coxofemoral e do joelho. Quando acomete a coluna é denominada mal de Pott. O quadro clínico é a tríade de dor lombar, com dor à palpação e sudorese noturna (Turgut, 2001, Caminero, 2003, Farga et al., 2011).

\section{Tuberculose em Pessoas que Vivem com HIV/aids}

Como relatado anteriormente a infecção pelo HIV é o maior fator de risco conhecido para o desenvolvimento da TB nas PVHA, independentemente do grau de imunodepressão (Antonucci et al., 1995, Caminero, 2003). A apresentação clínica da doença é influenciada pela imunidade, com formas atípicas nas pessoas com imunodepressão avançada, porém em geral a investigação diagnóstica é semelhante ao de uma pessoa imunocompetente. (Perlman et al., 1997). Apesar disso, as apresentações clínicas diversas na imunodepressão avançada, dificultam o diagnóstico da TB, com consequente aumento da mortalidade (Barnes et al., 2002; Sharma et al., 2005).

Assim como na população geral, calcula-se que no mundo cerca de um terço da população que vive com HIV esteja infectada pelo bacilo da TB (Dye et al., 1999, Farga et al., 2011). O HIV infecta e eventualmente destrói os LTCD4+, o que determina uma progressiva queda da imunidade celular e facilita a reativação de infecções intracelulares, como a tuberculose. Além disso, há a ação direta do vírus sobre os macrófagos, o que também favorece a infecção pela TB (Pawlowski et al., 2012, Farga et al, 2011).

Há três mecanismos básicos da TB em PVHA: a reativação endógena, progressão de infecções recentes e reinfecções exógenas. A reativação endógena é geralmente a mais frequente e ocorre por ativação de focos quiescentes de TB latente no organismo do hospedeiro coinfectado. Geralmente a PVHA que está com a imunidade preservada, apresenta um quadro clínico mais clássico da TB do adulto, com cavernas e baciloscopia positiva Pawlowski et al., 2012; Farga et al, 2011). 
Quando acontece a progressão de infecção recente, são casos de TB mais agudos e atípicos, de difícil diagnóstico e com maior gravidade. Situação mais frequente em crianças (Sant'Anna, 2002).

Quando ocorre reinfecção exógena da PVHA, mesmo tendo sido infectado anteriormente, há uma nova exposição de risco em um outro momento imunológico, favorecendo a progressão para doença (Pawlowski et al., 2012)

A interação entre o Mycobacterium tuberculosis e o HIV resulta em progressão mais rápida tanto da TB como da infecção pelo HIV. O HIV amplifica e acelera o desenvolvimento de formas graves de TB em decorrência da redução na contagem de LT-CD4+ (Geldmacher et al., 2010) e o M. tuberculosis intensifica a imunodeficiência causada pelo HIV, provavelmente, como resultado de um aumento da replicação viral (Canaday et al., 2009).

A apresentação clínica da TB depende do grau de imunodepressão. Quando LT-CD4+>350 cel/mm $/ \mathrm{mm}^{3}$ a apresentação clínica é semelhante a pacientes não infectados, sendo a tuberculose frequentemente delimitada aos pulmões (Perlman et al. 1997). Os sintomas mais frequentes são perda de peso, febre e sudorese, a tosse é menos frequente quando comparada ao HIV negativos. Por isso na presença de qualquer um dos sintomas como tosse, febre, emagrecimento ou sudorese pode significar tuberculose e deve ser investigada (Pawlowski et al., 2012, Brasil, 2013d).

Nos pacientes que já iniciaram a TARV, o diagnóstico de TB pode ser evidenciado pela síndrome inflamatória da reconstituição imune (SIRI) e inclui: febre, perda de peso e sinais de intensa reação inflamatória local, tais como linfadenite, consolidação pulmonar, infiltrados e nódulos (Narita et al., 1998).

\section{Diagnóstico}

O diagnóstico da TB nas PVHA se dá de maneira semelhante às pessoas HIV negativas, porém o diagnóstico bacteriológico é ainda mais importante para confirmar a presença de TB ativa, tornando-se essencial para o diagnóstico diferencial com outras infecções oportunistas. A coleta de escarro para baciloscopia e/ou teste rápido molecular para tuberculose (TRM-TB), 
cultura, identificação da espécie e de teste de sensibilidade (TS) deve ser insistentemente realizada como rotina de investigação de casos suspeitos de TB (Brasil, 2011a).

O diagnóstico da TB pode ser clínico-epidemiológico ou laboratorial. O diagnóstico laboratorial é de suma importância para identificação dos contaminantes para o controle da doença. O diagnóstico clínico-epidemiológico é definido como aquele em que a comprovação laboratorial não foi possível, e o diagnóstico se baseou na avaliação clínica, epidemiológica e/ou de exames de imagem (Brasil, 2011a).

A baciloscopia direta, ou pesquisa de bacilo BAAR por esfregaços em lâminas, é o método mais utilizado para diagnóstico da TB, por ser de baixo custo e exigir condições de biossegurança relativamente de baixa complexidade (Brasil, 2013a, WHO, 2014). Possui sensibilidade de 60 a 80\%, quando executada corretamente, é um importante método para o controle epidemiológico da doença, pois determina aqueles que transmitem a infecção (Brasil, 2011a). O exame é considerado um método simples e pode ser realizado por laboratórios públicos e privados, desde que tecnicamente habilitados e com condições adequadas de biossegurança. Consiste na pesquisa do BAAR em lâminas, por meio do método de Ziehl-Nilsen (Brasil, 2008a).

Para aumentar a sensibilidade do exame recomenda-se coletar no mínimo duas amostras de escarro, uma no momento do diagnóstico e outra na manhã seguinte, independentemente do resultado da primeira. Novas amostras podem ser coletadas de acordo com a necessidade. Está indicada a realização de baciloscopia em todos os casos com suspeita de TB pulmonar (clínica ou radiológica) que apresentem tosse com expectoração, principalmente os sintomáticos respiratórios (tosse por três semanas ou mais) (Brasil, 2011a). A baciloscopia de outras amostras, como no caso de TB extrapulmonar, pode ser realizada, porém apresenta sensibilidade variável, a depender da amostra analisada e da concentração de bacilo no material. Amostras como a de líquor geralmente apresentam poucos bacilos e baixa sensibilidade, diferente de amostras de linfonodos que geralmente apresentam maior carga bacilar (Brasil, 2008a, Brasil, 2014d). 
A partir de 2011 a Organização Mundial da Saúde (OMS) endossou uma nova tecnologia para o diagnóstico da TB, o GeneXpert ${ }^{\circledR}$ baseado na metodologia PCR (polimerase chain reaction - reação da polimerase em cadeia) em tempo real. O teste Xpert $M T B / R{ }^{\circledR}$ realizado no sistema GeneXpert ${ }^{\circledR}$ é um teste molecular rápido, realizado em ambiente laboratorial, que detecta o $M$. tuberculosis e também a resistência à rifampicina (Evans, 2011), foi produzido inicialmente para atender as demandas da atenção primária à saúde, exigindo as mesmas condições de biossegurança que a baciloscopia (WHO, 2011c). O GeneXpert ${ }^{\circledR}$ (no Brasil denominado de Teste Rápido Molecular da Tuberculose) no estudo de validação evidenciou uma sensibilidade de $98,2 \%$ e especificidade de $99,2 \%$, superior ao da baciloscopia. Além disso a capacidade de detecção de resistência à rifampicina possui especificidade de 97,6\% e sensibilidade de 98,1\% (Pasquié et al., 2010).

O Ministério da Saúde adquiriu 160 equipamentos de TRM-TB destinados a 150 laboratórios, distribuídos entre os 94 municípios que compõem a Rede de Teste Rápido para Tuberculose (RTR-TB). Todas as Unidades da Federação estão inseridas nessa rede e os critérios utilizados para disponibilização do equipamento foram carga de tuberculose, presença de populações prioritárias como indígenas e população privada de liberdade (Brasil, 2015).

O TRM-TB identifica o material genético do Complexo M. tuberculosis, não diferenciando a presença de bacilos vivos ou não, por isso não está indicado para o controle do tratamento ou para o diagnóstico da TB dos casos de retratamento, nesses casos a baciloscopia deverá ser realizada. Deve ser realizado em todos os suspeitos de TB pulmonar e laríngea de adultos e crianças. Em crianças $<10$ anos a sensibilidade do exame é menor, por isso resultados negativos não excluem a doença ativa e a investigação deverá ser continuada (Brasil 2014e).

O exame foi validado para algumas formas de TB extrapulmonar, desde que os laboratórios estejam tecnicamente habilitados (WHO, 2013c). As amostras de líquor, gânglios linfáticos e outros tecidos podem ser utilizadas. Como a sensibilidade é menor nessas amostras, o resultado negativo não exclui tuberculose, sendo necessário manter a investigação (Brasil, 2014e). 
O exame de cultura para micobactéria é o método "padrão ouro" para o diagnóstico da tuberculose e possui elevada sensibilidade e especificidade, permite um acréscimo de até 30\% no número de casos diagnosticados, quando comparada à baciloscopia (Brasil 2014c).

A cultura pode ser realizada por meio sólido ou líquido. A cultura sólida (Lowenstein-Jensen e Ogawa-Kudoh) é o método mais comum e apresenta menor custo e risco de contaminação. Os resultados variam de no mínimo 14 dias quando positivo, a até 60 dias quando negativos (Brasil, 2008a). Os meios de cultura líquidos, atualmente disponíveis em alguns estados do país, são com sistemas automatizados, com menor tempo para o crescimento bacteriano, sendo os resultados possíveis de 5 a 12 dias quando positivos, precisando se estender por até 42 dias para classificá-los como negativos (Brasil, 2014d).

A identificação da espécie é feita por métodos bioquímicos e fenotípicos ou pode ser analisada por meio de técnicas moleculares (Brasil, 2008a).

Atualmente o Ministério da Saúde recomenda a cultura universal, racionalizada por meio do TRM-TB, com o objetivo de ampliar cada vez mais a rede de diagnóstico do país. Todos os casos com TB diagnosticados pelo TRM-TB, deverão ser enviados para a realização de cultura com teste de sensibilidade. Quando o diagnóstico da TB for realizado por meio da baciloscopia, a cultura deve ser realizada em todos os casos com suspeita de tuberculose (Brasil, 2014e).

Os exames de imagem podem ser utilizados no diagnóstico da TB, sendo a radiografia de tórax, por exemplo, um método importante $\mathrm{e}$ fundamental na investigação, principalmente quando associado a avaliação clínica e epidemiológica (Burril et al., 2007). Diferentes achados radiológicos apontam para a TB ativa ou sequela, além da visualização do comprometimento pulmonar. Quando possível, deve ser solicitada para todo o paciente com suspeita clínica de TB pulmonar. (Brasil 2011a).

Outros exames podem ser utilizados no diagnóstico da TB, como os histopatológicos, citológicos, tomografia computadorizada, prova tuberculínica, broncoscopia e a adenosina deaminase (ADA), sendo que a sua indicação 
dependerá do quadro clínico e da disponibilidade dessas tecnologias (Liang et al., 2008, Brasil, 2014d).

O diagnóstico da TB em crianças pode ser mais complexo, principalmente nas crianças menores de 10 anos. A forma pulmonar costuma ser negativa ao exame bacteriológico pelo número reduzido de bacilos nas lesões, além da dificuldade para coleta de amostras. No Brasil foi validado um escore clínico para o diagnóstico da TB pediátrica em menores de 18 anos com exame negativo à baciloscopia ou quando impossível a coleta de escarro. $\mathrm{O}$ diagnóstico se baseia em uma adequada avaliação clínica, a realização de radiografia de tórax e prova tuberculínica, associada a história epidemiológica e avaliação do estado nutricional (Sant'Anna, 2006).

\section{Período de transmissibilidade}

Um indivíduo infectado pelo bacilo da tuberculose transmite $\circ M$ tuberculosis quando o elimina no escarro, o que é identificado por meio da baciloscopia, nesses casos a baciloscopia é positiva. Quanto maior a quantidade de bacilos eliminados pelo escarro, maior a transmissão da doença. As apresentações clínicas que frequentemente transmitem o bacilo são as formas pulmonar e laríngea. Com o tratamento a transmissibilidade diminui gradativamente, sendo mínima após 15 dias de seu início (Fiuza de Melo, 1993; Farga et al., 2011).

Pessoas com tuberculose e baciloscopia de escarro ou teste rápido molecular negativas, têm pouca participação na transmissão da doença (Brasil, 2014d).

\section{Tratamento}

A TB é uma doença curável em praticamente todos os casos, desde que obedecidos os princípios básicos da terapia medicamentosa, que é a associação adequada de fármaco, doses corretas e uso por tempo definido, além da adequada operacionalização do tratamento (Brasil, 2014d). A 
realização do tratamento diretamente observado (TDO) tem importância fundamental para o sucesso do tratamento (Brasil, 2011a, Brasil, 2011b).

O TDO consiste na observação diária da ingestão dos medicamentos antituberculose por um profissional de saúde capacitado na equipe. Essa observação da ingestão do medicamento deve ocorrer por no mínimo três vezes na semana durante os seis meses de tratamento (Brasil, 2011b). O TDO é uma estratégia que envolve a equipe multiprofissional e tem como pilar fundamental um bom acolhimento e o vínculo desse usuário com o serviço e profissionais de saúde que fazem o acompanhamento do seu tratamento (Brasil, 2011b).

No Brasil, o tratamento da TB é gratuito e garantido a toda a população pelo Sistema Único de Saúde (SUS). Cabe aos serviços de saúde prover os meios necessários para garantir que toda a pessoa com diagnóstico de TB seja tratada em tempo oportuno (Brasil, 2011a). A estreptomicina, primeira droga efetiva para o tratamento da TB foi produzida na década de 40. Na década de 60 que se iniciou a utilização da rifampicina, fármaco atualmente mais efetivo no tratamento da TB (WHO, 2014).

Em 2009, o Programa Nacional de Controle da Tuberculose reviu o esquema de tratamento da TB no Brasil. Com base nos resultados preliminares do II Inquérito Nacional de Resistência aos Medicamentos antiTB, que mostrou aumento da resistência primária a isoniazida (de 4,4\% para 6,0\%) (Brasil, 2011a), ocorreu a introdução do etambutol como quarto fármaco na fase intensiva/primeira fase (2 meses) do esquema básico para adultos. A apresentação farmacológica desse medicamento passou a ser em comprimidos de doses fixas combinadas dos quatro fármacos, a rifampicina, isoniazida, pirazinamida e etambutol (RHZE). Na fase de manutenção/segunda fase (4 meses) do tratamento se mantém a rifampicina em associação com a isoniazida $(\mathrm{RH})$ (Brasil, 2011a).

Para as crianças abaixo de 10 anos permanece a recomendação do esquema RHZ na fase intensiva e RH na fase de manutenção (Brasil, 2011a).

$\mathrm{Na}$ coinfecção TB-HIV a complexidade do manejo clínico deve ser considerada, principalmente na associação da terapia concomitante de ambas as doenças. A presença de interações medicamentosas, efeitos adversos, má 
adesão e a presença da SIRI devem ser considerados nesse grupo de pacientes (Velasco et al., 2009).

Assim como os antirretrovirais (ARV), os medicamentos para TB têm reconhecida toxicidade. $\mathrm{O}$ início concomitante dos dois esquemas aumenta $\mathrm{O}$ risco de intolerância medicamentosa e sobreposição/potencialização de efeitos adversos (aumentando assim a dificuldade de se identificar qual fármaco está associado a uma possível toxicidade), o que leva, na maioria das vezes, a interrupção de ambos os tratamentos (Brasil, 2013c).

$O$ tratamento da tuberculose nas PVHA segue as mesmas recomendações para os não infectados, tanto nos esquemas quanto na duração total do tratamento (Brasil, 2011a). Em PVHA, têm sido descritas maiores taxas de falha no tratamento da TB, de resistência aos fármacos e de recorrência da doença (Blumberg, 2003, Corbett et al., 2003). Apesar disso, as recomendações não fazem distinção quanto ao manejo clínico da tuberculose nos casos de retratamento em pessoas soropositivas e soronegativas (Pozniak et al., 1999; Corbett et al., 2003).

Sempre se deve dar preferência à utilização da rifampicina, o principal fármaco para o tratamento da tuberculose. A rifampicina é um potente indutor do citocromo P450 e da glicoproteina $\mathrm{P}$, por esse motivo, reduz de maneira importante as concentrações plasmáticas dos inibidores de protease (IP) e inibidores da transcriptase reversa não nucleosídeos (ITRNN), já que estes fármacos utilizam a mesma via de metabolização (Brasil, 2011a).

Algumas pessoas HIV positivas necessitam do uso do IP, nesses casos não poderá ser utilizada a rifampicina, devendo-se fazer uso da rifabutina para o tratamento da TB. A rifabutina é uma rifamicina que induz menos o sistema enzimático P-450 CYP3A e, por esse motivo, exerce um menor efeito na redução dos níveis séricos dos antirretrovirais. Porém os ARV podem ocasionar oscilação em seus níveis séricos, aumentando o risco de toxicidade. A substituição da rifampicina pela rifabutina deve ser individualizada e deve levando em consideração os riscos e benefícios relacionados a estruturação de um novo esquema de tratamento da TB e da opção do regime ARV (Brasil, 2013c, WHO, 2013a). 
Todas as PVHA com TB devem iniciar a TARV independentemente da forma clínica da tuberculose e da contagem de LT-CD4+(Brasil 2010). O início precoce da TARV reduz a mortalidade, especialmente em indivíduos com imunodeficiência grave (Franco et al., 2013).

Os esquemas de primeira escolha de TARV são aqueles que contém 2 inibidores de transcriptase reversa análogos de nucleosídeos (ITRN) + efavirenz para pacientes em uso de rifampicina e virgens de tratamento antirretroviral. Estudos farmacocinéticos e clínicos sugerem que o efavirenz pode ser usado com segurança na dosagem habitual de $600 \mathrm{mg}$ (Brasil, 2013c, WHO, 2013a).

Nas situações em que o efavirenz for contraindicado pode-se considerar a sua substituição por esquemas contendo nevirapina, ou pela associação de 3 ITRN. A combinação de 3 ITRN tem capacidade de supressão viral menos duradoura, particularmente em pacientes com carga viral elevada, devendo ser modificada assim que terminar o tratamento da tuberculose (Brasil, 2013c, WHO, 2013a).

Entretanto, para ter impacto na mortalidade o TARV deve ser iniciada entre a $2^{\mathrm{a}}$ e a $8^{\mathrm{a}}$ semana após o início do tratamento para TB. Para pacientes com LT-CD4 $+<200 \mathrm{cel} / \mathrm{mm}^{3}$ ou com sinais de imunodeficiência avançada, devem começar a TARV na $2^{\text {a }}$ semana após o início do tratamento para tuberculose (Garcia-Vidal et al., 2010; Franco et al., 2013). Vale ressaltar que não se recomenda o início concomitante do tratamento de ambas as doenças, pelo aumento dos efeitos adversos apresentados (Brasil, 2013c).

\section{Políticas de prevenção e controle}

\section{Profilaxia da TB}

A profilaxia da tuberculose (tratamento da infecção latente da TB- ILTB) está indicada para indivíduos infectados pelo $M$ tuberculosis com elevado risco de adoecimento. Pessoas infectadas pelo HIV são consideradas de elevado risco nas seguintes situações: quando contato com doente bacilífero, quando conversão da prova tuberculínica ou quando imagem radiológica sugestiva de 
cicatriz de TB sem história de tratamento anterior da TB (quando afastada a possibilidade de TB ativa) (Brasil, 2011a).

Para iniciar o tratamento da ILTB, é necessário afastar a possibilidade de tuberculose ativa por meio de avaliação clínica e outros exames diagnósticos, como a radiografia de tórax. Quando bem indicado, o tratamento da ILTB com isoniazida reduz em 60 a $90 \%$ o risco de adoecimento (Brasil, 2014d).

A isoniazida é o fármaco usado no tratamento da ILTB na dose de 5 a $10 \mathrm{mg} / \mathrm{kg}$ de peso, até a dose máxima de $300 \mathrm{mg} / \mathrm{dia}$ de seis a nove meses (Brasil, 2014d).

\section{Imunização pela BCG}

A vacina BCG, produzida a partir de cepas atenuadas do $M$ bovis, previne contra as formas graves da doença e apresenta proteção contra as formas miliar e meníngea da TB, em indivíduos não infectados pelo $M$. tuberculosis. No entanto, esta proteção pode variar conforme a prevalência dos agravos e a resposta de cada indivíduo (Brasil, 2014d).

A vacina $B C G$ é indicada para crianças de 0 a 4 anos de idade, prioritariamente em recém-nascidos. Crianças vacinadas na faixa etária preconizada que não apresentam cicatriz vacinal após seis meses da administração da vacina devem ser revacinadas apenas uma vez (Brasil, 2011a).

A portaria $n^{0} 1.498$, de 19 de julho de 2013 redefine o calendário nacional de vacinação, o calendário nacional de vacinação dos povos indígenas e as campanhas nacionais de vacinação, no âmbito do Programa Nacional de Imunizações, em todo o território nacional (Brasil, 2013b).

\section{Vigilância Epidemiológica da Tuberculose}

A 5 ${ }^{\text {a }}$ Conferência Nacional de Saúde, em 1975, recomendou ao Ministério da Saúde (MS) instituir o Sistema Nacional de Vigilância Epidemiológica, que por meio de uma legislação específica (Lei n 6.259/75 e 
Decreto $n^{\circ} 78.231 / 76$ ) tornaram obrigatórias a notificação de algumas doenças, dentre elas a tuberculose (Brasil, 2005). Atualmente pela portaria № 1.271, de 6 de junho de 2014 são cerca de 46 doenças ou agravos de notificação compulsória no país (Brasil, 2014g).

A vigilância epidemiológica da TB tem por objetivo conhecer a magnitude da doença (dados de morbidade e mortalidade), sua distribuição, fatores de risco e tendência no tempo, dando informações para as ações de controle (Brasil, 2011a).

Deve-se identificar as possíveis fontes de infecção, com isso a importância da avaliação e investigação dos contatos de todo caso de TB, prioritariamente, naqueles que convivam com doentes com baciloscopia positiva (Brasil, 2005).

O caso suspeito de tuberculose é o indivíduo que apresenta tosse por três semanas ou mais (sintomático respiratório), pode apresentar outros sinais e sintomas, como febre vespertina, sudorese noturna, emagrecimento, inapetência, com alteração ao exame de imagem, como radiografia de tórax, devendo portanto ser investigado (Brasil, 2014d). No Brasil somente o caso confirmado bacteriológica ou clínico-epidemiológico deverão ser notificados (Brasil, 2014d).

Após a confirmação do caso de TB, a unidade de saúde, podendo ser pública ou privada, que diagnostica o caso é a responsável por sua notificação. Outros serviços podem também ser fonte de notificação, como os laboratórios. Deve ser preenchida a ficha de notificação e investigação epidemiológica da tuberculose e as informações devem ser registradas no Sistema de Informação de Agravos de Notificação (Sinan). Nessa ficha, estão contempladas informações obtidas sobre o paciente, o lugar, a situação clínica e a classificação do caso de acordo com seu tipo de entrada. Uma vez confirmado o diagnóstico, o caso de tuberculose deve ser acompanhado até o seu encerramento. Após a digitação no Sinan da ficha de notificação e investigação pelo município de notificação, as informações migram para as regionais de saúde, esferas estaduais e esfera nacional, compondo a base de dados nacional de TB daquele ano (Brasil, 2014d). 
A classificação do caso no sistema, os tipos de entrada até o ano de 2014 eram caso novo, reingresso após abandono, recidiva, transferência ou não sabe (Anexo I). Os encerramentos eram cura, abandono, óbito por TB, óbito por outras causas, transferência, TB multidrogarresistente (MDR) ou mudança de diagnóstico (Anexo II) (Brasil 2005). No ano de 2015 ocorreu atualização das fichas do Sinan (versão 5.0) e atualmente as classificações do caso pelo tipo de entrada são: caso novo, recidiva, reingresso após abandono, não sabe, transferência e pós-óbito (Anexo III). Também ocorreu a atualização das situações de encerramento para: cura, abandono, abandono primário, óbito por TB, óbito por outras causas, transferência, mudança de diagnóstico, mudança de esquema, tuberculose drogarresistente (TBDR) e falência (Anexo IV) (Brasil, 2014d).

A vigilância também é responsável pelo acompanhamento do caso até o seu desfecho e ações específicas que irão contribuir no controle da doença: visita domiciliar para os casos diagnosticados e busca de faltosos, exame de contatos, vigilância em hospitais e outras instituições e vigilância da infecção tuberculosa (Brasil, 2011a).

Para o acompanhamento adequado dos casos a vigilância lança mão de vários instrumentos, entre eles: Livro de registro de sintomáticos respiratórios, Livro de registro e acompanhamento de tratamento dos casos de TB, Ficha de acompanhamento da tomada diária da medicação do TDO, Ficha de controle de contatos e Requisição de exames (Brasil, 2011a).

O Sinan tem como objetivo coletar, transmitir e disseminar dados sobre doenças de notificação, sendo a alimentação regular da base de dados nacional pelos municípios, estados e Distrito Federal obrigatória (Brasil, 2005). Além do Sinan, que é o principal instrumento para a vigilância da TB, outros sistemas de informação auxiliam na obtenção de informações epidemiológicas e sociodemográficas subsidiando as esferas de gestão na definição como o Sistema de Informações de Mortalidade (SIM) e o Sistema de Informação de Tratamentos Especiais de Tuberculose (SITETB) para os casos com resistência as drogas (Brasil, 2014d). 


\section{Vigilância Epidemiológica do HIV/aids}

No Brasil, desde a década de 80 , a vigilância epidemiológica da aids é baseada na notificação compulsória de casos de aids, o que permite caracterizar e monitorar tendências, perfil epidemiológico, riscos e vulnerabilidades na população infectada (Brasil 2014d).

A vigilância da infecção pelo HIV e da aids está baseada num modelo de vigilância de eventos: infecção pelo HIV, adoecimento (aids), e óbito, por meio de sistemas de informação e de rotina de estudos seccionais e longitudinais. Baseia-se em dados fornecidos pelo Sinan Aids, em registros de óbitos do SIM, do Sistema de Controle de Exames Laboratoriais (Siscel) e do Sistema de Controle Logístico de Medicamentos (Siclom) (Brasil, 2014d).

A infecção pelo HIV está incluída na Lista Nacional de Doenças de Notificação Compulsória, além dos casos de aids, gestantes/parturientes/puérperas com HIV e de crianças expostas. A notificação é registrada no Sinan mediante o preenchimento da ficha de Notificação/Investigação de Aids em Pacientes com 13 anos ou mais; ficha de Notificação/Investigação de Aids em Pacientes Menores de 13 anos; ficha de Notificação/Investigação de Criança Exposta ao HIV; e ficha de Investigação de Gestante HIV positiva, utilizada para notificar casos de gestante, parturiente e puérpera (Brasil, 2014d).

O fluxo da informação das fichas do Sinan para digitação, do primeiro nível informatizado até a esfera federal é o mesmo da migração da notificação (Brasil, 2014d).

\section{Cenário Mundial}

A OMS estima que um terço da população mundial esteja infectada pelo M. tuberculosis e estão em risco de desenvolver a doença (Brasil 2005). São estimados cerca de 9 milhões de casos novos ocorrendo anualmente, destes $95 \%$ dos casos e $98 \%$ dos óbitos ocorrem em países em desenvolvimento. São cerca de 1,8 milhão de mortes por ano no mundo. A população 
economicamente ativa (15 a 50 anos) representa $75 \%$ dos casos (WHO, 2014, Harries et al., 2004).

A OMS decretou a TB como uma emergência mundial no ano de 1993 devido ao recrudescimento da doença nos países desenvolvidos e sua expansão nos continentes asiático e americano. Esse aumento ocorreu devido ao advento da epidemia de HIV/aids, às desigualdades sociais, aos grandes movimentos migratórios e ao envelhecimento da população (Ruffino-Netto, 2002, Façanha, 2006).

Visando um melhor controle da doença, a diminuição do abandono, dos óbitos, além do alcance da cura, a OMS lançou a estratégia DOTS - Directly Observed Treatment Short-Course. A estratégia DOTS é composta por seis grandes componentes: compromisso político, detecção de casos por baciloscopia, esquemas de tratamento padronizados, tratamento diretamente observado (TDO), suprimento regular e ininterrupto dos medicamentos padronizados e sistema de registro / notificação dos casos (WHO, 2008).

A Organização das Nações Unidas (ONU) no ano 2000 estabeleceu oito Objetivos de Desenvolvimento do Milênio (ODM) ao analisar os maiores problemas mundiais. A TB foi incorporada no 6o objetivo intitulado: combater a aids, a malária e outras doenças. A OMS lançou o Plano Global para o Combate da Tuberculose 2011-2015 (The Global Planto Stop Tuberculosis 2011-2015) com a visão de livrar o mundo da TB. Seu objetivo é reduzir pela metade a incidência e a mortalidade por TB até 2015, comparados aos valores de 1990, de acordo com o que foi pactuado nos ODM. O plano está dividido em seis componentes: expandir a estratégia DOTS; priorizar a coinfecção TB-HIV, a tuberculose resistente e as populações mais vulneráveis; organizar o sistema de saúde baseado na atenção básica; fortalecer a sociedade civil organizada; articular todos os prestadores de serviços de saúde; e promover pesquisas. $O$ Plano ainda apresenta, como meta: eliminar a TB como problema de saúde pública até 2050 (Brasil, 2012).

Segundo a OMS, nas últimas duas décadas ocorreram progressos no mundo em relação ao número de casos e óbitos por TB, a meta de parar e reverter a incidência da TB do ODM, foi alcançada globalmente por vários anos. Nos países considerados de alta carga para TB que concentram $82 \%$ da 
carga da doença, grupo que o Brasil está incluso, as taxas de mortalidade e incidência estão em queda (WHO, 2012a, WHO, 2014).

Em julho de 2013 foi aprovada na Assembleia Mundial da Saúde a estratégia pós-2015, desde então a OMS iniciou a discussão sobre a sua construção. A estratégia, hoje nomeada de The End TB Strategy (ainda sem nome em português), tem a visão de um mundo livre da tuberculose, zero mortes, doença e sofrimento por TB, possui metas bem ousadas com 95\% de redução de mortes (comparada a 2015) e 90\% de redução da taxa de incidência ( $<10$ casos de TB/100.000 hab) até 2035. A estratégia se baseia em três pilares principais: 1- Assistência centrada no paciente, integração e prevenção; 2- Políticas sociais e sistemas de suporte; 3- Intensificar a pesquisa e inovação (WHO, 2014).

Dos 9 milhões de casos novos de TB estimados para 2013, 13\% são casos coinfectados TB-HIV (1,1 milhão). Geograficamente a carga de TB é maior na Ásia e África. A região da Ásia concentra $56 \%$ dos casos novos de TB do ano de 2013, seguida pela África com 29\%. Índia e China são responsáveis pelo maior número de casos, com $24 \%$ e $11 \%$ da carga global respectivamente. A região africana abrange um quarto do total de casos e as maiores taxas de incidência e mortalidade (280 óbitos/100.000 hab). A menor carga da doença se concentra na Região europeia, com 4\% da carga global (WHO, 2014).

Para o mesmo ano (2013) estima-se 1,5 milhão de óbitos, sendo 1,1 milhão de pessoas com resultado de HIV negativo e o restante em indivíduos coinfectados TB-HIV (360 mil) (WHO, 2014).

Referente à TB multidrogarresistente (TB MDR), globalmente estima-se que $5 \%$ dos casos novos e $20,5 \%$ dos casos previamente tratados de TB sejam MDR (WHO 2014). O nível de resistência entre os casos novos é menor que $3 \%$ em $75 \%$ dos países. Os países do Leste Europeu e a Asiáticos tem o maior nível de MDR, chegando a $35 \%$ dos casos novos e $75 \%$ dos retratamentos. No ano de 2013 , 9\% dos casos de TB MDR tiveram TB com resistência extensiva (TB XDR). Uma avaliação da tendência mundial dos casos de TB MDR nos períodos de 2008 a 2013 sugere que no mundo a estimativa da proporção de 
casos novos com MDR não mudou e se mantém constante em cerca de 3,5\% (WHO 2014).

Segundo o Relatório Global de Controle da Tuberculose desenvolvido pela Organização Mundial da Saúde (WHO 2014), as PVHA estão 21 a 34 vezes mais propensas a desenvolver TB ativa quando comparadas à população geral. Frequentemente o diagnóstico da infecção pelo HIV ocorre durante o curso da tuberculose (WHO, 2014).

No ano de 2013 foram estimados cerca de 1,1 milhão de pessoas com coinfecção TB-HIV, representando $13 \%$ dos casos novos de TB do mundo, concentrados principalmente na região africana. $O$ número de pessoas morrendo com TB-HIV vem caindo desde 2004, entretanto ainda são 360 mil óbitos, o que representa $25 \%$ de todos os óbitos por tuberculose. Com o objetivo de um maior controle da coinfecção TB-HIV a OMS elencou 41 países prioritários, que concentram mais de $90 \%$ da carga global da doença, incluindo o Brasil (WHO, 2014)

Coinfecção TB-HIV também é um grande problema de saúde pública nos países do leste europeu, principalmente a associação da infecção pelo HIV com a tuberculose resistente, problema que vem se agravando desde 2004 (Lawn, 2009).

Nas PVHA as reinfecções são frequentes em países endêmicos, como comprovado na África do Sul, diferente de países desenvolvidos, onde a ativação de uma antiga infecção parece ser mais frequente. Uma das estratégias de maior impacto para redução da mortalidade no curso da coinfecção TB-HIV é o advento da terapia antirretroviral, principalmente nos países em desenvolvimento com alta incidência de tuberculose ( Lawn, 2009).

Devido ao grave problema mundial da coinfecção TB-HIV, em 2004 a OMS publicou as atividades colaborativas TB HIV com recomendações para um melhor controle da coinfecção. As atividades colaborativas foram dispostas em três grandes grupos, grupo A que estabelece mecanismos de colaboração entre os programas de TB e HIV, incluindo aspectos da gestão e vigilância. O grupo B com atividades para diminuir a tuberculose entre as PVHA e o grupo C com atividades para diminuir o HIV entre as pessoas com TB (WHO, 2004) (Anexo V). A meta é reduzir a carga da TB e do HIV entre as pessoas com 
maior risco de adoecerem por ambas as enfermidades ou já afetadas por estas (WHO, 2012b). Para que estes objetivos sejam alcançados é necessário que a rede de atenção seja ágil e resolutiva, voltada ao cuidado integral do paciente (WHO, 2012b).

Uma importante estratégia é o diagnóstico do HIV nas pessoas com TB, no mundo $48 \%$ das pessoas com TB realizam o teste para diagnóstico do HIV, a maioria na região Africana (76\%). O progresso para o aumento da cobertura da testagem para o diagnóstico do HIV na população com TB teve um decréscimo entre 2012 e 2013 (WHO, 2014).

De 2012 a 2013 ocorreu um aumento da cobertura do tratamento antirretroviral de $60 \%$ para $70 \%$ nas pessoas com coinfecção TB-HIV, entretanto em 2013 o número de pacientes com TB-HIV que iniciaram a TARV foi de somente $32 \%$ (WHO, 2014).

Sobre a utilização de profilaxia com isoniazida, nos anos anteriores a maioria dos casos se concentrava na África do Sul, atualmente mais países africanos reportaram a sua utilização. Somente 41 países (21\%) em todo o mundo relatam oferta de profilaxia com isoniazida para PVHA (WHO, 2014).

A prevenção de mortes entre as PVHA requer profilaxia, diagnóstico e tratamento adequado para TB e início precoce dos ARV naqueles com coinfecção TB-HIV (WHO, 2014).

\section{Cenário Nacional}

Em 2013, o país notificou 73 mil casos novos de TB, correspondendo a uma taxa de incidência de 36,6 por 100 mil habitantes. Estes indicadores colocam o Brasil na 16ª posição em relação ao número de casos, porém na 22 $2^{\mathrm{a}}$ em relação a taxa de incidência, prevalência e mortalidade em relação aos 22 países de alta carga da OMS (WHO, 2014). A tendência da taxa de incidência no país é decrescente, com média de queda de 1,4\% entre 2001 e 2010, mas notam-se, ainda, altas taxas de incidência em algumas Unidades Federadas (De Oliveira et al. 2012). O Amazonas e o Rio de Janeiro possuem as maiores taxas de incidência do país, 70,5 e 68,1 casos por 100 mil hab., respectivamente (Gráfico 1) (Brasil, 2014i). 
Gráfico 1: Taxa de incidência de TB (100.000 habitantes), por Unidade Federada, 2013.

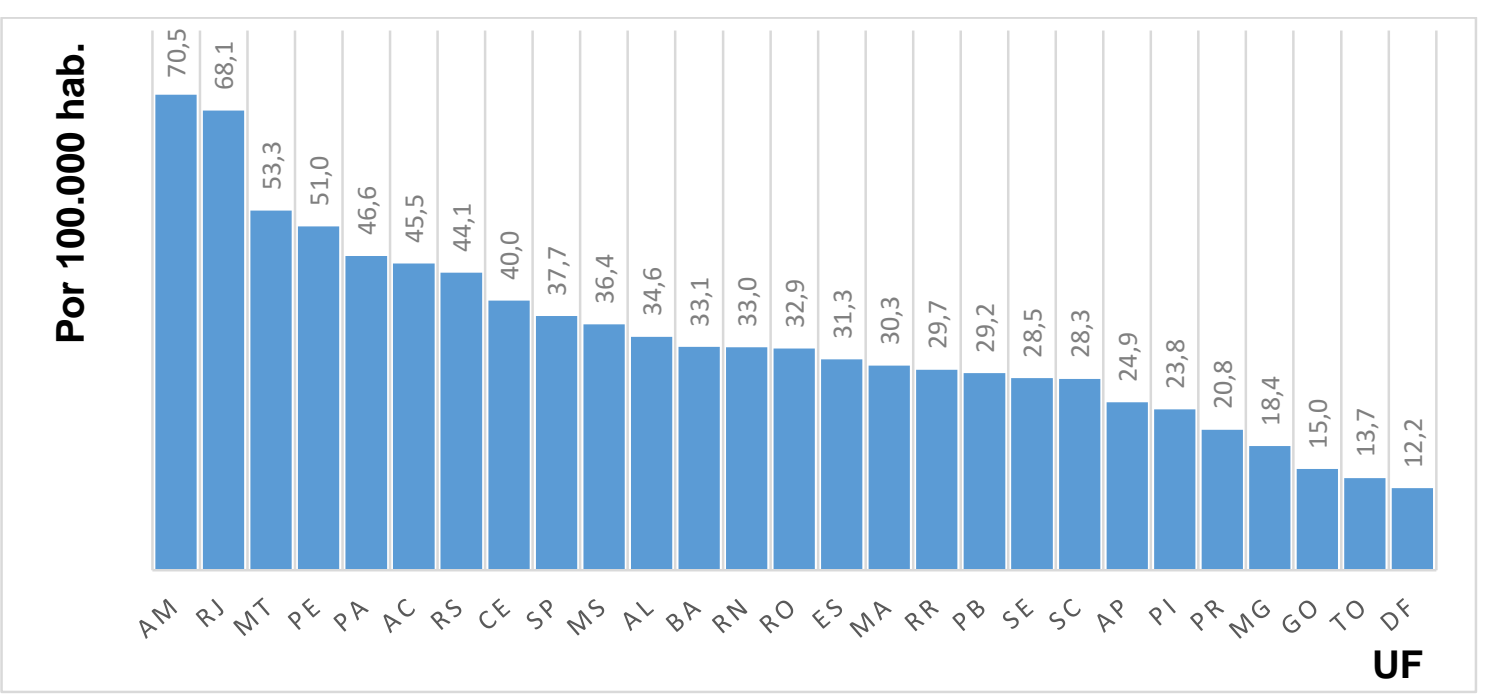

Fonte: Sinan/MS e IBGE

A taxa de mortalidade no país mantém a tendência de queda, com média de 1,5\% desde 1990, apesar disso, anualmente ainda morrem 4.600 pessoas por TB, doença curável e evitável. Em 2010 a TB foi a 4ª causa de morte por doenças infecciosas e a $1^{\text {a }}$ causa de morte dentre as doenças infecciosas definidas dos pacientes com aids (De Oliveira et al. 2012). A taxa de mortalidade por TB para o Brasil em 2013 foi de 2,3 óbitos por 100 mil hab. Os estados do Rio de Janeiro e Pernambuco apresentam as maiores taxas de mortalidade, 5,0 e 3,8 óbitos por 100 mil hab., respectivamente (Gráfico 2) (Brasil, 2014i, Brasil, 2014h). 
Gráfico 2: Taxa de mortalidade por TB (100.000 habitantes), por Unidade Federada, 2013.

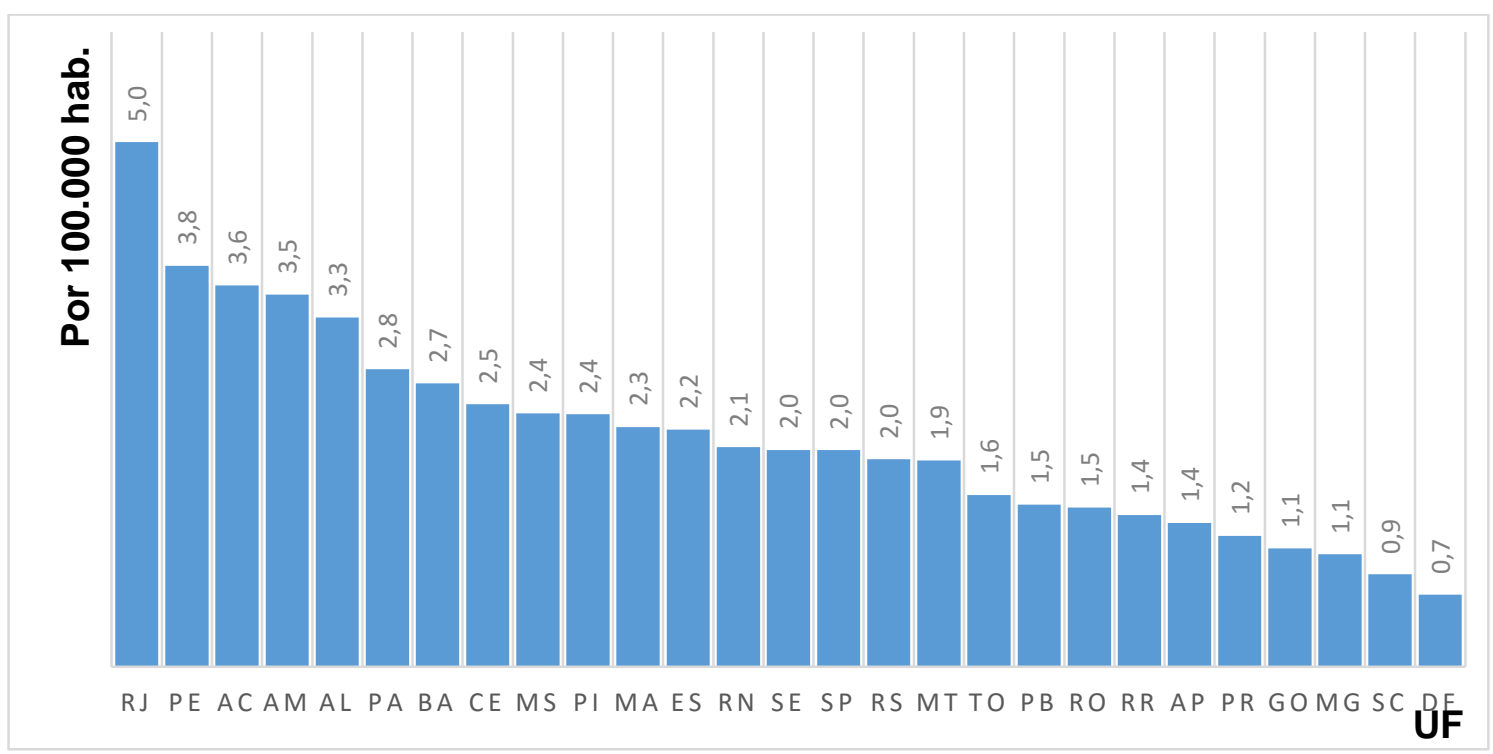

Fonte: Sinan/MS, SIM/MS e IBGE

Mesmo com todos os esforços e com as tendências de queda das taxas de incidência e mortalidade nos últimos anos, o Brasil ainda não conseguiu alcançar as metas recomendadas pela OMS de curar $85 \%$ dos casos novos bacilíferos e de reduzir o abandono para menos de 5\%. Essas metas auxiliam na interrupção da cadeia de transmissão e no controle de bacilos resistentes, contribuindo para o efetivo controle da TB no país. Mesmo com esses resultados para os indicadores de cura e abandono, de acordo com a OMS, o Brasil já alcançou em 2012 a meta para a taxa de mortalidade (WHO, 2012a).

Pela OMS o Brasil não está entre os países de alta carga para coinfecção TB-HIV, apesar disso ainda há necessidade de grandes esforços para o controle da doença no país. A descoberta da soropositividade para HIV pode ocorrer durante o diagnóstico de TB, por isso a importância da oferta do teste do HIV a todas as pessoas com tuberculose (Brasil 2011a). Dentre os 73 mil casos novos de TB no Brasil no ano de 2013, 69,7\% realizaram o teste de HIV, com uma taxa de coinfecção TB-HIV nacional foi de 10,1\%. O percentual de casos TB que realizaram o exame anti-HIV de 2001 a 2013 (gráfico 3) (Brasil, 2014i). Estimativas nacionais indicam que a letalidade da TB na PVHA 
é cerca de $6 \%$, três vezes maior do que a observada na população geral (Brasil, 2014i, Brasil, 2014c).

Gráfico 3: Percentual de casos novos de TB que realizaram exame anti-HIV. Brasil, 2001-2013.

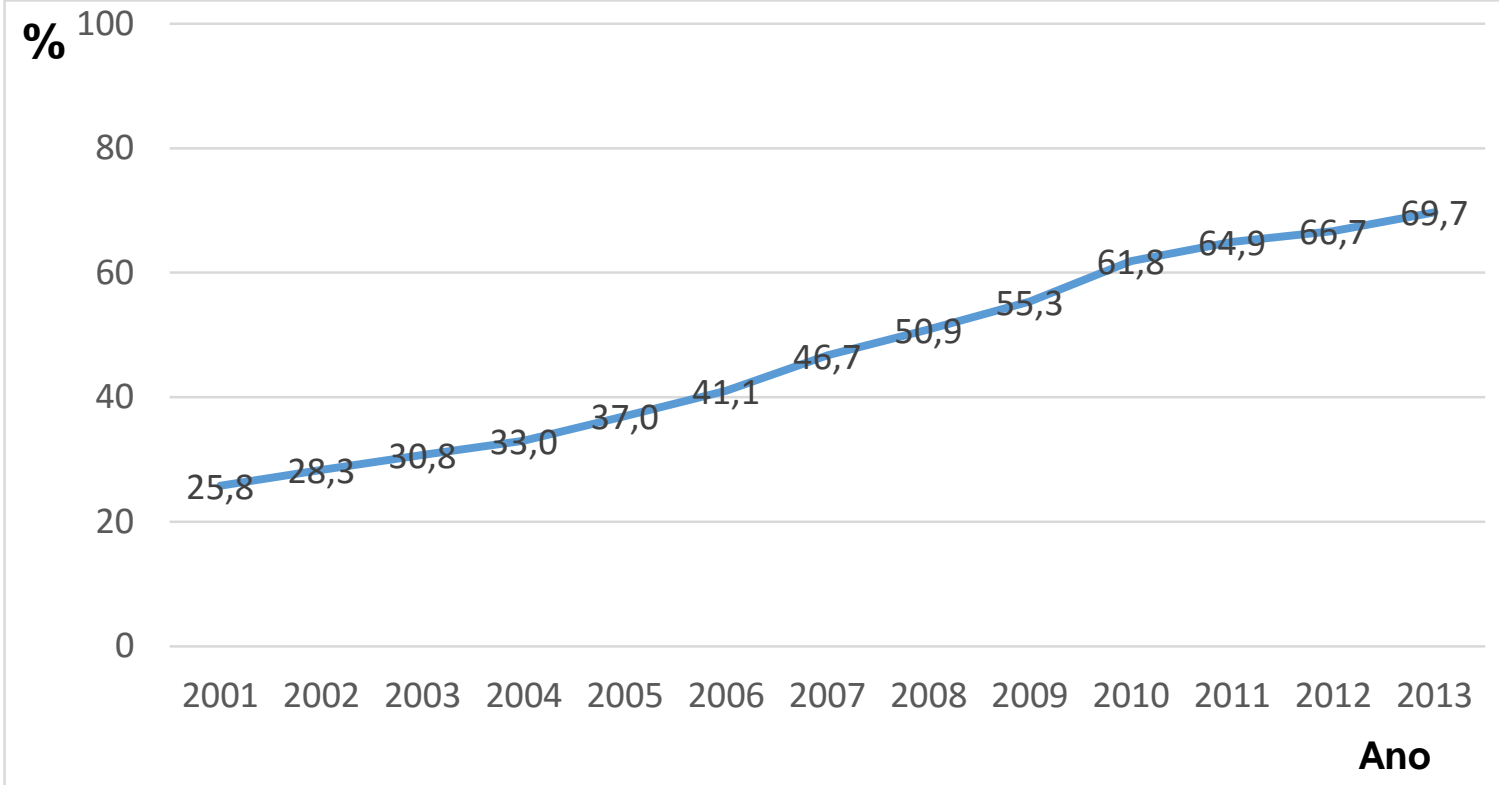

Fonte: Sinan/MS 


\section{JUSTIFICATIVA}

Como a tuberculose ativa em PVHA, entre todos os fatores, é a condição de maior impacto na mortalidade por HIV no país e pela alta morbimortalidade do coinfecção TB-HIV há necessidade de se identificar os fatores de risco relacionados ao óbito na coinfecção, com uma análise mais detalhada dos dados nacionais para apoio às políticas públicas o controle de ambas as doenças. 


\section{OBJETIVOS}

\subsection{Objetivo Geral:}

- Identificar fatores associados ao óbito na coinfecção TB-HIV no Brasil no ano de 2011 a partir de dados secundários.

\subsection{Objetivos Específicos:}

- Descrever o relacionamento de dados como estratégia para qualificação dos bancos de dados da saúde;

- Descrever o perfil clínico-epidemiológico da população do estudo;

- Descrever os óbitos por coinfecção TB-HIV no Brasil no ano de 2011;

- Identificar na população de estudo os possíveis fatores associados ao óbito por coinfecção TB-HIV no Brasil no ano de 2011. 


\section{MATERIAL E MÉTODOS}

\subsection{Tipo de estudo:}

Um estudo descritivo e um estudo analítico tipo caso-controle para estudar fatores associados ao óbito por coinfecção tuberculose e HIV no Brasil no ano de 2011.

\subsection{Fontes de dados:}

Foi utilizado o Sinan como fonte de dados para os casos de TB. Para qualificação dos dados, o Sinan tuberculose foi relacionado aos bancos de dados do Departamento de DST, Aids e Hepatites Virais, o Sinan Aids, Sistema de Controle de Exames Laboratoriais (Siscel), o Sistema de Controle Logístico de Medicamentos (Siclom) e o Sistema de Informações de Mortalidade para a identificação dos óbitos (SIM). Os modelos das fichas de registro desses sistemas, utilizados no ano de 2011 encontram-se nos anexos I, II, VI, VII, VIII e IX.

\subsection{População do estudo}

Para o estudo foram utilizados os casos novos de TB do Brasil notificados no Sinan TB, no período de 01 de janeiro a 31 de dezembro de 2011 que foram identificados como portadores do vírus HIV. Foi considerado "caso" para o estudo caso-controle os casos novos de TB com coinfecção com HIV que foram identificados como óbito após o relacionamento do banco de dados do Sinan TB com o SIM. Os "controles" foram os casos novos de TB identificados como tendo coinfecção TB-HIV que se curaram do tratamento da TB. A população de estudo foi composta por 848 casos e 3.602 controles, uma proporção de 1:4.

Para a análise dos óbitos notificados no SIM, foram utilizados aqueles que apresentaram como causa básica ou associada os códigos referentes à TB 
(compreendidos no intervalo de A15 a A19 da Classificação Internacional de Doenças/10 a revisão), de janeiro de 2011 a dezembro de 2012. Foram

encontrados 4.466 óbitos com causa básica ou associada TB e, após o relacionamento identificou-se 848 pacientes que foram à óbito e apresentavam infecção pelo HIV. As bases de dados utilizadas foram exportadas em 16/02/2014. A população de estudo foi descrita em um algoritmo (Figura 1).

\subsection{Critérios de inclusão e exclusão}

\subsubsection{Critérios de inclusão}

Para o estudo foram incluídos os casos novos de TB notificados de 01 de janeiro a 31 de dezembro de 2011 no Brasil, que apresentavam coinfecção TB-HIV. O paciente foi considerado com coinfecção TB-HIV quando apresentava HIV positivo no Sinan TB ou foi encontrado em algum dos sistemas de informação da vigilância da Aids (Sinan Aids, Siscel e Siclom).

Foram considerados como óbitos os casos novos de TB notificados no Sinan TB que foram identificados durante o linkage com o SIM, sistema considerado padrão ouro para mortalidade no Brasil. Foram incluídos como controles somente os casos novos de TB HIV positivos que encerraram como cura no Sinan TB.

\subsubsection{Critérios de exclusão}

Para o estudo foram excluídos os seguintes tipos de entrada no Sinan TB: recidiva, reingresso após abandono e transferência. Foram também excluídos os casos de TB HIV negativos. O caso HIV negativo foi definido como aquele com a variável HIV no Sinan TB identificado como negativo, em andamento ou não realizado e que não foram encontrados no Sinan Aids, Siscel ou Siclom. Também foram excluídos dos controles os casos com encerramento no Sinan TB como abandono, óbito por TB, óbito por outras 
causas, transferido, TB multirresistente e ignorados que não foram encontrados no SIM.

\subsection{Relacionamento das bases de dados}

Como as bases de dados utilizadas não continham variável identificadora única entre elas, utilizou-se o método de relacionamento probabilístico de registros com auxílio do aplicativo RecLink III. Este método baseia-se na utilização conjunta de campos comuns de identificação presentes em ambos os bancos de dados, com o objetivo de identificar o quanto é provável que um par de registros se refira a um mesmo indivíduo ( Camargo Jr et al., 2012).

Durante o relacionamento probabilístico é executado um conjunto de etapas até a obtenção da base final com a identificação dos registros que foram pareados.

\section{Etapas:}

1- Padronização dos campos comuns das bases de dados a serem utilizados no linkage: é uma forma de uniformização dos campos comuns de modo que erros fonéticos e de grafia sejam contornados, minimizando sua influência no processo de pareamento dos registros;

2- Blocagem: consiste na criação de blocos lógicos de registros dos arquivos a serem relacionados, permitindo que a comparação entre registros se faça de uma forma mais otimizada, restrita aos registros dos blocos formados;

3- Aplicação de algoritmos: comparação aproximada de cadeias de caracteres que levam em consideração possíveis erros fonéticos e de digitação;

4- Cálculo de escores que sumarizam o grau de concordância global entre registros do mesmo par (feito pelo software RecLink III);

5- Pareamento: consiste na definição de limiares para a classificação dos pares de registros relacionados em pares verdadeiros, não pares e pares duvidosos dentro de cada etapa de blocagem;

6- Revisão manual dos pares duvidosos: classificação de todos os pares como pares verdadeiros ou não pares (Camargo Jr et al., 2012). 
O processo de linkage, utilizando o software RecLink III, foi realizado em três etapas. A primeira etapa foi o relacionamento entre os sistemas do Departamento de DST, Aids e Hepatites Virais: Sinan Aids, Siscel e Siclom. Na segunda etapa o banco resultado desse relacionamento (banco R1) foi novamente relacionado, agora com o Sinan TB (banco R2).

\subsubsection{Linkage com o SIM}

A terceira etapa foi o relacionamento entre o banco de dados resultante dos linkages anteriores (banco R2) com o SIM, também utilizando-se software RecLink III. Foi obtida a base de dados final (banco final R3), que foi utilizada para a análise. Representação esquemática dos relacionamentos dos bancos de dados (Figura 2).

O linkage desenvolvido nesse trabalho relacionou o banco R2 com o SIM. Foram relacionados 85.340 registros da base R2 resultante com 20.602 registros do SIM que mencionaram TB como causa básica ou associada (Classificação Internacional de Doenças/10 ${ }^{\text {a }}$ revisão; A15 a A19) de 01 de janeiro de 2011 a 31 de dezembro de 2012. Optou-se por utilizar um período maior para os registros do SIM com o objetivo de possibilitar a captação dos casos que foram notificados em 2011 no Sinan e registrados no SIM no ano de 2012, ainda durante o tratamento da TB.

Foi necessário criar a variável identificadora (ID) na base de dados do SIM e selecionar, além da variável ID, as variáveis de identificação necessárias para o linkage: nome do paciente, data de nascimento, nome da mãe, sexo, município e UF de residência, endereço, número, bairro e complemento. Para o SIM, antes do processo de padronização realizado pelo RecLink III, foi necessário adequar as variáveis que continham datas. As datas foram transformadas em formato texto para evitar problemas na leitura desses campos pelo RecLink III. Durante a padronização realizada pelo RecLink III também foram criadas as variáveis soundex do primeiro e último nome. Utilizou-se a estimativa de parâmetros disponibilizada no manual do RecLink III. Os escores superiores a 10,6 foram considerados pares verdadeiros e os 
inferiores a 0,02 não pares, permanecendo os escores intermediários como duvidosos.

Para o pareamento de registros, utilizaram-se as variáveis nome do paciente e data de nascimento. A revisão manual dos pares duvidosos foi realizada por um único investigador e durante esse processo a reclassificação desses em pares verdadeiros e não pares obedeceu ao seguinte critério de desempate: nome do paciente, data de nascimento, nome da mãe e logradouro de residência. A revisão foi realizada ao final de cada passo de blocagem e os registros que permaneceram classificados como duvidosos após a revisão manual foram considerados não pares.

A etapa de blocagem foi realizada quatro vezes, partindo de uma chave de relacionamento mais restrita e ao final utilizando uma chave mais ampla. As chaves utilizadas foram as seguintes:

1- Soundex do primeiro e último nome, UF de residência e sexo;

2- Soundex do primeiro nome, UF de residência e sexo;

3- Soundex do último nome, UF de residência e sexo;

4- Soundex do primeiro nome e UF de residência;

Ao final de todos os passos do linkage foram considerados pares verdadeiros aqueles encontrados em ambas as bases.

Não foram utilizados os dados do Sinan TB em relação aos óbitos por TB ou por outras causas pois ainda não há uma rotina de investigação de óbito para a tuberculose, podendo esse dado não representar a realidade.

\subsection{Análise dos dados e definição das variáveis}

Os dados foram processados e analisados nos softwares Microsoft Office ${ }^{\circledR}$ Excel, Epi Info $7^{\circledR}$ e Stata $12^{\circledR}$. Os bancos de dados foram relacionados utilizando o programa RecLink versão III.

Para verificar se as populações eram iguais ou diferentes foi realizado o teste de proporções (qui-quadrado de Pearson) de duas amostras segundo as variáveis categóricas sobre as características sóciodemográficas e clínicas entre os casos e controles. Na hipótese nula os dois grupos seriam 
semelhantes e na hipótese alternativa os dois grupos seriam diferentes. Quando o $p$-valor do teste foi menor que $0,05(p<0,05)$ a hipótese nula foi considerada rejeitada.

Com base no resultado do teste das proporções foi criado o modelo de regressão logística não condicional e foram calculados os odds ratios e os intervalos com $95 \%$ de confiança. As variáveis com significância estatística e com boa completitude ( $>80 \%$ ) foram incluídas no modelo.

Foram utilizadas as seguintes variáveis sóciodemográficas: sexo, idade em anos, raça/cor, escolaridade e informação sobre institucionalização. A categorização da variável idade definiu os seguintes grupos: 0-14 anos, 15-49 anos e 50 ou mais anos, com base no perfil da tuberculose que se concentra na população de 15 a 49 anos de idade (Piller, 2012). A variável raça/cor foi classificada como brancos e não brancos, com o objetivo de transforma-la em dicotômica. A variável escolaridade foi classificada como categóricas conforme os anos de estudo como: nenhum, 1-4, 5-8, 9-11, 12 ou mais, conforme disponível no Sinan. Os privados de liberdade foram avaliados na variável institucionalizados do Sinan TB e representam os casos de TB diagnosticados em presídios.

Foram também inclusas as seguintes variáveis clínicas: diabetes, uso de álcool, LT-CD4+, terapia antirretroviral, forma clínica da TB e tratamento diretamente observado. A diabetes é uma variável auto referida no Sinan TB, não representando o rastreio da doença entre pessoas com tuberculose. $O$ uso de álcool é interpretado como o uso abusivo de álcool, com os LT-CD4+ foram feitas duas análises, uma levando em consideração a realização do exame, na tentativa de se avaliar acesso aos serviços de saúde, e outra com faixas de contagens LT-CD4+. Na caracterização da faixa levou-se em consideração estudos internacionais que evidenciam maior risco de mortalidade quando LT$\mathrm{CD} 4+<200 \mathrm{cel} / \mathrm{mm}^{3}$, as faixas escolhidas foram: $<200,349-200,500-350 \mathrm{e}$ $>500 \mathrm{cel} / \mathrm{mm}^{3}$ (Ajayi et al., 2009).

O início da terapia antirretroviral é um importante fator de morbimortalidade e foi incluída como uma variável dicotômica, sim ou não. Infelizmente com os dados atualmente disponíveis não foi possível avaliar a oportunidade de início da terapia. A forma clínica de TB está diretamente 
relacionada ao grau de imunidade do paciente, e as formas disseminadas, mais presentes em pessoas com imunidade comprometida, se correlaciona a altos valores de mortalidade na coinfecção TB-HIV (Yang et al. 2004). Para o estudo foram incluídas as variáveis pulmonar, extrapulmonar e pulmonar / extrapulmonar, como base em dados disponíveis na literatura (Kingkaew et al. 2009).

O tratamento diretamente observado para a tuberculose foi considerado como a observação da ingestão do medicamento por no mínimo três vezes na semana durante todo o tratamento.

A variável gravidez não foi incluída na análise por não possuírem óbitos em grávidas no período analisado e a carga viral pela completitude muito baixa da variável, sendo inferior a $50 \%$.

\subsection{Aspectos éticos}

A pesquisa proposta foi desenvolvida de acordo com os princípios éticos de respeito pela pessoa, beneficência e justiça, seguindo as diretrizes e normas regulamentares da resolução no 466/2012 do Conselho Nacional de Saúde (Brasil, 2013e). Foi garantido o anonimato e o sigilo dos dados coletados. O projeto foi desenvolvido a partir de fontes de dados secundários, não implicando em nenhum risco para os sujeitos da pesquisa ou necessidade de aplicação do Termo de Consentimento Livre e Esclarecido. Os dados foram analisados e referenciados de forma agregada sem uso de nomes ou quaisquer tipos de caracterização pessoal na divulgação dos resultados, podendo trazer benefício para os sujeitos da pesquisa no momento do conhecimento dos resultados do estudo realizado.

Para solicitação das bases de dados utilizadas ao MS foi preenchido o Termo de responsabilidade que traz algumas considerações relacionadas à não divulgação ou realização de práticas que possam comprometer a integralidade da base de dados, bem como a tomada de decisões sobre a identidade das pessoas doentes ou falecidas diante da cessão das bases de dados nominais de sistemas de informação gerenciados pela Secretaria de Vigilância em Saúde e exigidos pelo CEP. No anexo $\mathrm{X}$ encontre o termo de responsabilidade 
de uso de base de dados e no anexo XI a liberação para uso da base de dados da Secretaria de Vigilância em Saúde/Ministério da saúde.

O projeto foi enviado para o Comitê de Ética em Pesquisa da Fundação de Ensino e Pesquisa das Ciências da Saúde- FEPECS no dia 28/11/2014 e obteve aprovação em 02/02/2015, registro na Plataforma Brasil $n^{\circ}$ 39872114.2.0000.5553, número do parecer 943.158 (Anexo XII). 


\section{RESULTADOS}

Os resultados desta dissertação serão apresentados em formato de artigo a ser submetido ao periódico "Plos One"

\section{Título: Fatores associados ao óbito por coinfecção Tuberculose e HIV no Brasil em 2011.}

Risk factors for death in tuberculosis and HIV co-infection in Brazil in 2011

Autores: Fernanda Dockhorn Costa Johansen ${ }^{1,2 *}$, Patrícia Oliveira Bartholomay ${ }^{1,2}$, Denise Arakaki-Sanchez ${ }^{3}$, Maria do Socorro Evangelista Nantua ${ }^{1,4}$, Mauro Niskier Sanchez ${ }^{2}$, Wildo Navegantes de Araújo ${ }^{2}$

Afiliações: 1 - Programa Nacional de Controle da Tuberculose, Secretaria de Vigilância em Saúde (SVS), Ministério de Saúde (MS); 2- Programa de PósGraduação em Medicina Tropical, Faculdade de Medicina, Universidade de Brasília; 3- Organização Panamericana da Saúde - Representação Brasil; 4programa de Pós-Graduação em Saúde Coletiva, faculdade de Medicina, Universidade de Brasília;

* Autor correspondente: Fernanda D. C. Johansen, SCS Quadra 04, Bloco A, Ed. Principal $1^{\circ}$ andar. Brasília/DF. E-mail: fernanda.dockhorn@saude.gov.br; fedcosta@gmail.com. Telf: +55 61 3213-8039.

Título resumido: Fatores associados ao óbito por TB-HIV

RESUMO: Ainda com o advento da terapia antorretroviral a tuberculose continua como a principal causa de óbito por doença infecciosa definida entre as pessoas que vivem com HIV/aids. O objetivo desse trabalho foi verificar os fatores associados ao óbito na coinfecção TB-HIV no Brasil no ano de 2011. Foi realizado um estudo do tipo caso controle, com análise por regressão logística multivariada. A fonte de dados para os casos de tuberculose foi o 
Sinan TB. Com o objetivo qualificar os dados, o Sinan TB foi relacionado com o Sinan Aids, Siscel e Siclom. Para verificação dos óbitos foi realizado o relacionamento com o SIM. Nos resultados, foram consideradas fatores de risco para o óbito: idade $>50$ anos $(\mathrm{OR}=2,48$; IC95\% 1,01 a 6,08), uso de álcool (OR=1,84; IC95\% 1,45 a 2,34) e forma clínica da TB pulmonar e extrapulmonar (OR=1,85; IC95\% 1,36 a 2,52). Os fatores considerados de proteção foram: a realização do LT-CD4+ (OR=0,68; IC95\% 0,54 a 0,86), estar em TARV (OR=0,50; IC95\%0,39 a 063) e estar em TDO (OR=0,69; IC95\% 0,39 a 0,63). Os resultados demonstram uma situação de alerta em relação a coinfecção TBHIV no Brasil, apesar dos avanços na estruturação da assistência à saúde no país, o acesso a um seguimento da coinfecção TB-HIV integral ainda é limitado, o que favorece a alta mortalidade nessa população. Há necessidade de revisão das estratégias nacionais, com priorização da coinfecção TB-HIV pelos programas de tuberculose e de HIV/Aids, matriciamento da assistência de tal modo que profissionais capacitados façam o diagnóstico oportuno da tuberculose e do HIV, além do início em tempo adequado do tratamento antirretroviral.

PALAVRAS CHAVES: tuberculose; HIV; óbito; fatores associados; casocontrole;

ABSTRACT: Even with the advent of antiretroviral therapy, tuberculosis still remains the main cause of death from infectious disease among people living with HIV / AIDS. The purpose of this study was to verify the associated factors with TB and HIV co-infection deaths in Brazil in 2011. A case-control study was conducted through multivariate logistic regression analysis. The Information System for Notifiable Diseases (Sinan) was the data source for TB cases, and for data qualification other databases from the Ministry of Health were used, such as: laboratory (Siscel), antiretroviral (Siclom) and Sinan AIDS databases, and from the Mortality Information System (SIM). The results were considered risk factors for mortality: age> 50 years (OR=2.48; IC95\% 1.01 to 6.08 ), alcohol use $(\mathrm{OR}=1.84 ; \mathrm{IC} 95 \% 1.45$ to 2.34$)$ and clinical form of pulmonary and extrapulmonary TB (OR=1.85; IC95\% 1.36 to 2.52). Factors considered 
protection were the LT-CD4+ conducted ( $\mathrm{OR}=0.68$; IC95\% 0.54 to 0.86 ), being on (OR=0.50; IC95\%0.39 a 0.63) and be in DOT (OR=0.69; IC95\% 0.39 a $0.63)$. The results describe an alarm situation related to TB/HIV co-infection in Brazil. Despite the progresses related to the structure reform in the health care services in the country, access to TB/HIV integral follow up is still limited, which favors high mortality rates among this population. There is an evident need for national strategies updates regarding recognizing the importance of TB/HIV coinfection to both diseases programmes (TB and HIV/AIDS). The organization of assistance so that trained providers are able to early diagnose TB and HIV, in addition to timely starting antiretroviral treatment.

KEY WORDS: tuberculosis; HIV; death; associated factors; case-control.

\section{INTRODUÇÃO:}

A tuberculose (TB) se mantém como um grave problema de saúde pública de relevância mundial, apesar de todos os esforços das últimas décadas para seu controle (Caminero, 2003; Kritski et al., 2007). Obedece a todos os critérios de priorização de um agravo em saúde pública, pois apresenta grande magnitude, transcendência e vulnerabilidade (Brasil, 2014g).

A manutenção da TB como um problema de saúde pública no Brasil e no mundo deve-se entre outros fatores, ao empobrecimento de grande parte da população mundial, o uso de drogas injetáveis, aumento de migrações internas e externas, envelhecimento da população mundial, má nutrição, ao aparecimento da resistência a múltiplos medicamentos antituberculose e em grande parte ao advento da endemia do HIV na década de 80 (Brasil, 2007; Kritski et al., 2007; Guimarães et al., 2010).

A infecção pelo HIV é considerada um dos fatores mais importantes relacionados ao risco de adoecer por TB, acarretando transformações epidemiológicas em ambas as doenças, modificando a sua evolução clínica, história natural e epidemiologia (Daley et al., 1992; Corbett et al., 2003). A coinfecção tuberculose e HIV (TB-HIV) é considerada um dos grandes 
responsáveis pelo aumento da morbimortalidade por tuberculose no mundo (Karim et al., 2009).

Conforme os dados da Organização Mundial da Saúde (OMS), em 2013 foram 1,1 milhão de pessoas diagnosticadas como tendo coinfecção TB-HIV, cerca de $13 \%$ do total de casos de casos de TB diagnosticados no mundo. A região da África concentra 78\% dos casos incidentes (WHO, 2014).

Em 2013, o Brasil notificou 73 mil casos novos de TB, correspondendo a uma taxa de incidência de 36,6 casos novos por 100 mil habitantes. Com isso, o Brasil se encontra na $16^{\underline{a}}$ posição em relação ao número de casos e $22^{\underline{a}} \mathrm{em}$ relação a taxa de incidência, prevalência e mortalidade em relação aos 22 países de alta carga da OMS (WHO, 2014). A tendência da taxa de incidência no país é decrescente, com média de queda de 1,4\% entre 2001 e 2010, mas notam-se, ainda, altas taxas de incidência em algumas Unidades Federadas (de Oliveira et al., 2012), como Amazonas (70,5/100.000hab) e Rio de Janeiro (Brasil, 214d).

Dentre os 73 mil casos novos de TB no ano de $2013,69,7 \%$ realizaram o teste de HIV, com uma taxa de coinfecção TB-HIV nacional foi de 10,1\%(Brasil, 2014c). Estimativas nacionais indicam que a letalidade é cerca de $6 \%$, três vezes maior do que a observada na população geral (Brasil, 2014d). Indivíduos acometidos pelo HIV apresentam risco aumentado de adoecimento por tuberculose, podendo ser de 20 a 37 vezes maior quando comparados à população geral (WHO, 2011b). Além disso, o risco de desenvolver TB em um indivíduo sem infecção pelo HIV é de 5 a $15 \%$ ao longo de sua vida, enquanto que, nos infectados pelo HIV o risco aumenta para $10 \%$ ao ano, ou cerca de 50\% no decorrer da vida (Antonucci et al., 1995; Lourdes et al., 2009).

A infecção pelo HIV altera a resposta imunitária dos linfócitos e macrófagos contra o bacilo da TB, potencializando a suscetibilidade de ter tuberculose ativa. A infecção pelo HIV é um forte fator de risco para TB, acrescido pela imunodepressão, favorecendo ao aparecimento de apresentações clínicas em focos extrapulmonares, como linfonodos, pleura, meníngea e forma disseminada (Pestana et al., 1993).

Pessoas com HIV que vivem em regiões com alta prevalência da infecção pelo Mycobacterium tuberculosis com frequência adquirem a TB 
doença e rapidamente ficam imunocomprometidos, o que também favorece ao aparecimento de outras infecções oportunistas (Kantipong et al., 2012) . As interações medicamentosas (Santos \& Beck, 2009; WHO, 2013), a presença de reações adversas (Yee et al., 2003; Marks et al., 2009) e questões sociais como o alcoolismo e uso de outras drogas podem favorecer aos desfechos desfavoráveis e ao óbito (Tabarsi et al., 2012).

Apesar do advento do tratamento antirretroviral, a mortalidade na coinfecção TB-HIV ainda é alta (Schmaltz et al., 2009, WHO, 2014), indicando outros fatores de risco podem estar associados ao óbito nessa comorbidade. Esse estudo visa analisar fatores associados ao óbito na coinfecção TB-HIV no Brasil que possam influenciar nesse cenário nacional ainda tão negativo.

\section{MATERIAIS E MÉTODOS:}

Foi realizado um descritivo e um estudo tipo caso-controle para analisar os fatores de associados ao óbito por coinfecção tuberculose e HIV no Brasil no ano de 2011.

A fonte de dados utilizada para os casos de TB foi o Sistema de Informação de Agravos de Notificação (Sinan) da tuberculose e para qualificação dos dados, o Sinan tuberculose foi relacionado aos bancos de dados do sistema de vigilância de DST, Aids e Hepatites Virais (Sinan Aids) o Sistema de Controle de Exames Laboratoriais (Siscel), o Sistema de Controle Logístico de Medicamentos (Siclom). Posteriormente foi realizado o relacionamento com o sistema de informações de mortalidade (SIM) para confirmação dos óbitos utilizando a metodologia de relacionamento probabilístico de dados ( Camargo Jr et al., 2012). Foram utilizados os casos novos de TB do Brasil notificados no Sinan TB, no período de 01 de janeiro a 31 de dezembro de 2011 identificados apresentando a infecção pelo vírus do HIV.

Os casos do estudo foram os casos novos de TB com coinfecção com HIV que foram identificados como óbito após o relacionamento dos bancos de dados. Os controles foram os casos novos de TB identificados como tendo coinfecção TB-HIV que se curaram do tratamento da TB. Foram excluídos do 
estudo os pacientes no Sinan TB recidiva, reingresso após abandono e transferência. Como o objetivo do estudo é avaliar fatores relacionados ao óbito na coinfecção TB-HIV foram também excluídos os casos de TB HIV negativos. O caso HIV negativo foi definido como aquele com a variável HIV no Sinan TB preecnhida como negativo, em andamento ou não realizado e que não foram encontrados no Sinan Aids, Siscel ou Siclom. Também foram excluídos dos controles aqueles com encerramento no Sinan TB como abandono, óbito por TB, óbito por outras causas, transferido, TB multirresistente e ignorados que não foram encontrados no SIM. A população de estudo foi composta por 848 casos e 3.602 controles, uma proporção de $1: 4$.

Para a análise dos óbitos notificados no SIM, foram utilizados aqueles que apresentaram como causa básica ou associada os códigos referentes à TB (compreendidos no intervalo de A15 a A19 da Classificação Internacional de Doenças/10ª revisão), de janeiro de 2011 a dezembro de 2012.

\section{Relacionamento das bases de dados:}

Como as bases de dados utilizadas não continham variável identificadora única entre elas, utilizou-se o método de relacionamento probabilístico de registros do aplicativo RecLink III. Este método baseia-se na utilização conjunta de campos comuns de identificação presentes em ambos os bancos de dados, com o objetivo de identificar o quanto é provável que um par de registros se refira a um mesmo indivíduo (Camargo Jr et al., 2012).

Durante o relacionamento probabilístico é executado um conjunto de etapas até a obtenção da base final com a identificação dos registros que foram pareados, a padronização dos campos comuns das bases de dados a serem utilizados no linkage, a blocagem, a aplicação de algoritmos para comparação entre os caracteres, o cálculo de escores que sumarizam o grau de concordância global entre registros do mesmo par (feito pelo software RecLink III), o pareamento que consiste na definição de limiares para a classificação dos pares de registros relacionados em pares verdadeiros, não 
pares e pares duvidosos e a revisão manual dos pares duvidosos ( Camargo Jr et al., 2012).

O processo de linkage, utilizando o software RecLink III, foi realizado em três etapas A primeira etapa foi o relacionamento entre os sistemas de informação da vigilância epidemiológica do Departamento de DST, Aids e Hepatites Virais do MS: Sinan Aids, Siscel e Siclom. Na segunda etapa o banco resultado desse relacionamento (banco R1) foi novamente relacionado, agora com o Sinan TB. Essas duas primeiras etapas foram realizadas anteriormente a essa atual análise. A terceira etapa foi o relacionamento entre o banco de dados resultante dos linkages anteriores (banco R2) com o SIM, também utilizando-se software RecLink III. Foi obtida a base de dados final (banco final R3), que foi utilizada para a análise.

No linkage com do banco R2 com o SIM, foi utilizada uma base do SIM com causa básica ou associada a TB de 01 de janeiro de 2011 a 31 de dezembro de 2012. Optou-se por utilizar um período maior para os registros do SIM com o objetivo de possibilitar a captação dos casos que foram notificados em 2011 no Sinan e registrados no SIM no ano de 2012, ainda durante 0 tratamento da TB. O linkage foi também realizado com o programa RecLink III com as mesmas etapas descritas anteriormente, as variáveis de identificação necessárias para o linkage: nome do paciente, data de nascimento, nome da mãe, sexo, município e UF de residência, endereço, número, bairro e complemento. Para o pareamento de registros, utilizaram-se as variáveis nome do paciente e data de nascimento. A revisão manual dos pares duvidosos foi realizada por um único investigador e durante esse processo a reclassificação desses em pares verdadeiros e não pares obedeceu ao seguinte critério de desempate: nome do paciente, data de nascimento, nome da mãe e logradouro de residência. A revisão foi realizada ao final de cada passo de blocagem e os registros que permaneceram classificados como duvidosos foram considerados não pares. Ao final de todos os passos do linkage foram considerados pares verdadeiros aqueles encontrados em ambas as bases.

Após os processos de relacionamento, obteve-se a base de dados final (banco final R3) utilizado no presente estudo contendo os casos do Sinan notificados em 2011, com as informações obtidas pelo Sinan Aids, Siscel, 
Siclom e com as informações da Declaração de Óbito a partir do relacionamento. Representação esquemática dos relacionamentos dos bancos de dados (Figura 2).

Para verificar se as populações eram iguais ou diferentes foi realizado $o$ teste de proporções (qui-quadrado de Pearson) de duas amostras segundo, e a hipótese nula foi rejeitada quando o $p$-valor do teste foi menor que 0,05 $(p<0,05)$ a hipótese nula foi considerada rejeitada. Com base no resultado do teste das proporções foi-se criado o modelo de regressão logística condicional e foram calculados os odds ratios e os intervalos com $95 \%$ de confiança. As variáveis com significância estatística e com boa completitude $(>80 \%)$ foram incluídas no modelo.

As bases de dados foram disponibilizadas pela Secretaria de Vigilância em Saúde do MS. Essas continham dados de identificação do paciente (nome e endereço), necessárias para esse tipo de relacionamento realizado por meio de metodologia proposta por Camargo Jr et al, com o software RecLink III (Camargo et al., 2000). Os dados foram processados e analisados nos softwares Microsoft Office ${ }^{\circledR}$ Excel, Epi Info $7^{\circledR}$ e Stata $12^{\circledR}$. O trabalho foi aprovado pelo Comitê de Ética em Pesquisa da Fundação de Ensino e Pesquisa das Ciências da Saúde- FEPECS no dia 02/02/2015, com registro $n^{\circ}$ 943.158.

\section{RESULTADOS:}

Na figura 1 está descrito o algoritmo de inclusão na população de estudo. $O$ banco final após a realização dos três relacionamentos apresentou 85.340 registros de casos de TB notificados no ano de 2011 no Brasil. Destes foram excluídos 6.084 casos de TB por recidiva, 5.515 casos de TB por reingressos após abandono e 275 transferidos, restando 73.466 casos novos de tuberculose. Como o objetivo do estudo foi avaliar os fatores associados ao óbito na coinfecção tuberculose e HIV foram excluídos do banco os casos novos de TB HIV negativos, ou que não apresentavam resultado do teste de HIV nos diferentes bancos de dados (65.903 registros), permanecendo 7.563 casos novos de TB HIV positivos. 
Após o relacionamento entre o banco de dado R2 e o SIM foram identificados 848 óbitos (casos) nesse período e não foram encontrados no SIM 6.715 registros de coinfecção TB-HIV. Destes não encontrados no SIM foram excluídos da análise todos aqueles que foram encerrados no Sinan como abandono, óbito, transferidos, TB multirresistente e ignorados (3.113 registros), restando 3.602 registros de coinfecção TB-HIV que encerraram a TB como cura no Sinan (controles) (figura 1).

No Sinan TB antes do relacionamento eram identificados 7.189 registros de casos novos de TB HIV positivos. Nos bancos da Aids foram encontrados 5.667 registros de HIV positivos também presentes no Sinan TB, desse grupo somente 374 estavam registrados inicialmente como HIV negativos ou não realizados no Sinan TB. Foram 1.522 registros de HIV positivos no Sinan TB que não foram encontrados em nenhum dos bancos de vigilância do HIV/aids no período, podendo significar que $20 \%$ das pessoas identificadas como positivas durante o tratamento da TB não realizaram LT-CD4+, iniciaram 0 ARV ou foram notificadas no Sinan Aids até o fim do período de análise.

As características sóciodemográficas dos casos (óbitos com coinfecção TB-HIV) e dos controles (coinfecção TB-HIV com cura da TB) estão apresentadas na tabela 1. $\mathrm{Na}$ análise bivariada comparando os casos e controles foram consideradas associada ao risco de óbito a faixa etária, raça/cor, educação e o fato de ser privado de liberdade.

A faixa etária mais frequente em ambos os grupos foi de 15-49 anos, com $79,5 \%$ (656) entre os casos e $83,8 \%$ (2.917) entre os controles. A faixa etária de $0-14$ anos apresentou $0,8 \%$ (7) e 1,7\% (60) e 50 anos ou mais apresentou 19,7\% (162) e 14,5\% (503) entre casos e controles respectivamente $(p=0,000)$. Na raça/cor o não branco foi mais frequente em ambos os grupos com $59,7 \%$ (461) entre os casos e $54,2 \%$ (1.825) entre os controles $(p=0,005)$. Ambas as variáveis apresentavam completitude superior a $80 \%$ e foram incluídas no modelo de regressão logística.

A educação foi associada ao risco de óbito $(p=0,000)$, porém como a completitude foi baixa (57\%) não foi incluída no modelo de regressão logística. Entre os casos 5,2\% (24) eram analfabetos, 22,9\% (106) estudaram de 1 a 4 anos, $46,1 \%$ (213) de 5 a 8 anos, 20,8\% (96) de 9 a 11 anos e 5\% (23) com 12 
ou mais anos. Entre os controles 4,1\% (84) eram analfabetos, 16,6\% (342) estudaram de 1 a 4 anos, 46,3\% (954) de 5 a 8 anos, 22\% (453) de 9 a 11 anos e $11 \%$ (226) com 12 ou mais anos.

Quando avaliada a variável institucionalizados por ser privados de liberdade, foram $44(5,4 \%)$ casos e $271(7,7 \%)$ controles $(p=0,024)$. Em relação ao sexo não apresentou significância $(p=0,055)$ e em ambos os grupos o sexo masculino foi mais frequente com $68,2 \%$ (578) entre os casos e $71,5 \%$ (2.575) entre os controles. As duas variáveis foram incluídas no modelo de regressão logística, sendo que o sexo foi incluído, apesar de não apresentar significância, pela sua importância como fator de confundimento, e a prevalência maior de casos de TB e de HIV no sexo masculino no Brasil.

As características clínicas entre os casos e dos controles estão apresentadas na tabela 2.

Foram observadas como associadas ao risco de óbito as variáveis uso de álcool, ter realizado teste para $\mathrm{LT}-\mathrm{CD}^{+}$, como proxy de acesso e faixa de LT-CD4+, terapia antirretroviral, forma clínica da TB e realização do tratamento diretamente observado. A variável diabetes não apresentou diferença entre os grupos analisados ( $p=664)$ e não foi incluída na análise multivariada.

Quando avaliada a variável uso de álcool, dos casos 22,1\% (164) faziam uso e $83,8 \%$ (576) não faziam. Dos controles $14,9 \%$ (490) faziam uso e $85,1 \%$ (2.799) não faziam, essa diferença entre os grupos foi estatisticamente significante com $\mathrm{p}=0,000$ (tabela 2 )

A variável clínica LT-CD4+ foi avaliada de duas maneiras, quanto a realização e o resultado. Quando avaliada a realização a maioria dos casos e controles $(74,7 \%)$ teve acesso ao exame.Entre aqueles que se curaram da TB $78,3 \%$ (2.820) realizaram o exame, enquanto somente $59,67 \%$ (506) dos controles o realizaram $(p=0,000)$. Quando avaliado o resultado, a maioria [78,66\%(398)] dos controles apresentavam LT-CD4 ${ }^{+}<200 \mathrm{cel} / \mathrm{mm}^{3}$, enquanto que os casos tiveram somente $25,6 \%$ (719) dos exames com menos de 200 $\mathrm{cel} / \mathrm{mm}^{3}$ de LT-CD4 ${ }^{+}$. Nos controles a frequência das faixas com a contagem de células foi: $23,6 \%$ (667) com 200 a $349 \mathrm{cel} / \mathrm{mm}^{3}$ 20,6\% (581) com 350 a 500 $\mathrm{cel} / \mathrm{mm}^{3}$ e $30,2 \%$ (853) com $>500 \mathrm{cel} / \mathrm{mm}^{3}$, essa diferença foi estatisticamente 
significativa com $p=0,000$. A faixa de LT-CD4+ não foi incluída no modelo de regressão pois somente $75 \%$ apresentava o resultado do exame (tabela 2).

Quanto ao tratamento antirretroviral a maioria $[60,1 \%(2.166)]$ dos controles estavam em tratamento, enquanto somente $38,2 \%$ (324) dos casos estavam em uso do ARV no período do estudo $(p=0,000)$. A forma clínica da TB predominante foi a pulmonar com $65,3 \%$, sendo $64,7 \%$ (549) para os casos e $65,4 \%(2,356)$ para os controles. Quanto as formas extrapulmonar e pulmonar mais extrapulmonar, as proporções foram de 21\%(178), 14,3\% (121) e $25,3 \%(912), 9,3 \%$ (334) entre casos e os controles, respectivamente $(p=0,000)$ (tabela 2).

A maioria dos pacientes do estudo não estava em tratamento diretamente observado (55,5\%), sendo $37,3 \%$ (245) dos casos e $46,1 \%$ (1.395) dos controles estavam em TDO, essa diferença foi estatisticamente significativa com $\mathrm{p}=0,000$ (tabela 2).

As variáveis que apresentaram associação $(p<0.05)$ na análise bivariada com preenchimento superior a $80 \%$ foram inclusas no modelo de regressão logística, sendo elas: idade, raça/cor, privados de liberdade, uso de álcool, LTCD4+ (realização), terapia aintirretroviral, forma clínica da tuberculose e tratamento diretamente observado. Foi incluído também o sexo pela sua importância e frequência da infecção pela TB e HIV maior no sexo masculino, e naturalmente como possível fator de confundimento.

$\mathrm{Na}$ tabela 3 encontram-se os fatores associados independentemente com o óbito em pacientes com coinfecção tuberculose e HIV no Brasil no ano de 2011. $\mathrm{Na}$ análise multivariada foram identificadas fatores de risco para $\mathrm{O}$ óbito: idade $>50$ anos (OR 2,48, IC95\% 1,01 a 6,08), uso de álcool (OR=1,84; IC95\% 1,45 a 2,34) e forma clínica da TB pulmonar e extrapulmonar (OR=1,85; IC95\% 1,36 a 2,52). Os fatores considerados de proteção foram: a realização do LT-CD4+ (OR=0,68; IC95\% 0,54 a 0,87), estar em TARV (OR=0,50; IC95\% 0,40 a 0,63) e estar em TDO (OR=0,69; IC95\% 0,56 a 0,85).

Não permaneceram associados com o risco de evolução à óbito as variáveis sexo, faixas etárias de 0-14 anos e 15-49 anos, raça/cor, o fato de ser privado de liberdade e as apresentações clínicas da TB pulmonar ou extrapulmonar. 


\section{DISCUSSÃO:}

Mesmo com o advento da terapia antirretroviral a tuberculose é um importante marcador de óbito em pessoas que vivem com HIV/Aids, principalmente em países subdesenvolvidos (Schmaltz et al., 2009, WHO, 2014). Atualmente, na era HAART a tuberculose continua com alta mortalidade entre as pessoas HIV positivas, realidade também presente no Brasil. Estudos nacionais apontam a tuberculose como a principal causa de óbito por doença infecciosa definida em pessoas que vivem com HIV/aids (Saraceni et al., 2008). Nos dias atuais outros fatores além da terapia antirretroviral podem influenciar nos desfechos negativos da coinfecção TB-HIV, isso demonstra a necessidade de políticas públicas para a melhoria desse quadro (Komati et al., 2010).

No presente trabalho o perfil dos pacientes com coinfecção TB-HIV analisados foram principalmente masculinos, com idade entre 15 a 49 anos, semelhante ao encontrado por Cheade et al., 2009, Lourdes et al., 2009; Lins et al., 2012. Além disso dados internacionais evidenciam que o perfil da coinfecção TB-HIV geralmente acompanha ambas as epidemias (HIV e TB), dado a interação entre os dois agentes (Santos et al., 2009). Quanto a raça/cor o estudo evidenciou uma prevalência maior de pessoas da raça não branca na população de estudo, fato que segue os achados nacionais em TB e da infecção pelo HIV (Brasil, 2014b, Brasil 2014c). No presente estudo não foram fatores de risco para óbito quando analisados no modelo de regressão o sexo, a raça/cor e as faixas etárias de 0 a 14 anos e de 15 a 49 anos.

Foram identificados três fatores de risco independentes para o óbito na coinfecção TB-HIV: pessoas com idade igual ou maior que 50 anos, o uso de álcool e forma da tuberculose pulmonar e extrapulmonar.

Quanto a faixa etária a maior parte dos casos e controles se apresentavam na faixa de adultos jovens, seguida da faixa de 50 anos ou mais. Quando avaliados somente os casos a proporção de pessoas na faixa de 50 anos ou mais era maior do que a encontrada nos controles, evidenciado uma proporção maior de pacientes na faixa de 50 anos ou mais, dado semelhante ao demonstrado em outros estudos nacionais e internacionais (Pelaquin et al., 2007; Cheade et al., 2009; Lourdes et al., 2009). 
O presente trabalho identifica a idade superior ou igual a 50 anos como aumenta risco de óbito em $150 \%$. A idade 50 anos ou mais também foi considerada fator independente para o óbito em um estudo no estado de SP, justificado pelo autor pelas condições de saúde da população levando a um importante retardo no diagnóstico da TB, maior gravidade da doença e pela presença de comorbidades (Pelaquin et al., 2007). Entretanto Kantipong et al (2012) evidenciaram que a idade acima de 45 anos é um fator de risco para óbito por TB somente em pessoas HIV negativas, fato diferente do que foi encontrado neste presente estudo.

Um estudo no Estado de Pernambuco, em serviços de HIV do Recife, relatou a idade maior que 50 anos como preditor de óbito por TB, principalmente pela presença de comorbidades, somado às dificuldades de acesso ao diagnóstico da TB nesse grupo de pacientes, o que pode levar ao atraso no tratamento e piora da doença (Pablos-Mendez et al., 1996; Domingos et al., 2008). Pacientes idosos podem apresentar manifestações clínicas da TB atípicas, com diagnóstico complexo, há um aumento dos quadros clínicos de tuberculose extrapulmonar e disseminada, o que contribui para o aumento da mortalidade (Millet et al., 2011; Coimbra et al., 2012).

Quando analisada a variável uso de álcool, o risco para óbito aumentou $84 \%$. O alcoolismo é relatado em vários estudos como relacionado ao desfecho desfavorável do tratamento da TB, tanto para o óbito, quando abandono, em HIV positivos e negativos (Tabarsi et al. 2012). Nesse presente trabalho 0 álcool foi evidenciado como fator de risco para o óbito na coinfecção TB-HIV, dado reconhecido também encontrado em estudos em São Paulo e Pernambuco (Pelaquin et al. 2007; Albuquerque et al. 2001). Do total de participantes do estudo $16,2 \%$ eram usuários de álcool, sendo que $22,1 \%$ dos óbitos faziam uso de álcool. Publicações nacionais revelam dados mais alarmantes, como do Ceará em que $42 \%$ dos pacientes da TB faziam uso de álcool (Pires et al. 2012).

Quando analisados estudos internacionais, os resultados são semelhantes, no Irã $86 \%$ dos casos de coinfecção TB-HIV eram usuários de álcool e em Barcelona 27,3\%, as duas publicações demonstraram associação com desfechos desfavoráveis para tuberculose quando associação com o uso 
de álcool (Millet et al. 2011; Tabarsi et al. 2012). Em vários estudos o uso abusivo de álcool é considerado fator de risco independente para não adesão ao tratamento da TB e desfecho óbito, de maneira semelhante ao uso de drogas injetáveis (Sterling et al 2006; Caylà et al 2009; Straetemans et al 2011; Tabarsi et al., 2012).

Além do mais Conigliato et al descreveu que o uso abusivo de álcool é frequente entre as PVHA (Conigliaro et al., 2003) e está associado à desnutrição, o que pode favorecer ao desenvolvimento da tuberculose (Guimarães et al., 2010).

A definição de estratégias diferenciadas em relação ao uso de álcool são necessárias para um melhor seguimento clínico, favorecendo a adesão ao tratamento e diminuindo a mortalidade na coinfecção TB-HIV. Há também necessidade da articulação entre as equipes multiprofissionais, saúde mental e assistência social, para qualificar esse atendimento e a assistência ao usuário.

Quanto à forma da TB, a apresentação pulmonar foi a mais frequente entre os casos e controles, seguida da apresentação extrapulmonar e pulmonar mais extrapulmonar, estudos de outros países evidenciaram dados semelhantes entre pacientes HIV positivos (Kingkaew et al., 2009; Millet et al., 2011; Pires et al., 2012; Lins et al., 2012). Ficou evidenciado que o fato de ter TB pulmonar mais extrapulmonar é um fator de risco para o óbito em pacientes com coinfecção TB-HIV, aumentando o risco de óbito com 85\%. Dado confirmado por outros estudos que evidenciam o acometimento do pulmão associado a um ou mais órgãos, aumenta a gravidade da doença e leva a desfechos negativos, como óbito (Orofino et al., 2006; Kingkaew et al., 2009; Millet et al., 2011;Kantipong et al., 2012; Orofino et al., 2012).

Alguns autores caracterizam a tuberculose pulmonar associada ao acometimento de um ou mais órgãos como tuberculose disseminada (Marcy et al., 2014). Estudos evidenciam que a TB disseminada é considerada fator de risco para óbito na coinfecção, incluindo um estudo brasileiro que evidenciou um risco de 9,09 vezes maior para evolução a óbito (Orofino et al. 2006; Marcy et al. 2014). A importância dessa associação ainda pode ser subestimada no Brasil, visto que a tuberculose miliar (disseminada) está descrita como tuberculose pulmonar no manual de recomendações do Ministério da Saúde, 
justificada pela sua imagem pulmonar característica (Brasil, 2011a), deste modo os óbitos por TB disseminada podem estar classificadas como pulmonar.

Alguns fatores específicos do manejo clínico da TB podem contribuir para o aumento da mortalidade, como a interrupção ou $\mathrm{o}$ inadequado tratamento da doença. Tratamentos padronizados permitem a diminuição dos casos com tratamentos inadequados, porém a presença de reações adversas e a associação com questões sociais, como o uso de álcool e drogas, podem favorecer na interrupção do tratamento e consequente óbito (Alvarez-Uria et al. 2013). Estudos identificam a importância da adesão ao tratamento aos ARV como fator de risco de óbito em PVHA (Moore et al. 2011).

Foram também identificados três fatores de proteção ao óbito na coinfecção: a realização de LT-CD4+, o início da terapia antirretroviral e o tratamento diretamente observado.

Os linfócitos T CD4+ (LT-CD4+), são importantes marcadores para imunodepressão e quanto menor seu nível, maior o risco de ter tuberculose. Ademais a imunodepressão está associada ao aumento das formas graves de TB (extrapulmonar e disseminadas) e consequente aumento da mortalidade nas PVHA (Jones et al., 1993). A queda dos LT-CD4+ são marcadores não só para a TB, mas também de um amplo espectro de infecções oportunistas (Kantipong et al., 2012). Um estudo da Coréia do Sul evidenciou que o nível de $\mathrm{LT}-\mathrm{CD} 4^{+}<200 \mathrm{cels} / \mathrm{mm}^{3}$ é um preditor independente de risco para ter TB em pessoas HIV positivas (Hwang et al., 2013).

Na presente avaliação foi analisado tanto a realização do exame, quanto o nível de LT-CD4+. Na população de estudo a maioria teve acesso ao exame laboratorial, sendo que um terço apresentava LT-CD4 ${ }^{+}<200 \mathrm{cels} / \mathrm{mm}^{3}$. Quando avaliados somente os óbitos 40,3\% tiveram acesso ao exame, destes $78,66 \%$ apresentam LT-CD4 $4^{+}<200$ cels $/ \mathrm{mm}^{3}$, demonstrando que a grande maioria dos óbitos não tiveram acesso ao exame laboratorial, e quando o fazem apresentam o diagnóstico tardio da Infecção pelo HIV, com imunodepressão avançada com maior mortalidade (Lins et al., 2012). No presente estudo somente a realização do exame foi associado ao risco de óbito para coinfecção TB-HIV, com redução de risco de $32 \%$, evidencia corroborada por outros achados na literatura, principalmente em países subdesenvolvidos (Ajayi et al., 
2009; Moore et al., 2011; Vijay et al., 2011; Lins et al, 2012; Alvarez-Uria et al., 2013; Cortes et al., 2013). Não foi possível incluir no modelo de regressão as faixas de LT-CD4+ devido a colinearidade com a realização do exame e pelo baixo preenchimento da variável.

Além disso está bem clara a evidência da importância do início da TARV precoce quando da imunodepressão avançada com redução da mortalidade na coinfecção TB-HIV. Quando LT-CD4+ $<200$ cels $/ \mathrm{mm}^{3}$ o ARV deve ser iniciado na segunda semana do diagnóstico da TB (Garcia-Vidal et al., 2010; Abdool Karim et al., 2011; Blanc et al., 2011). Apesar de melhorias importantes na qualidade do atendimento das PVHA no mundo, ainda existem limitações de acesso ao $\mathrm{LT}^{-C D} 4^{+}$, principalmente em países africanos, dificuldades relacionais ao acesso à novas tecnologias, custo-efetividade dos exames, organização da rede assistencial e questões sócio culturais da população (Peter et al., 2008) como aparentemente aconteceu no Brasil. No Brasil nos últimos anos ocorreu um grande avanço e investimento na rede laboratorial para o atendimento das PVHA, tal fato contribuiu de maneira significativa para ampliar o tratamento ARV (Hallal et al. 2010). Entretanto esforços ainda maiores devem ser feitos para dar acesso aos serviços de saúde à população com coinfecção TB-HIV, que por questões clínicas, sociais ou talvez até geográficas não está sendo dado o acesso adequado aos serviços de atendimento às pessoas com HIV/aids.

O não início da terapia antirretroviral é uma das principais condições para óbito na coinfecção. No presente estudo somente pouco mais da metade dos pacientes com coinfecção TB-HIV estavam em TARV no período analisado, apesar das recomendações nacionais da época já recomendarem a TARV para todos os casos com tuberculose desde 2008 (Brasil, 2008 e 2011a). Quando analisado o risco de óbito quem estava em TARV apresentou metade do risco de óbito de quem não estava em TARV, fato condizente com vários estudos encontrados (Lawn et al. 2009; Vijay et al. 2011; Kantipong et al. 2012;). Quando avaliados somente os óbitos, pouco mais de um terço estavam em TARV, dado inferior ao encontrado em uma publicação do estado do Ceará que descreveu $61,9 \%$ de TARV entre os óbitos e de $90 \%$ entre os que curaram a TB (Pires et al. 2012). 
Após o diagnóstico da tuberculose em uma PVHA, há indicação do início imediato do tratamento da TB acompanhado do início em tempo precoce dos $A R V$. Essa oportunidade é de suma importância no manejo clínico da coinfecção (WHO, 2013). Foram publicados três grandes estudos com evidência do tempo ideal para início da TARV na coinfecção TB-HIV, o estudo SAPIT- Starting Antiretroviral therapy at three Points in Tuberculosis therapy (Abdool Karim et al. 2011), CAMELIA- Cambodian Early versus Late Introduction of Antiretroviral Drugs (Blanc et al. 2011) e STRIDE- Immediate Versus Deferred Start oh Anti-HIV Therapy in HIV-Infected Being Adults Treated for Tuberculosis (Garcia-Vidal et al. 2010). Os três estudos concluíram que pacientes com imunodepressão avançada $\left(\right.$ LT-CD4 $\left.{ }^{+}<200 \mathrm{cels} / \mathrm{mm}^{3}\right)$ devem começar o ARV em duas semanas após o início do tratamento da TB com importante redução na mortalidade durante 0 tratamento da tuberculose. Quando contagem de LT-CD4+> $200 \mathrm{cels} / \mathrm{mm}^{3}$, esse benefício não foi evidente, podendo-se esperar oito semanas para o início da TARV. Após oito semanas do tratamento da TB há redução dos medicamentos em uso (fase de manutenção com rifampicina e isoniazida) com aparecimento de menos efeitos adversos aos medicamentos (Garcia-Vidal et al. 2010; Abdool Karim et al. 2011; Blanc et al. 2011;). Infelizmente no presente estudo não foi possível avaliar o início dos ARV e correlacionar o óbito ao início dos ARV.

Historicamente vários fatores vêm desempenhando papel negativo no início oportuno da terapia antirretroviral, como a presença de reações adversas (Yee et al. 2003; Marks et al. 2009) e interações medicamentosas, limitação dos ARV disponíveis, visto que as interações medicamentosas são frequentes (Santos et al., 2009; WHO, 2013) e o risco da Síndrome inflamatória da reconstituição imune (SIRI) (Naidoo et al., 2012).

Os profissionais de saúde devem estar atentos à presença de reações adversas, pois as pessoas HIV positivas apresentam mais efeitos adversos quando comparadas as HIV negativas. Há também a potencialização desses efeitos quando determinados fármacos são utilizados em conjunto. A hepatotoxicidade e neuropatia são mais frequentes entre as PVHA e foram correlacionados com $\mathrm{O}$ abandono ao tratamento da TB nesse grupo de pacientes (Yee et al., 2003; Marks et al., 2009). 
A SIRI é uma reconstituição da imunidade que ocorre durante o tratamento antirretroviral e está associada à terapia ARV precoce em pessoas com coinfecção TB-HIV (Naidoo et al. 2012). Pode levar a piora clínica daqueles pacientes já em tratamento da TB, ou a TB é diagnosticada juntamente com um quadro de SIRI. Outras infecções oportunistas podem também estar associadas ao quadro e quando manejada de maneira inadequada apresenta altos índices de mortalidade. Apesar da gravidade do quadro e do aumento da sua frequência, seu manejo clínico adequado não aumentou o risco de óbito com a terapia antirretroviral precoce (Garcia-Vidal et al. 2010; Abdool Karim et al. 2011;Blanc et al. 2011).

O início oportuno da TARV é a estratégia fundamental para reverter esse quadro de alta mortalidade na coinfecção TB-HIV no Brasil. Somente com equipes multidisciplinares capacitadas no manejo dos pacientes, uma rede de saúde acessível e condizente com as questões sociais da população será possível garantir o acesso da população ao seguimento e tratamento adequados.

Outros benefícios apontados com a política de acesso universal ao tratamento do HIV é a prevenção da transmissão do vírus do HIV e a prevenção da TB (Franco et al., 2013). No Brasil, apesar da recomendação de "testar e tratar" (Brasil, 2013b), como identificado neste presente estudo, vários fatores como questões sociais, o uso de álcool e outras drogas, e o próprio acesso aos serviços de saúde, podem influenciar ao não início ou na demora no início da terapia antirretroviral. A organização dos serviços de saúde do Brasil para o tratamento da TB e do HIV se deram em momentos e lógicas diferentes, a localização geográfica, o atendimento de ambas as doenças em serviços/níveis distintos, o que pôde ter agido negativamente no seguimento da coinfecção TB-HIV. A TB sofreu a descentralização ao longo das últimas décadas, se concentrando principalmente na atenção básica, enquanto a assistência da AIDS é relativamente recente e concentrada em serviços especializados e verticalizados (Jamal \& Moherdaui, 2007). Somente nos últimos anos se iniciou tentativas do Ministério da Saúde e demais níveis de governo para descentralização do HIV para a atenção básica no país (Brasil, 2014a). 
Outra estratégia para adesão ao tratamento é o tratamento diretamente observado (TDO). Nesse trabalho as PVHA com coinfecção TB-HIV em TDO apresentam uma proteção para o óbito, com redução de risco de $31 \%$. O TDO consiste na observação da toma da medicação da tuberculose é considerado fundamental pela Organização Mundial da Saúde e foi reforçado com a estratégia Direct Observed Treatment Strategy, Short Course (DOTS) publicada em 2006. Outras publicações apresentaram resultados semelhantes com maior probabilidade de cura quando realizado o TDO, quando comparados à aqueles que não realizam o TDO (Thorn, 2008).

O TDO é considerado um momento de vínculo entre o usuário e o profissional de saúde e serviço. Quando realizado, proporciona cuidado, apoio ao paciente, além de importante momento para transmitir informações sobre a doença (Brasil, 2011b). O Brasil segue as recomendações da OMS desde 1999, com oferta do TDO para todos os pacientes, entretanto devido às questões de organização da rede de saúde local e também da cobertura da atenção básica, somente parte dos usuários têm acesso ao TDO (Brasil, 2013a).

Importante informar que o preenchimento da variável TDO no Sinan apresenta limitações que podem influenciar nos resultados encontrados. Apesar de por definição só ser considerado TDO quando observada a toma da medicação por profissional de saúde por no mínimo três vezes na semana, durante todo o tratamento da tuberculose (Brasil, 2011a), a variável no Sinan é dicotômica (sim/não). Fica a cargo do profissional de saúde a avaliação quanto a frequência de uso do medicamento, não contendo essa informação no sistema de informação.

Nahid et al (2007) estudaram os fatores relacionados ao desfecho de tratamento de pessoas com coinfecção TB-HIV e encontraram associação com - TDO, pessoas sem TDO apresentavam mais recaídas e desfechos desfavoráveis quando comparadas àquelas com TDO (Nahid et al., 2007).

Outros fatores estudados não apresentaram associação com o risco de óbito, como a comorbidade com diabetes mellitus e pessoas privadas de liberdade. A escolaridade foi uma variável mal preenchida e por isso não foi incluída no modelo de regressão. 
O estudo apresenta como limitação do uso dos dados secundários, como o preenchimentos dos dados Sinan, a indisponibilidade de outras variáveis e as próprias limitações referentes ao relacionamento probabilístico dos bancos de dados. O relacionamento com o SIM utilizou somente a causa básica e associada da TB, assim podem haver perdas de casos com óbito por aids em que a tuberculose não foi descrita como causa associada. O banco de dados foi de 2011, porém não ocorreram grandes mudanças nas recomendações nacionais até o final de 2013. Há necessidade de repetição desse estudo agora com a nova política nacional de "teste e trate" para a avaliação se ocorreram mudanças dos fatores analisados. Em um futuro estudo também seria interessante a avaliação sobre a oportunidade do início da TARV nesse grupo de pacientes.

Algumas variáveis que podem influenciar na mortalidade não foram analisadas por não estarem disponíveis no Sinan, como o uso de drogas ilícitas, a população em situação de rua e o nível do LT-CD4+ em que se iniciou a TARV, são fatores que podem de alguma maneira influenciar os resultados encontrados.

Além disso os dados utilizados são de 2011, podendo não representar exatamente o contexto atual da coinfecção TB-HIV do país. Como entre 2011, 2012 e 2013 não ocorreram grandes mudanças nas recomendações do tratamento de ambas as doenças, se imagina que o cenário analisado continue semelhante.

O presente estudo, apesar de suas limitações, possibilitou uma visão geral do perfil da coinfecção TB-HIV e os fatores associados ao óbito nessa população brasileira. Apesar dos grandes avanços e da estruturação da assistência à saúde no Brasil, o acesso das PVHA aos serviços de saúde ainda

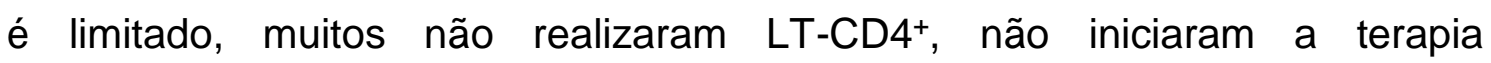
antirretroviral e não realizaram o TDO. As articulações dentro e fora do setor saúde, como como parcerias saúde mental e assistência social, devem ser implementadas de forma a minimizar a influência de hábitos como o etilismo. Ainda são grandes os desafios nacionais para reversão do cenário atual para óbito na coinfecção TB-HIV, esse estudo visa colaborar com a tomada de decisão de políticas públicas para melhoria do cuidado à pessoa com 
coinfecção TB-HIV no país e apontar para possíveis cenários semelhantes em outras países.

\section{REFERÊNCIAS:}

Abdool Karim, S.S., Naidoo, K., Grobler, A., Padayatchi, N., Baxter, C., Gray, A. L., Gengiah, T., Gengiah, S., Naidoo, A., Jithoo, N., Nair, G., El-Sadr, W.M. \& Friedland, G.. 2011. Integration of antiretroviral therapy with tuberculosis treatment. Nejm, 365(16), pp.1492-501.

Ajayi, A.O., Ajayi, E.A, Fasakin, K.A. 2009. CD4+ T-Lymphocytes cell counts in adults with human immunodeficiency virus infection at the medical department of a tertiary health institution in Nigeria. Annals of African Medicine: 8(4):257260.

Albuquerque, M.D.F.M, Ximenes, R.A.A., Lucena-Silva N., Souza W.V., Dantas A.T., Dantas, M.S. et al. De et al., 2001. Fatores prognósticos para o desfecho do tratamento da tuberculose pulmonar em Recife, Pernambuco, Brasil. Revista Panamericana de Salud Pública, 9(6), pp.368-374.

Alvarez-Uria, G., Naik, P.K.,Pakam, R.\& Midde, M. 2013. Factors associated with attrition, mortality, and loss to follow up after antiretroviral therapy initiation: Data from an HIV cohort study in India. Global Health Action, 6(1), pp.1-8.

Antonucci, G., Girardi, E, Raviglione, M.C., Al, E. 1995. Risk factors for tuberculosis in hiv-Infected persons: A prospective cohort study. JAMA, 274(2), pp.143-148.

Barreira, D. \& Grangeiro, A., 2007. Avaliação das estratégias de controle da tuberculose no Brasil. Revista saúde pública, 41, pp.4-8.

Bartholomay, P., De Oliveira, G.P., Pinheiro, R.S.\& Vasconcelos, A.M.N. 2014. Melhoria da qualidade das informações sobre tuberculose a partir do 
relacionamento entre bases de dados. Cad. Saúde Pública, 30(11), pp.24592469.

Blanc, F.-X., Sok, T., Laureillard, D., Borand, L., Rekacewicz, C., Nerrienet, E., Madec, Y., Marcy, O., Chan, S. \& Prak, N. 2011. Earlier versus later start of antiretroviral therapy in HIV-infected adults with tuberculosis. New England Journal of Medicine, 365(16), pp.1471-1481.

Brasil. Ministério da Saúde. Centro de Referência Professor Hélio Fraga. 2007. Tuberculose Multirresistente - Guia de Vigilância Epidemiológica. Guia de Vigilância Epidemiológica. 1ª Edição. Rio de Janeiro. 94p.

Brasil. Ministério da Saúde. Secretaria de Vigilância em Saúde. Departamento de DST, Aids e Hepatites Virais. 2008. Recomendações para Terapia Antiretroviral em Adultos Infectados pelo HIV 2008. Brasília: Série Manuais n`2. $224 p$.

Brasil. Ministério da Saúde. Secretaria de Vigilância em Saúde. Departamento de Vigilância Epidemiológica. Programa Nacional de Controle da Tuberculose. 2011a. Manual de Recomendações para o Controle da Tuberculose no Brasil. Brasília: Série A: manuais e normas técnicas. $1^{1 \underline{a}}$ edição; $284 p$

Brasil. Ministério da Saúde. Secretaria de Vigilância em Saúde. Departamento de Vigilância Epidemiológica. Programa Nacional de Controle da Tuberculose. 2011b. Tratamento Diretamente Observado (TDO) da Tuberculose na Atenção Básica. Protocolo de enfermagem. Brasília. Série F: Comunicação e Educação em Saúde. 1를 edição; 2011; 172 p.

Brasil. Ministério da Saúde Secretaria de Vigilância em Saúde. Departamento de Vigilância das Doenças Transmissíveis. 2012. Boletim Epidemiológico: Especial Tuberculose no Brasil, realidades e perspectivas. Disponível em: (Acessado em 22 de março de 2015). 
Brasil. Ministério da Saúde Secretaria de Vigilância em Saúde. Departamento de Vigilância das Doenças Transmissíveis. Programa Nacional de Controle da Tuberculose. 2013a. Boletim Epidemiológico. Tuberculose: alinhada com o social, afinada com a tecnologia. Disponível em: http://portalsaude.saude.gov.br/images/pdf/2014/maio/06/boletim2-2013-tbweb.pdf. (Acessado em 22 de março de 2015).

Brasil. Ministério da Saúde. Secretaria-Executiva. 2013b. Recomendações para o Manejo da co-infecção TB-HIV em Serviços de Atenção Especializada a pessoas vivendo com HIV/aids. Brasília. $1^{a}$ edição; $28 p$.

Brasil. Ministério da Saúde Secretaria de Vigilância em Saúde. Departamento de DST, Aids e Hepatites Virais. 2014a. 5 Passos para a implementação do Manejo da Infecção pelo HIV na Atenção Básica. Guia para Gestores. Disponível

em: http://www.aids.gov.br/sites/default/files/anexos/publicacao/2014/55883/coorde ndores_pdf_46953.pdf (Acessado em 04 de julho de 2015).

Brasil. Ministério da Saúde Secretaria de Vigilância em Saúde. Departamento de Vigilância das Doenças Transmissíveis. 2014b. Boletim Epidemiológico: O controle da tuberculose no Brasil: avanços, inovações e desafios. Disponível em: http://portalsaude.saude.gov.br/images/pdf/2014/maio/29/BE-2014-45--2-tb.pdf (Acessado em 22 de março de 2015).

Brasil. Ministério da Saúde. Secretaria de Vigilância em Saúde. Departamento de DST, Aids e Hepatites Virais. 2014c. Boletim epidemiológico HIV.Aids. Boletim AIDS 2014. Ano III-n ${ }^{\circ} 1-27^{\mathrm{a}}$ à $52^{\mathrm{a}}$ semanas epidemiológicas- julho a dezembro de 2013. Ano III-n ${ }^{\circ} 1^{-01^{a}}$ à $26^{\underline{a}}$ semanas epidemiológicas- janeiro a junho de 2014.2 Disponivel em: http:/www.aids.gov.br/sites/default/files/anexos/publicacao/2014/56677/boletim _2014_final_pdf_15565.pdf (Acessado em 05 de julho de 2015). 
Camargo Junior, K.R.,. \& Coeli, C.M. 2000. Reclink: an application for database linkage implementing the probabilistic record linkage method. Cad Saude Publica, Apr-Jun 16(2), 439-47.

Brasil. Ministério da Saúde. Secretaria de Vigilância em Saúde. Departamento de Vigilância Epidemiológica. Programa Nacional de Controle da Tuberculose 2014d. Panorama da tuberculose no Brasil Indicadores epidemiológicos e operacionais. Brasília; 92p.

Brasil. Ministério da Saúde Secretaria de Vigilância em Saúde. Departamento de Vigilância das Doenças Transmissíveis. 2015. Boletim Epidemiológico: Detectar, tratar e curar: desafios e estratégias brasileiras frente à tuberculose. Disponível em: http://u.saude.gov.br/images/pdf/2015/marco/27/2015-007---BETuberculose---para-substitui----o-no-site.pdf (Acessado em 22 de março de 2015).

Caminero, J.A. 2003. Guía de la Tuberculosis para Médicos Especialistas.Unión Internacional Contra la Tuberculosis y Enfermidades Respiratorias (UICTER). Paris, França.

Caylà, J.A., Rodrigo, T., Ruiz-Manzano, J., Caminero, J.A., Vidal, R., García, J.M., Blanquer, R. \& Casals, M. 2009. Tuberculosis treatment adherence and fatality in Spain. Respiratory research, 10(1), p.121.

Cheade, M.D.F.M. Siqueira, P.H., Sá, R.G. \& Honer, M.R. 2009. Characterization of tuberculosis among HIVIAIDS patients at a referral center in Mato Grosso do Sul. Revista da Sociedade Brasileira de Medicina Tropical, 42(2), pp.119-125.

Coimbra, I., Maruza, M., Militão-Albuquerque, M.D.F.P., Moura, L.V.,Diniz, G.T.N., Miranda-Filho, D.D.B., Lacerda, H.R., Rodrigues, L.C., Ximenes, R.D.A. 2012. Associated factors for treatment delay in pulmonary tuberculosis in HIV- 
infected individuals: a nested case-control study. BMC Infectious Diseases, 12, p.208.

Conigliaro, J., Gordon, A.J., McGinnis, K.A., Rabeneck, L. \& Justice, A.C. 2003. How harmful is hazardous alcohol use and abuse in HIV infection: do health care providers know who is at risk. Journal of acquired immune deficiency syndromes (1999), 33(4), pp.521-525.

Corbett, E.L., Watt CJ, Walke, N., Maher, D., Williams, B.G., Raviglione, M.C. et al. 2003. The growing burden of tuberculosis: global trends and interactions with the HIV epidemic. Archives of internal medicine, 163(9), pp.1009-1021.

Cortes, C.P., Cortes, Claudia P., Wehbe, F.H, McGowan, C.C., Shepherd, B.E., Duda, S.N., Jenkins, C., Gonzalez, E., Carriquiry, G., Schechter, M., Padgett, D., Cesar, C., Madero, J.S., Pape, J.W., Masys, D.R., Sterling, T.R., Cortes, C.P., Wolff, M., Arancibia, J.M., Saavedra, F., Salinas, C., Gonzalez, E., Carriquiry, G., Mayer, E., Condorhuaman, P., Gotuzzo, E., Schechter, M., Tuboi, S.H., Padgett, D., Cesar, C., Fink, V., Sued, O., Cahn, P., Crabtree, B., Madero, J.S., Bacon, M., Williams, C., Wehbe, F.H. \& Sterling, T.R. 2013. Duration of Anti-Tuberculosis Therapy and Timing of Antiretroviral Therapy Initiation: Association with Mortality in HIV-Related Tuberculosis. PLoS ONE, 8(9), pp.1-8.

Daley, C.L., Small, P.M., Schecter, G.F., Schoolnik, G.K., McAdam, R.A., Jacobs, W.R.J. et al. 1992. An Outbreak of Tuberculosis with Accelerated Progression among Persons Infected with the Human Immunodeficiency Virus: An Analysis Using Restriction-Fragment_Length Polymorphisms. New England journal of medicine, 326(4), pp.231-235.

Domingos, M.P., Caiaffa, W.T. \& Colosimo, E.A., 2008. Mortality, TB/HIV coinfection, and treatment dropout: predictors of tuberculosis prognosis in Recife, Pernambuco State, Brazil. Cadernos de saude publica, 24(4), pp.887-896. 
Fanning, A. 1999. Tuberculosis: 6. Extrapulmonary disease. Cmaj, 160(11), pp.1597-1603.

Franco, R. a \& Saag, M.S. 2013. When to start antiretroviral therapy: as soon as possible. BMC medicine, 11(1), p.147.

Garcia-Vidal, C., Salvado, M. \& Salavert, M., 2010. Timing of antiretroviral drugs during tuberculosis therapy. The New England journal of medicine, 362(22), pp.2137-2138; author reply 2138-2139.

Guimarães, R.M., Lobo, A.D.P., Siqueira, E.A., Franco, T., Borges, F., Cristina, S. \& Melo, C. 2010. Características clínico-demográficas de pacientes hospitalizados com tuberculose no Brasil, no período de 1994 a 2004. 38(5), pp.511-517.

Hallal, R., Ravasi, G., Kuchenbecker, R., Greco, D. \& Simão, M. 2010. O acesso universal ao tratamento antirretroviral no Brasil. Revista Tempus Actas em saúde coletiva, 4(2), pp.53-65.

Hwang, J. \& Choe, P., 2013. Incidence and Risk Factors of Tuberculosis in Patients with Human Immunodeficiency Virus Infection. Journal of Korean, pp.374-377.

Jamal, L.F. \& Moherdaui, F., 2007. Tuberculose e infecção pelo HIV no Brasil: magnitude do problema e estratégias para o controle. Revista de Saúde Pública, 41, pp.104-110.

Jones, B.E., Jones, Brenda E., Young, S.M.M., Antoniskis, D., Davidson, P.T., Kramer, F. \& Barnes, P.F., 1993. Relationship of the Manifestations of Tuberculosis to CD4 Cell Counts in Patients with Human Immunodeficiency Virus Infection. American Review of Respiratory Disease, 148(5), pp.12921297. 
Kantipong, P. , Murakami, K., Moolphate, S., Aung, M.N. \& Yamada, N., 2012. Causes of mortality among tuberculosis and HIV co-infected patients in chiang rai, northern Thailand. HIV/AIDS - Research and Palliative Care, 4, pp.159-168.

Karim, S.S.A., Churchyard, G.J., Karim, Q.A. \& Lawn, S.D., 2009. HIV infection and tuberculosis in South Africa: an urgent need to escalate the public health response. the Lancet, 374(9693), pp.921-933.

Camargo Jr, K.R., Coeli, C.M.. 2012. Reclink III versão 3.1.6.3160. Guia do Usuário. Disponível em http://www.iesc.ufrj.br/reclink. (Acessado em 01 de julho de 2015).

Kingkaew, N., Sangtong, B., Amnuaiphon, W., Jongpaibulpatana, J., Mankatittham, W., Akksilp, S., Sirinak, C., Nateniyom, S., Burapat, C., Kittikraisak, W. Monkongdee, P. \& Varma, J.K., 2009. HIV-associated extrapulmonary tuberculosis in Thailand: epidemiology and risk factors for death. International Journal of Infectious Diseases, 13(6), pp.722-729.

Komati, S., Shaw, P., Stubbs, N., Mathibedi, M.J., Malan, L., Sangweni, P., Metcalf, J. \& Hass, S., 2010. Tuberculosis Risk Factors and Mortality for HIV Infected Persons Receiving Antiretroviral Therapy in South Africa. Aids, 24(12), pp.1849-1855.

Kritski, A.L., Villa, T.S., Trajman, A., Lapa E.S., Medronho,J.P., Roberto, A \& Ruffino-Netto, A., 2007. Two decades of research on tuberculosis in Brazil: state of the art of scientific publications. Revista de saúde pública, 41 Suppl 1, pp.9-14.

Lawn, S.D., Kranzer, K. \& Wood, R., 2009. Antiretroviral Therapy for Control of the HIV-associated Tuberculosis Epidemic in Resource-Limited Settings. Clinics in Chest Medicine, 30(4), pp.685-699. 
Lins, T.B. Soares, E.M., Santos, F.M.S., Mandacaru, P.M.P., Pina, T. \& AraújoFilho, J.A. 2012. Mycobacterium tuberculosis and human immunodeficiency virus coinfection in a tertiary care hospital in Midwestern Brazil. Le infezioni in medicina: rivista periodica di eziologia, epidemiologia, diagnostica, clinica e terapia delle patologie infettive, 20(2), pp.108-116.

Lourdes, M.D., Geraldes, S., Helena, S., Vendramini, F., Wysocki, A.D., 2009. A dimensão epidemiológica da coinfecção tb / hiv. Rev Latino-am Enfermagem. 17(5).

Marcy, O., Laureillard, D, .Madec, Y., Chan, S., Mayaud, C., Borand, L., Prak, N., Kim, C., Lak, K.K., Hak, C., Dim, B., Sok, T., Delfraissy, J.F., Goldfeld, A.E. \& Blanc, F.X., 2014. Causes and determinants of mortality in HIV-infected adults with tuberculosis: An analysis from the CAMELIA ANRS 1295-CIPRA KH001 randomized trial. Clinical Infectious Diseases, 59(3), pp.435-445.

Marks, D.J.B., Dheda, K., Dawson, R., Ainslie, G. \& Miller, R.F., 2009. Adverse events to antituberculosis therapy: influence of HIV and antiretroviral drugs. International journal of STD \& AIDS, 20(5), pp.339-345.

Millet, J.P., Orcau, A., Rius, C., Casals, M., De Olalla, P.G., Moreno, A., Nelson, J.L. \& Caylà, J., 2011. Predictors of death among patients who completed tuberculosis treatment: A Population-Based cohort study. PLoS ONE, 6(9), pp.4-11.

Moore, D.M., Yiannoutsos, C.T., Musick, B.S., Tappero, J., Degerman, R., Campbell, J., Were, W., Kaharuza, F., Alexander, L.N.\& Downing, R., 2011. Determinants of early and late mortality among HIV-infected individuals receiving home-based antiretroviral therapy in rural Uganda. Journal of acquired immune deficiency syndromes (1999), 58(3), p.289.

Nahid, P., Gonzalez, L.C., Rudoy, I.D.J., Bouke C., Unger, A., Kawamura, L.M.O., Dennis, H., Hopewell, P.C. \& Daley, C.L., 2007. Treatment Outcomes of 
Patients with HIV and Tuberculosis. American Journal of Respiratory and Critical Care Medicine, 175(11), pp.1199-1206.

Naidoo, K., Yende-Zuma, N., Padayatchi, N., Naidoo, K., Jithoo, N., Nair, G., Bamber, S., Gengiah, S., El-Sadr, W.M., Friedland, G., Karim, S.A., 2012. The immune reconstitution inflammatory syndrome after Antiretroviral Therapy Initiation in Patients with Tuberculosis: Findings from the SAPiT Trial. Annals of Internal Medicine, 157(5), pp.313-324.

De Oliveira, G.P; Pinheiro, R.S; Coeli, C.M; Barreira, D \& Codenotti, S.B. 2012. Mortality information system for identifying underreported cases of tuberculosis in Brazil. Revista brasileira de epidemiologia $=$ Brazilian journal of epidemiology, 15(3), pp.468-77.

Orofino, R.D.L., Brasil, P.E.A.,Trajman, A., Schmaltz, C.A.S., Dalcolmo, M. \& Rolla, V.C., 2012. Preditores dos desfechos do tratamento da tuberculose . Jornal Brasileiro de Pneumologia , 38 , pp.88-97.

Pablos-Mendez, A., Sterling, T.R. \& Frieden, T.R., 1996. The relationship between delayed or incomplete treatment and all-cause mortality in patients with tuberculosis. JAMA, 276(15), pp.1223-1228.

Pelaquin, M.H.H., Silva, R.S. e \& Ribeiro, S.A., 2007. Fatores associados ao óbito por tuberculose na zona leste da cidade de São Paulo, 2001. Jornal Brasileiro de Pneumologia , 33 , pp.311-317.

Pestana, E., Telo, L., Gomes, M.J. \& Amaral-Marques, R., 1993. Extrapulmonary tuberculosis. Acta medica portuguesa, 6(5), pp.175-180.

Peter, T., Badrichani, A., Wu, E., Freeman, R., Ncube, B., Ariki, F., Daily, J., Shimada, Y.\& Murtagh, M. 2008. Challenges in implementing CD4 testing in resource-limited settings. Cytometry Part B: Clinical Cytometry, 74B(S1), pp.S123-S130. 
Pires, J., Rosilene, R., Gadelha, M., Herzer, T.L., Peres, D.A., Jesus, M., Leitão, S., Façanha, M.C., Holanda, C.N., Girão, E.S. \& Oliveira, M.C.N. 2012. Características clínico-epidemiológicas de pacientes com coinfecção HIV / tuberculose acompanhados nos serviços de referência para HIV / AIDS em Fortaleza , Ceará, entre 2004 e 2008. Cad Saúde Colet. 20(2): 244-9.

Santos, S. \& Beck, S.T., 2009. A coinfecção tuberculose e HIV : um importante desafio - Artigo de revisão. Revista brasileira de análises clínicas, 41(3), pp.209-215.

Saraceni, V., King, B.S., Cavalcante, S.C., Golub, J.E., Lauria, L.M., Moulton, L.H., Chaisson, R.E., Durovni, B., 2008. Tuberculosis as primary cause of death among AIDS cases in Rio de Janeiro, Brazil. The international journal of tuberculosis and lung disease: the official journal of the International Union against Tuberculosis and Lung Disease, 12(7), pp.769-772.

Schmaltz, C.A.S., Sant'Anna, F.M., Neves, S.C., Velasque, L.S., Lourenço, M.C., Morgado, M.G.et al. 2009. Influence of HIV infection on mortality in a cohort of patients treated for tuberculosis in the context of wide access to $H A A R T$, in Rio de Janeiro, Brazil. Journal of acquired immune deficiency syndromes (1999), 52(5), pp.623-628.

Sterling, T.R., Zhao, Z., Khan, A., Chaisson, R.E., Schluger, N., Mangura, B., Weiner, M., Vernon, A., 2006. Mortality in a large tuberculosis treatment trial: modifiable and non-modifiable risk factors. The international journal of tuberculosis and lung disease: the official journal of the International Union against Tuberculosis and Lung Disease, 10(5), pp.542-549.

Straetemans M., Glaziou P., Bierrenbach A.L., Sismanidis C., Van Der Werf, M.J., 2011. Assessing Tuberculosis Case Fatality Ratio: A Meta-Analysis. PLoS ONE 6(6): e20755. 
Tabarsi, P., Chitsaz, E., Moradi, A., Baghaei, P., Farnia, P., Marjani, M., Shamai, M., Amiri, M., Nikaein, S., Mansouri, D., 2012. Treatment outcome, mortality and their predictors among HIV-associated tuberculosis patients. International journal of STD \& AIDS, 23(9), pp.e1-e4.

TEMPRANO ANRS 12136 STUDY GROUP et al. 2015. A Trial of Early Antiretrovirals and Isoniazid Preventive Therapy in Africa. The New England journal of medicine. Disponível em: <http://www.nejm.org/doi/pdf/10.1056/NEJMoa1507198> (acesso em 31 de agosto de 2015).

Thorn, P., 2008. La tuberculosis: información y consejos para vencer la enfermedad. StopTB Partnership. Disponível em: http://www.stoptb.org/assets/documents/resources/publications/acsm/TB\%20TI PS\%20SPN\%20WEB.pdf (Acesso em 05 de julho de 2015).

Vijay, S., Kumar, P., Chauhan, L.S., Narayan R.S.V., Vaidyanathan, P. 2011. Treatment Outcome and Mortality at One and Half Year Follow-Up of HIV Infected TB Patients Under TB Control Programme in a District of South India. PloS one, 6(7), p.e21008.

WHO. World Health Organization. 2013. Consolidated guidelines on the use of antiretroviral drugs for treating and preventing HIV infection. Recomendations for a Public Health Approach. Genebra: World Health Organization.

WHO. World Health Organization. 2014. Global tuberculosis report 2014 Genebra: World Health Organization.

WHO. World Health Organization. 2011. Guidelines for intensified tuberculosis case-finding and isoniazid preventive therapy for people living with HIV in resourceconstrained settings. Department of HIV/Aids, Stop TB Department. Geneva: World Health Organization. 
Yee, D., Valiquette, C., Pelletier, M., Parisien, I., Rocher, I., Menzies, D., 2003. Incidence of Serious Side Effects from First-Line Antituberculosis Drugs among Patients Treated for Active Tuberculosis. American Journal of Respiratory and Critical Care Medicine, 167(11), pp.1472-1477.

Agradecimentos: Ao Programa Nacional de Controle da Tuberculose e ao Departamento de DST, Aids e Hepatites Virais da Secretaria de Vigilância em Saúde do Ministério da Saúde pela cessão dos dados para análise.

Conflito de interesses: Os autores referem não haver conflito de interesse. 
Figura 1- Algoritmo de inclusão na população de estudo.

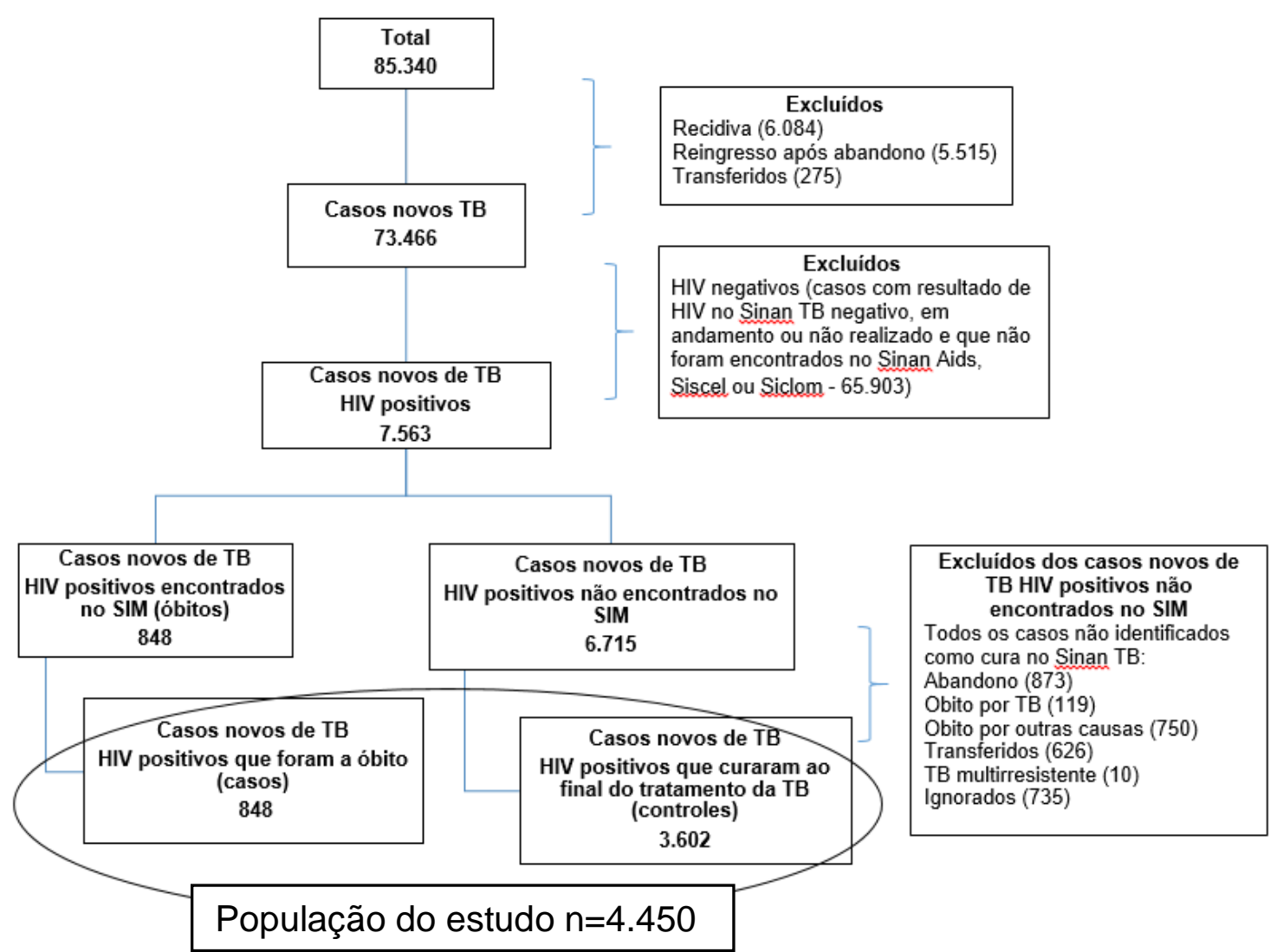

Fonte: Bases de dados do MS- Sinan TB e Aids, Siscel, Siclom e SIM 
Figura 2- Representação do relacionamento dos bancos de dados do estudo.

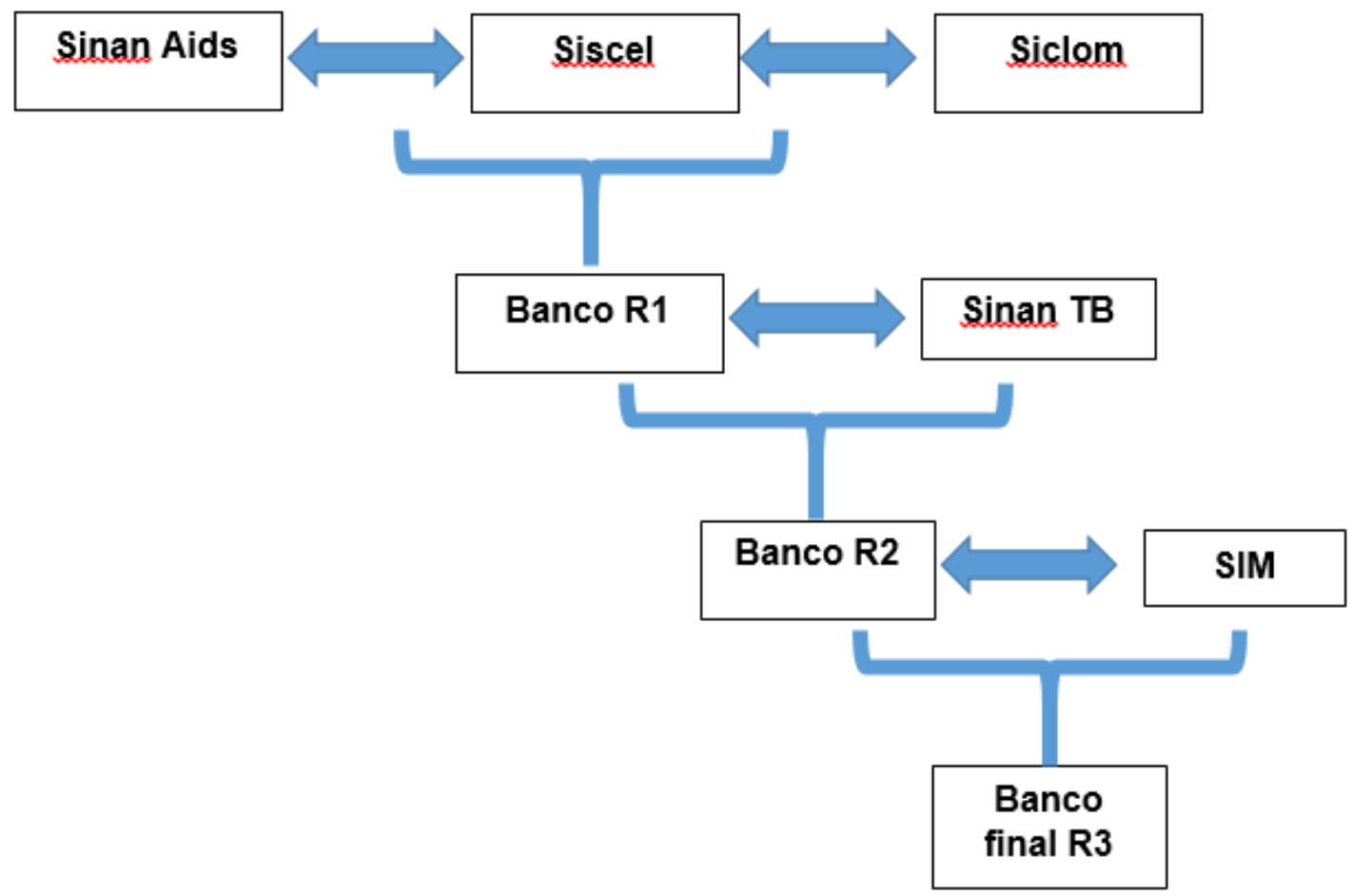


Tabela 1: Distribuição das características sociodemográficas entre os casos (óbitos com coinfecção TB-HIV) e dos controles (coinfecção TB-HIV com cura da TB) no Brasil, 2011.

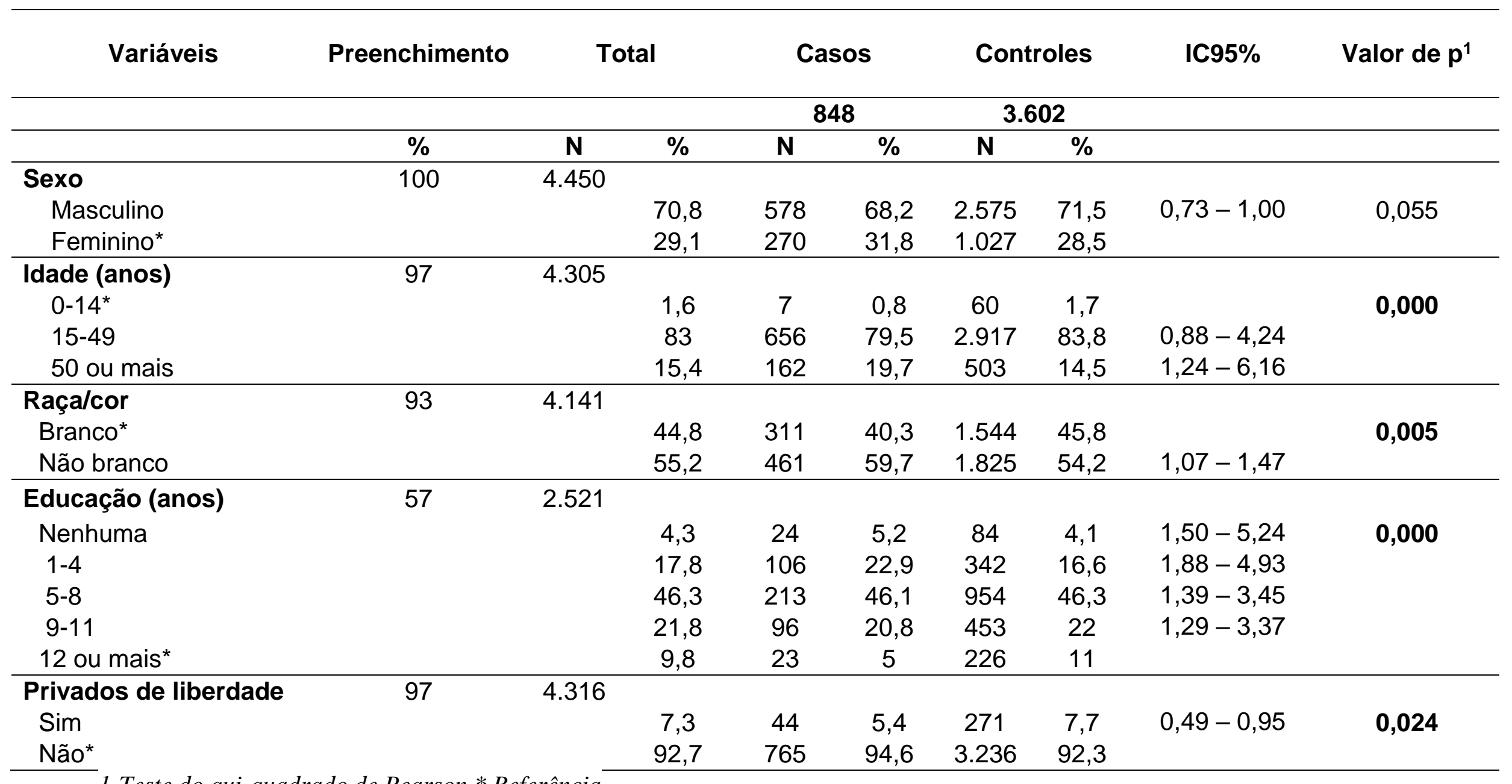

1-Teste do qui-quadrado de Pearson * Referência 
Tabela 2: Distribuição das características clínicas entre os casos (óbitos com coinfecção TB-HIV) e os controles (coinfecção TB-HIV com cura da TB) no Brasil, 2011.

\begin{tabular}{|c|c|c|c|c|c|c|c|c|c|}
\hline \multirow[t]{3}{*}{ Variáveis } & \multirow{3}{*}{$\begin{array}{c}\text { Preenchimento } \\
\% \\
\%\end{array}$} & \multicolumn{2}{|c|}{ Total } & \multicolumn{2}{|c|}{ Casos } & \multicolumn{2}{|c|}{ Controles } & \multirow[t]{2}{*}{ IC95\% } & \multirow[t]{2}{*}{ Valor de $p^{1}$} \\
\hline & & & & \multicolumn{2}{|c|}{848} & \multicolumn{2}{|c|}{3.602} & & \\
\hline & & $\mathbf{N}$ & $\%$ & $\mathbf{N}$ & $\%$ & $\mathbf{N}$ & $\%$ & & \\
\hline Diabetes & 91 & 4.033 & & & & & & & \\
\hline Sim & & & 3 & 21 & 2,8 & 102 & 3,1 & $0,56-1,45$ & 0,664 \\
\hline Não* & & & 97 & 728 & 97,2 & 3,182 & 96,9 & & \\
\hline Uso de álcool & 91 & 4.029 & & & & & & & \\
\hline $\operatorname{Sim}$ & & & 16,2 & 164 & 22,1 & 490 & 14,9 & $1,33-1,98$ & 0,000 \\
\hline Não* & & & 83,8 & 576 & 77,8 & 2.799 & 85,1 & & \\
\hline LT-CD4+2 & 100 & 4.450 & & & & & & & \\
\hline Realizado & & & 74,7 & 506 & 59,67 & 2.820 & 78,3 & $0,35-0,49$ & 0,000 \\
\hline Não realizado* & & & 25,3 & 342 & 40,33 & 782 & 21,7 & & \\
\hline LT-CD4+2 ${ }^{2}\left(\mathrm{cel} / \mathrm{mm}^{3}\right)$ & 75 & 3.326 & & & & & & & \\
\hline$>500^{*}$ & & & 26,3 & 22 & 4,3 & 853 & 30,2 & & 0,000 \\
\hline $500-350$ & & & 18,5 & 34 & 6,7 & 581 & 20,6 & $1,31-3,92$ & \\
\hline $349-200$ & & & 21,6 & 52 & 10,3 & 667 & 23,6 & $1,82-5,03$ & \\
\hline$<200$ & & & 33,6 & 398 & 78,7 & 719 & 25,6 & $13,8-33,3$ & \\
\hline Terapia antirretroviral & 100 & 4.450 & & & & & & & \\
\hline Sim & & & 56 & 324 & 38,2 & 2.166 & 60,1 & $0,35-0,48$ & 0,000 \\
\hline Não* & & & 44 & 524 & 61,8 & 1.436 & 39,9 & & \\
\hline Forma clínica da TB & 100 & 4.450 & & & & & & & \\
\hline Pulmonar* & & & 65,3 & 549 & 64,7 & 2.356 & 65,4 & & 0,000 \\
\hline
\end{tabular}




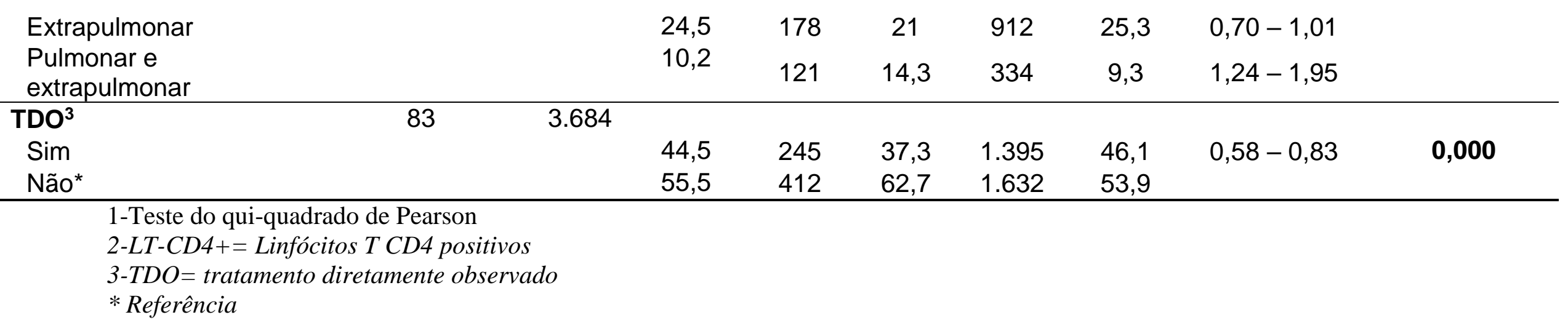


Tabela 3: Fatores associados ao óbito em pacientes com coinfecção tuberculose e HIV no Brasil, 2011.

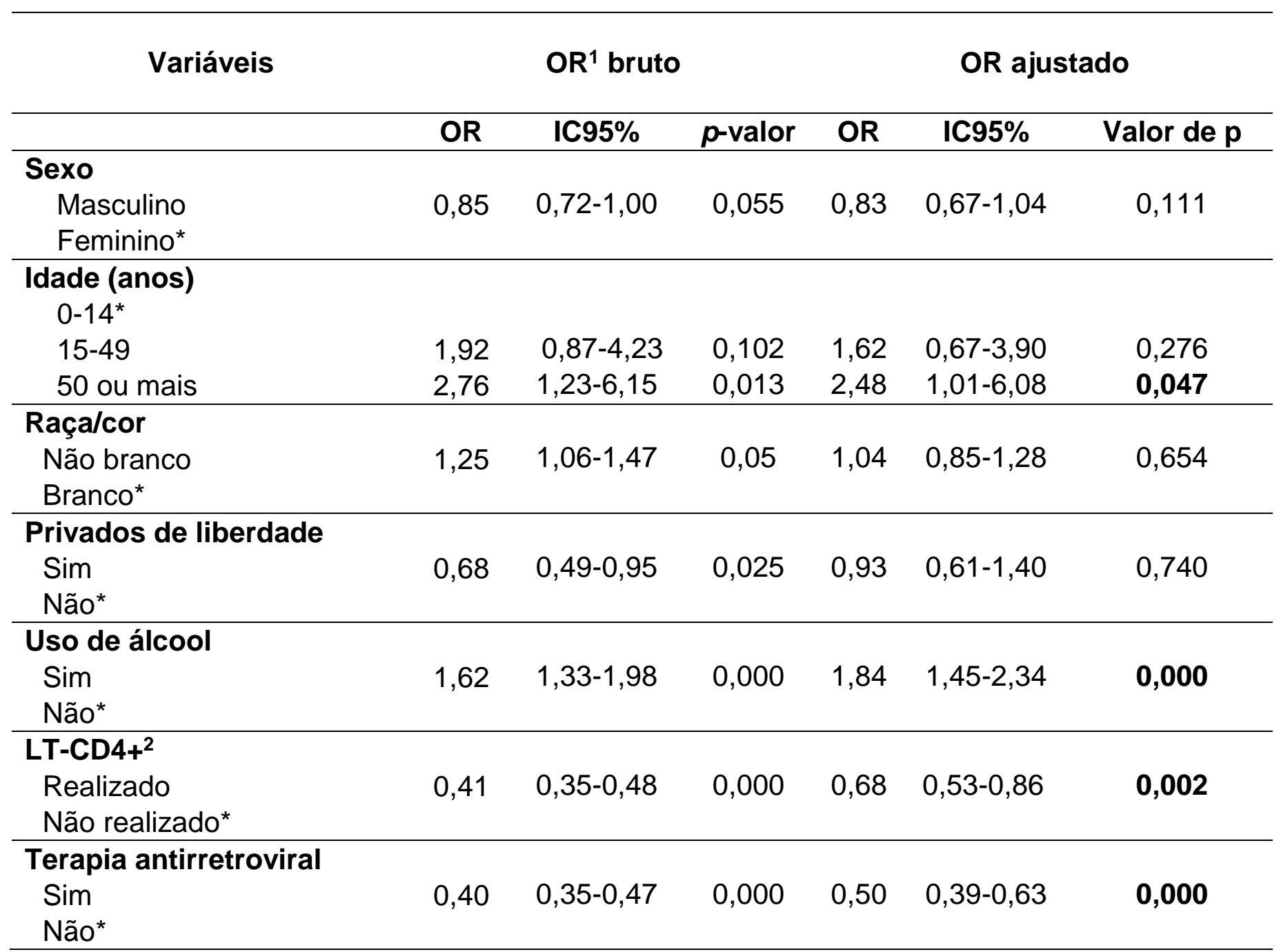




\begin{tabular}{|c|c|c|c|c|c|c|}
\hline \multicolumn{7}{|l|}{ Forma clínica da TB } \\
\hline Extrapulmonar & 0,83 & $069-1,00$ & 0,061 & 1,02 & $0,79-1,30$ & 0,865 \\
\hline Pulmonar e extrapulmonar & 1,55 & $1,23-1,95$ & 0,000 & 1,85 & $1,36-2,52$ & 0,000 \\
\hline \multicolumn{7}{|l|}{ TDO $^{3}$} \\
\hline $\begin{array}{l}\text { Sim } \\
\text { Não* }\end{array}$ & 0,69 & $0,58-0,82$ & 0,000 & 0,69 & $0,56-0,84$ & 0,000 \\
\hline $\begin{array}{l}\text { Análise multivariada por reg } \\
\text { 1- } \mathrm{OR}=\text { Odds Ratio } \\
\text { 2- } L T-C D 4+=\text { Linfócitos } T C D \\
\text { 3- } T D O=\text { tratamento diretamen } \\
\quad * \text { Referência }\end{array}$ & $\begin{array}{l}\text { são log } \\
\text { ositivos } \\
\text { observa }\end{array}$ & ica não con & onal. $\mathrm{N}=$ & $961(66$ & & \\
\hline
\end{tabular}




\section{CONSIDERAÇÕES FINAIS}

Em uma etapa inicial, antes da análise dos dados, foi necessário qualificar as informações contidas no Sinan TB por meio do relacionamento dos bancos de dados da vigilância do HIV, o Sinan Aids, Siscel e Siclom. Para verificação dos óbitos foi realizado também o linkage com o SIM. Como não existe um banco de dados único no país, individualizado no paciente, ou pelo menos a existência de uma variável comum entre os bancos, há necessidade de se realizar esse tipo relacionamento na tentativa de qualificar as informações e também de encontrar outras informações importantes existentes em diferentes bancos.

Na população do estudo a maioria eram homens, adultos jovens e não brancos e apresentavam entre 5 a 8 anos de estudo, seguindo as epidemias de HIV e tuberculose do país. Mais da metade teve acesso à realização do LTCD4+, embora com o diagnóstico do HIV ainda tardio (LT-CD4+<200 cel/ $\left./ \mathrm{mm}^{3}\right)$. Um pouco mais que a metade estava em tratamento antirretroviral e a apresentação clínica mais frequente foi a TB pulmonar e uma proporção importante faz uso de álcool.

Quando avaliados o perfil dos óbitos identificados no ano de 2011, o sexo masculino manteve-se predominante, assim como a faixa etária de adultos jovens, não brancos com 5 a 8 anos de estudo. Uma parcela importante era etilista, maior do que aqueles que curaram ao tratamento da TB, e com quadro clínico de TB pulmonar, com imunodepressão avançada não fazendo uso de antirretrovirais.

Apesar de suas limitações, o presente estudo conseguiu identificar alguns fatores associados ao óbito na coinfecção TB-HIV do Brasil no ano de 2011. Os resultados descrevem uma situação de alerta e que apesar dos avanços na estruturação da assistência à saúde no país, o acesso a um seguimento da coinfecção TB-HIV integral ainda é limitado, o que favorece a alta mortalidade nessa população. Aspectos como diagnóstico tardio da infecção pelo HIV associado às apresentações clínicas graves como a TB disseminada, o não início de TARV e a não realização do TDO influenciam fortemente no óbito dessa população. Há necessidade de revisão das estratégias nacionais, com maior integração entre os programas de TB e 
HIV/Aids, matriciamento da assistência de tal modo que profissionais capacitados façam o diagnóstico oportuno da tuberculose e do HIV, além do início em tempo adequado do tratamento antirretroviral.

Como os dados utilizados são de 2011, futuros estudos com dados mais atualizados e com a incorporação de outras variáveis, como o uso de drogas ilícitas, população em situação de rua, da oportunidade do diagnóstico da TB e do início da terapia antirretroviral se fazem necessárias para um melhor entendimento dos fatores associados ao óbito nesse grupo de pacientes. Ainda são os grandes desafios nacionais para reversão do cenário atual para óbito na coinfecção TB-HIV, esse estudo pode auxiliar na tomada de decisão sobre políticas públicas para melhoria do cuidado à pessoa com coinfecção TB-HIV no Brasil. 


\section{REFERÊNCIAS BIBLIOGRÁFICAS}

Abdool Karim, S.S., Naidoo, K., Grobler, A., Padayatchi, N., Baxter, C., Gray, A. L., Gengiah, T., Gengiah, S., Naidoo, A., Jithoo, N., Nair, G., El-Sadr, W.M. \& Friedland, G.. 2011. Integration of antiretroviral therapy with tuberculosis treatment. Nejm, 365(16), pp.1492-501.

Ajayi, A.O., Ajayi, E.A, Fasakin, K.A. 2009. CD4+ T-Lymphocytes cell counts in adults with human immunodeficiency virus infection at the medical department of a tertiary health institution in Nigeria. Annals of African Medicine: 8(4):257260.

Albuquerque, M.D.F.M, Ximenes, R.A.A., Lucena-Silva N., Souza W.V., Dantas A.T., Dantas, M.S. et al. De et al., 2001. Fatores prognósticos para o desfecho do tratamento da tuberculose pulmonar em Recife, Pernambuco, Brasil. Revista Panamericana de Salud Pública, 9(6), pp.368-374.

Alvarez-Uria, G., Naik, P.K.,Pakam, R.\& Midde, M. 2013. Factors associated with attrition, mortality, and loss to follow up after antiretroviral therapy initiation: Data from an HIV cohort study in India. Global Health Action, 6(1), pp.1-8.

Antonucci, G., Girardi, E, Raviglione, M.C., Al, E. 1995. Risk factors for tuberculosis in hiv-Infected persons: A prospective cohort study. JAMA, 274(2), pp.143-148.

Barnes, P.F., Lekey, D.L. \& Burman, W.J. 2002. Tuberculosis in patients with HIV infection. Infectious Disease Clinics of North American, 16, pp.107-126.

Barreira, D. \& Grangeiro, A., 2007. Avaliação das estratégias de controle da tuberculose no Brasil. Revista saúde pública, 41, pp.4-8.

Bartholomay, P., De Oliveira, G.P., Pinheiro, R.S.\& Vasconcelos, A.M.N. 2014. Melhoria da qualidade das informações sobre tuberculose a partir do relacionamento entre bases de dados. Cad. Saúde Pública, 30(11), pp.24592469.

Bauer, A.L., Hogue, I. B., Marino, S., Kirschner, D. 2008. The effects of HIV-1 infection on latent tuberculosis. Mathematical Modelling of Natural Phenomena, 3(07), pp.229-266.

Blanc, F.-X., Sok, T., Laureillard, D., Borand, L., Rekacewicz, C., Nerrienet, E., Madec, Y., Marcy, O., Chan, S. \& Prak, N. 2011. Earlier versus later start of antiretroviral therapy in HIV-infected adults with tuberculosis. New England Journal of Medicine, 365(16), pp.1471-1481. 
Blumberg, H. M. et al. 2003 American Thoracic Society. Centers for Disease Control and Prevention. Infectious Diseases Society of America: treatment of tuberculosis. American Journal of Respiratory and Critical Care Medicine, New York, v. 167, n. 4, p. 603-662,.

Brasil. Ministério da Saúde. Secretaria de Vigilância em Saúde. 2005. Guia de Vigilância Epidemiológica.Série A. Normas e Manuais Técnicos. 816p.

Brasil. Ministério da Saúde. Centro de Referência Professor Hélio Fraga. 2007. Tuberculose Multirresistente - Guia de Vigilância Epidemiológica. Guia de Vigilância Epidemiológica. 1를 Edição. Rio de Janeiro. 94p.

Brasil. Ministério da Saúde. Secretaria de Vigilância em Saúde. Departamento de Vigilância Epidemiológica. 2008a. Manual Nacional de Vlgilância Laboratorial da Tuberulose e outras Micobactérias. Série A. Normas e Manuais Técnicos. 436p.

Brasil. Ministério da Saúde. Secretaria de Vigilância em Saúde. Programa Nacional de DST e Aids. 2008b. Recomendações para Terapia Anti-retroviral em Adultos Infectados pelo HIV. Série Manuais n². 244p.

Brasil. Ministério da Saúde. Secretaria de Vigilância em Saúde. Departamento de DST, Aids e Hepatites Virais. 2010. Recomendações para Terapia Antirretroviral em Adultos Infectados pelo HIV 2008. Critérios para Início do Tratamento Antirretroviral. Suplemento II. 28p

Brasil. Ministério da Saúde. Secretaria de Vigilância em Saúde. Departamento de Vigilância Epidemiológica. Programa Nacional de Controle da Tuberculose. 2011a. Manual de Recomendações para o Controle da Tuberculose no Brasil. Brasília: Série A: manuais e normas técnicas. 1a edição; 284p

Brasil. Ministério da Saúde. Secretaria de Vigilância em Saúde. Departamento de Vigilância Epidemiológica. Programa Nacional de Controle da Tuberculose. 2011b. Tratamento Diretamente Observado (TDO) da Tuberculose na Atenção Básica. Protocolo de enfermagem. Brasília. Série F: Comunicação e Educação em Saúde. $1^{a}$ edição; 172 p.

Brasil. Ministério da Saúde Secretaria de Vigilância em Saúde. Departamento de Vigilância das Doenças Transmissíveis. 2012. Boletim Epidemiológico: Especial Tuberculose no Brasil, realidades e perspectivas. Disponível em: (Acessado em 22 de março de 2015). 
Brasil. Ministério da Saúde Secretaria de Vigilância em Saúde. Departamento de Vigilância das Doenças Transmissíveis. Programa Nacional de Controle da Tuberculose. 2013a. Boletim Epidemiológico. Tuberculose: alinhada com o social, afinada com a tecnologia. Disponível em: http://portalsaude.saude.gov.br/images/pdf/2014/maio/06/boletim2-2013-tbweb.pdf. (Acessado em 22 de março de 2015).

Brasil. Ministério da Saúde.2013b. Portaria No 1.498, de 19 de julho de 2013. Redefine o Calendário Nacional de Vacinação, o Calendário Nacional de Vacinaçãodos Povos Indígenas e as Campanhas Nacionais de Vacinação em todo o território nacional. Diário Oficial da União Disponível em: $<$ www.in.gov.br> (Acessado em 22 de março de 2015).

Brasil. Ministério da Saúde. Secretaria de Vigilância em Saúde. 2013c. Protocolo Clínico e Diretrizes Terapêuticas para Manejo da Infecção pelo HIV em Adultos.220p. Disponível em: <www.aids.gov.br> (Acessado em 22 de março de 2015)

Brasil. Ministério da Saúde. Secretaria-Executiva. 2013d. Recomendações para o Manejo da co-infecção TB-HIV em Serviços de Atenção Especializada a pessoas vivendo com HIV/Aids. Brasília. $1^{\text {a }}$ edição; 28p.

Brasil. Ministério da Saúde. Conselho Nacional de Saúde. 2013e. Resolução ${ }^{\circ}$ 466, de 12 de dezembro de 2012. Normatiza a Ética em Pesquisa em Seres Humanos Lei Federal $n^{\circ}$ 8.142, de 28 de dezembro de 1990. Disponível em: <http://conselho.saude.gov.br/resolucoes/2012/Reso466.pdf> (Acessado em 17 de julho de 2015).

Brasil. Ministério da Saúde Secretaria de Vigilância em Saúde. Departamento de DST, Aids e Hepatites Virais. 2014a. 5 Passos para a implementação do Manejo da Infecção pelo HIV na Atenção Básica. Guia para Gestores. Disponível em: http://www.aids.gov.br/sites/default/files/anexos/publicacao/2014/55883/coorde ndores_pdf_46953.pdf (Acessado em 04 de julho de 2015).

Brasil. Ministério da Saúde. Secretaria de Vigilância em Saúde. Departamento de DST, Aids e Hepatites Virais. 2014b. Boletim epidemiológico HIV.Aids. Boletim AIDS 2014. Ano III-n $1-27^{\text {a }}$ à $52^{a}$ semanas epidemiológicas- julho a dezembro de 2013. Ano III- $n^{\circ} 1^{-1} 01^{\text {a }}$ à $26^{\underline{a}}$ semanas epidemiológicas- janeiro a junho de 2014.2 Disponível em: http://www.aids.gov.br/sites/default/files/anexos/publicacao/2014/56677/boletim _2014_final_pdf_15565.pdf (Acessado em 05 de julho de 2015). 
Brasil. Ministério da Saúde Secretaria de Vigilância em Saúde. Departamento de Vigilância das Doenças Transmissíveis. 2014c. Boletim Epidemiológico: O controle da tuberculose no Brasil: avanços, inovações e desafios. Disponível em: http://portalsaude.saude.gov.br/images/pdf/2014/maio/29/BE-2014-45--2-tb.pdf (Acessado em 22 de março de 2015).

Brasil. Ministério da Saúde. Secretaria de Vigilância em Saúde. 2014d. Guia de vigilância em Saúde. 812p Disponível em:<www.saude.gov.br/bvs> (Acessado em 22 de março de 2015),

Brasil. Ministério da Saúde. Secretaria de Vigilância em Saúde. Departamento de Vigilância de Doenças Transmissíveis. Programa Nacional de Controle da tuberculose. 2014e. Nota informativa $N^{\circ} 9$ de 2014. CGPNCT/DEVEP/SVS/MS. Recomendações sobre o diagnóstico da tuberculose por meio do teste rápido molecular para a tuberculose. 6p. Disponível em:<www.saude.gov.br/tuberculose> (Acessado em 22 de março de 2015).

Brasil. Ministério da Saúde. Secretaria de Vigilância em Saúde. Departamento de Vigilância Epidemiológica. Programa Nacional de Controle da Tuberculose 2014f. Panorama da tuberculose no Brasil Indicadores epidemiológicos e operacionais. Brasília; 92p.

Brasil. Ministério da Saúde. 2014g. Portaria ํㅜ 1.271, de 6 de junho de 2014. Define a Lista Nacional de Notificação Compulsória de doenças, agravos e eventos de saúde públicos e privados. Diário Oficial da União N 108, de 09 de junho de 2014. Seção 1. Disponível em: <www.in.gov.br> (Acessado em 22 de março de 2015).

Brasil. Ministério da Saúde. Secretaria de Vigilância em Saúde. Departamento de Análise de Situação de Saúde. Coordenação Geral de Informações e Análise Epidemiológica. 2014h. Sistema de Informações de Mortalidade (SIM). Disponível em: Sistama de Informações de Mortalidade (SIM). Disponível em: <http://bvsms.saude.gov.br/bvs/publicacoes/declaracao_de_obito_final.pdf > (Acessado em 17 de março de 2015)

Brasil. Ministério da Saúde. Secretaria de Vigilância em Saúde. Departamento de Vigilância Epidemiológica. 2014i. Sistema de Informação de Agravos de Notificação (Sinan). Disponível em: <www.saude.gov.br/sinan> (Acessado em 17 de março de 2015)

Brasil. Ministério da Saúde Secretaria de Vigilância em Saúde. Departamento de Vigilância das Doenças Transmissíveis. 2015. Boletim Epidemiológico: Detectar, tratar e curar: desafios e estratégias brasileiras frente à tuberculose. Disponível em: <http://u.saude.gov.br/images/pdf/2015/marco/27/2015-007--- 
BE-Tuberculose---para-substitui----o-no-site.pdf> (Acessado em 22 de março de 2015).

Burril, J., Williams, C.J., Bain, G., Conder, G., Hine, A.L. \& Misra, R.R., 2007. Tuberculosis: a radiologic review. Radiographics: a review publication of the Radiological Society of North America. , pp.1255-73.

Camargo Junior, K.R.,. \& Coeli, C.M. 2000. Reclink: an application for database linkage implementing the probabilistic record linkage method. Cad Saude Publica, Apr-Jun 16(2), 439-47.

Caminero, J.A. 2003. Guía de la Tuberculosis para Médicos Especialistas.Unión Internacional Contra la Tuberculosis y Enfermidades Respiratorias (UICTER). Paris, França.

Canaday, D.H. ,Wu, M., Lu, S., Aung, H., Peters, P., Baseke, J., Mackay, W., Mayanja-Kizza, H.\& Toossi, Zahra. 2009. Induction of HIV type 1 expression correlates with $\mathrm{T}$ cell responsiveness to mycobacteria in patients coinfected with HIV type 1 and Mycobacterium tuberculosis. AIDS research and human retroviruses, 25(2), pp.213-216.

Caylà, J.A., Rodrigo, T., Ruiz-Manzano, J., Caminero, J.A., Vidal, R., García, J.M., Blanquer, R. \& Casals, M. 2009. Tuberculosis treatment adherence and fatality in Spain. Respiratory research, 10(1), p.121.

Charisson, R. \& Martinson, N., 2008. Tuberculosis en Africa - Combating an HIV-Driven Crisis. The New England journal of medicineNew england journal, pp.1089-1092.

Cheade, M.D.F.M. Siqueira, P.H., Sá, R.G. \& Honer, M.R. 2009. Characterization of tuberculosis among HIV/AIDS patients at a referral center in Mato Grosso do Sul. Revista da Sociedade Brasileira de Medicina Tropical, 42(2), pp.119-125.

Coimbra, I., Maruza, M., Militão-Albuquerque, M.D.F.P., Moura, L.V.,Diniz, G.T.N., Miranda-Filho, D.D.B., Lacerda, H.R., Rodrigues, L.C., Ximenes, R.D.A. 2012. Associated factors for treatment delay in pulmonary tuberculosis in HIVinfected individuals: a nested case-control study. BMC Infectious Diseases, 12, p.208.

Comstock, G.W., Livesay, V.T. \& Woolpert, S.F., 1974. The prognosis of a positive tuberculin reaction in childhood and adolescence. American journal of epidemiology, 99(2), pp.131-138. 
Conigliaro, J., Gordon, A.J., McGinnis, K.A., Rabeneck, L. \& Justice, A.C. 2003. How harmful is hazardous alcohol use and abuse in HIV infection: do health care providers know who is at risk. Journal of acquired immune deficiency syndromes (1999), 33(4), pp.521-525.

Corbett, E.L., Watt CJ, Walke, N., Maher, D., Williams, B.G., Raviglione, M.C. et al. 2003. The growing burden of tuberculosis: global trends and interactions with the HIV epidemic. Archives of internal medicine, 163(9), pp.1009-1021.

Cortes, C.P., Cortes, Claudia P., Wehbe, F.H, McGowan, C.C., Shepherd, B.E., Duda, S.N., Jenkins, C., Gonzalez, E., Carriquiry, G., Schechter, M., Padgett, D., Cesar, C., Madero, J.S., Pape, J.W., Masys, D.R., Sterling, T.R., Cortes, C.P., Wolff, M., Arancibia, J.M., Saavedra, F., Salinas, C., Gonzalez, E., Carriquiry, G., Mayer, E., Condorhuaman, P., Gotuzzo, E., Schechter, M., Tuboi, S.H., Padgett, D., Cesar, C., Fink, V., Sued, O., Cahn, P., Crabtree, B., Madero, J.S., Bacon, M., Williams, C., Wehbe, F.H. \& Sterling, T.R. 2013. Duration of Anti-Tuberculosis Therapy and Timing of Antiretroviral Therapy Initiation: Association with Mortality in HIV-Related Tuberculosis. PLOS ONE, 8(9), pp.1-8.

Cosivi, O., Grange, J M; Daborn, C J., Raviglione, M C., Fujikura, T., Cousins, D., Robinson, R A., Huchzermeyer, H F., de Kantor, I.\& Meslin, F X . 1998. Zoonotic tuberculosis due to Mycobacterium bovis in developing countries. Emerging Infectious Diseases, 4(1), pp.59-70.

Daley, C.L., Small, P.M., Schecter, G.F., Schoolnik, G.K., McAdam, R.A., Jacobs, W.R.J. et al. 1992. An Outbreak of Tuberculosis with Accelerated Progression among Persons Infected with the Human Immunodeficiency Virus: An Analysis Using Restriction-Fragment-Length Polymorphisms. New England journal of medicine, 326(4), pp.231-235.

Domingos, M.P., Caiaffa, W.T. \& Colosimo, E.A., 2008. Mortality, TB/HIV coinfection, and treatment dropout: predictors of tuberculosis prognosis in Recife, Pernambuco State, Brazil. Cadernos de saude publica, 24(4), pp.887-896.

Dye, C., Scheele, S., Dolin, P., Pathania, V \& Raviglione, M C et al., 1999. Consensus statement. Global burden of tuberculosis: estimated incidence, prevalence, and mortality by country. WHO Global Surveillance and Monitoring Project. JAMA, 282(7), pp.677-686.

Evans, C.A., 2011. GeneXpert--a game-changer for tuberculosis control? PLoS medicine, 8(7), p.e1001064.

Farga, V. \& Caminero J. 2011. Tuberculosis. Rev Med Chile, pp.681-682. 
Façanha, M.C., 2006. Tuberculose: subnotificação de casos que evoluíram para óbito em fortaleza-CE. Rev Brasi Epidemiol; 32(6):553-8.

Fanning, A. 1999. Tuberculosis: 6. Extrapulmonary disease. Cmaj, 160(11), pp.1597-1603.

Ferreira et al, 2005. Abandono do tratamento da tuberculose pulmonar em Cuiabá - MT- Brasil. J Bras Penumologia, 31(5), pp.427-435.

Fiuza de Melo FA, A.J., 1993. Transmissão e imunopatogenia da Tuberculose. In Jornal de Pneumologia São Paulo, 19(1): 19-24.

Franco, R. a \& Saag, M.S. 2013. When to start antiretroviral therapy: as soon as possible. BMC medicine, 11(1), p.147.

Garcia-Vidal, C., Salvado, M. \& Salavert, M., 2010. Timing of antiretroviral drugs during tuberculosis therapy. The New England journal of medicine, 362(22), pp.2137-2138; author reply 2138-2139.

Geldmacher, C., Ngwenyama, N., Schuetz, A., Petrovas, C., Reither, K., Heeregrave, E.J., Casazza, J.P.,Ambrozak, David R., Louder, M., Ampofo, W., Pollakis, G., Hill, B.,

Sanga, E., Saathoff, E., Maboko, L., Roederer, M., Paxton, W., Hoelscher, M. \& Koup, R. 2010. Preferential infection and depletion of Mycobacterium tuberculosis-specific CD4 T cells after HIV-1 infection. The Journal of experimental medicine, 207(13), pp.2869-2881.

Guimarães, R.M., Lobo, A.D.P., Siqueira, E.A., Franco, T., Borges, F., Cristina, S. \& Melo, C. 2010. Características clínico-demográficas de pacientes hospitalizados com tuberculose no Brasil, no período de 1994 a 2004. J Bras Pneumol. 38(5), pp.511-517.

Hallal, R., Ravasi, G., Kuchenbecker, R., Greco, D. \& Simão, M. 2010. O acesso universal ao tratamento antirretroviral no Brasil. Revista Tempus Actas em saúde coletiva, 4(2), pp.53-65.

Harries, A.; Maher, D.; Graham, S., 2004. TB/HIV- A clinical manual., World Health Organization. Disponível em:<http://whqlibdoc.who.int/hq/2004/who_htm_tb_2004.330.pdflnhttp://www.w ho.int/tb/publications/who_htm_tb_2004_329/en/.> (Acessado e 22 de março de2015). 
Hijjar, M.A., Gerhardt, G., Teixeira, G.M., Procópio, M.J. 2007. Retrospecto do controle da tuberculose no Brasil. Revista de Saúde Pública, 41, pp.50-57.

Hwang, J. \& Choe, P., 2013. Incidence and Risk Factors of Tuberculosis in Patients with Human Immunodeficiency Virus Infection. Journal of Korean, pp.374-377.

Jamal, L.F. \& Moherdaui, F., 2007. Tuberculose e infecção pelo HIV no Brasil: magnitude do problema e estratégias para o controle. Revista de Saúde Pública, 41, pp.104-110.

Jones, B.E., Jones, Brenda E., Young, S.M.M., Antoniskis, D., Davidson, P.T., Kramer, F. \& Barnes, P.F., 1993. Relationship of the Manifestations of Tuberculosis to CD4 Cell Counts in Patients with Human Immunodeficiency Virus Infection. American Review of Respiratory Disease, 148(5), pp.12921297.

Kantipong, P. , Murakami, K., Moolphate, S., Aung, M.N. \& Yamada, N., 2012. Causes of mortality among tuberculosis and HIV co-infected patients in chiang rai, northern Thailand. HIV/AIDS - Research and Palliative Care, 4, pp.159-168

Karim, S.S.A., Churchyard, G.J., Karim, Q.A. \& Lawn, S.D., 2009. HIV infection and tuberculosis in South Africa: an urgent need to escalate the public health response. the Lancet, 374(9693), pp.921-933.

Kenneth Rochel de Camargo Jr; Claudia Medina Coeli, 2012. Guia do Usuário: OpenRecLink. $\quad$ p.55p. Disponível em: < http://download2.polytechnic.edu.na/pub4/sourceforge/r/re/reclink/guiausuario.p df> (Acessado em 17 de março de 2015).

Kingkaew, N., Sangtong, B., Amnuaiphon, W., Jongpaibulpatana, J., Mankatittham, W., Akksilp, S., Sirinak, C., Nateniyom, S., Burapat, C., Kittikraisak, W. Monkongdee, P. \& Varma, J.K., 2009. HIV-associated extrapulmonary tuberculosis in Thailand: epidemiology and risk factors for death. International Journal of Infectious Diseases, 13(6), pp.722-729.

Komati, S. et al., 2010. Tuberculosis Risk Factors and Mortality for HIV Infected Persons Receiving Antiretroviral Therapy in South Africa. Aids, 24(12), pp.1849-1855.

Kritski, A.L., Villa, T.S., Trajman, A., Lapa E.S., Medronho,J.P., Roberto, A \& Ruffino-Netto, A., 2007. Two decades of research on tuberculosis in Brazil: state of the art of scientific publications. Revista de saúde pública, 41 Suppl 1, pp.9-14. 
Liang, Q -L., Shi, H.-Z., Wang, K., Qin, S.-M., Qin, X.-J. 2008. Diagnostic accuracy of adenosine deaminase in tuberculous pleurisy: A meta-analysis. Respiratory Medicine, 102(5), pp.744-754.

Lins, T.B. Soares, E.M., Santos, F.M.S., Mandacaru, P.M.P., Pina, T. \& AraújoFilho, J.A. 2012. Mycobacterium tuberculosis and human immunodeficiency virus coinfection in a tertiary care hospital in Midwestern Brazil. Le infezioni in medicina: rivista periodica di eziologia, epidemiologia, diagnostica, clinica e terapia delle patologie infettive, 20(2), pp.108-116.

Lourdes, M.D., Geraldes, S., Helena, S., Vendramini, F., Wysocki, A.D., 2009. A dimensão epidemiológica da coinfecção tb / hiv. Rev Latino-am Enfermagem. 17(5).

Mandell, G.L., Bennett, J.B. \& Dolin, R. 2010 Principles and Practice of Infectious Diseases, 7th Edition. Ed Elsevier Saundes. 4.320p.

Marcy, O., Laureillard, D, .Madec, Y., Chan, S., Mayaud, C., Borand, L., Prak, N., Kim, C., Lak, K.K., Hak, C., Dim, B., Sok, T., Delfraissy, J.F., Goldfeld, A.E. \& Blanc, F.X., 2014. Causes and determinants of mortality in HIV-infected adults with tuberculosis: An analysis from the CAMELIA ANRS 1295-CIPRA KH001 randomized trial. Clinical Infectious Diseases, 59(3), pp.435-445.

Marks, D.J.B., Dheda, K., Dawson, R., Ainslie, G. \& Miller, R.F., 2009. Adverse events to antituberculosis therapy: influence of HIV and antiretroviral drugs. International journal of STD \& AIDS, 20(5), pp.339-345.

Millet, J.P., Orcau, A., Rius, C., Casals, M., De Olalla, P.G., Moreno, A., Nelson, J.L. \& Caylà, J., 2011. Predictors of death among patients who completed tuberculosis treatment: A Population-Based cohort study. PLoS ONE, 6(9), pp.4-11.

Moore, D.M., Yiannoutsos, C.T., Musick, B.S., Tappero, J., Degerman, R., Campbell, J., Were, W., Kaharuza, F., Alexander, L.N.\& Downing, R., 2011. Determinants of early and late mortality among HIV-infected individuals receiving home-based antiretroviral therapy in rural Uganda. Journal of acquired immune deficiency syndromes (1999), 58(3), p.289.

Mugusi, F.M., Mehta, S., Villamor, E., Urassa, W., Saathoff, E., Bosch, R.J., Fawzi, W. 2009. Factors associated with mortality in HIV-infected and uninfected patients with pulmonary tuberculosis. BMC public health, 9, p.409. 
Nahid, P., Gonzalez, L.C., Rudoy, I.D.J., Bouke C., Unger, A., Kawamura, L.M.O., Dennis, H., Hopewell, P.C. \& Daley, C.L., 2007. Treatment Outcomes of Patients with HIV and Tuberculosis. American Journal of Respiratory and Critical Care Medicine, 175(11), pp.1199-1206.

Naidoo, K., Yende-Zuma, N., Padayatchi, N., Naidoo, K., Jithoo, N., Nair, G., Bamber, S., Gengiah, S., El-Sadr, W.M., Friedland, G., Karim, S.A., 2012. The immune reconstitution inflammatory syndrome after Antiretroviral Therapy Initiation in Patients with Tuberculosis: Findings from the SAPiT Trial. Annals of Internal Medicine, 157(5), pp.313-324.

Narita, M., Ashkin, D., Hollender, E. S., Pitchenik, A. E. 1998. Paradoxical worsening of tuberculosis following antiretroviral therapy in patients with aids. American Journal of Respiratory and Critical Care Medicine, 158(1), pp.157161.

De Oliveira, G.P; Pinheiro, R.S; Coeli, C.M; Barreira, D \& Codenotti, S.B. 2012. Mortality information system for identifying underreported cases of tuberculosis in Brazil. Revista brasileira de epidemiologia Brazilian journal of epidemiology, 15(3), pp.468-77.

Orofino, R.D.L., Brasil, P.E.A.,Trajman, A., Schmaltz, C.A.S., Dalcolmo, M. \& Rolla, V.C., 2012. Preditores dos desfechos do tratamento da tuberculose . Jornal Brasileiro de Pneumologia , 38 , pp.88-97.

Pasquié, J., Cavée, C., Bordachar, P., Clémenty, J., Haïssaguerre, M.. 2010. Rapid Molecular Detection of Tuberculosis and Rifampin Resistance. New England Journal of Medicine., pp.2373-2383.

Pawlowski, A., Jansson, M., Sköld, M., Rottenberg, M.E.. 2012. Tuberculosis and HIV Co-Infection. PLoS Pathog, 8(2).

Pelaquin, M.H.H., Silva, R.S. e \& Ribeiro, S.A., 2007. Fatores associados ao óbito por tuberculose na zona leste da cidade de São Paulo, 2001. Jornal Brasileiro de Pneumologia , 33 , pp.311-317.

Perlman, D.C., El-Sadr, W., Nelson, E.T., Matts, J.P., Telzak, E.E., Salomon, N., Chirgwin, K., Hafner, R. 1997. Variation of chest radiographic patterns in pulmonary tuberculosis by degree of human immunodeficiency virus-related immunosuppression. Clinical infectious diseases, 25(2), pp.242-246.

Pestana, E., Telo, L., Gomes, M.J. \& Amaral-Marques, R., 1993. Extrapulmonary tuberculosis. Acta medica portuguesa, 6(5), pp.175-180. 
Peter, T., Badrichani, A., Wu, E., Freeman, R., Ncube, B., Ariki, F., Daily, J., Shimada, Y.\& Murtagh, M. 2008. Challenges in implementing CD4 testing in resource-limited settings. Cytometry Part B: Clinical Cytometry, 74B(S1), pp.S123-S130.

Piller, R.V.B., 2012. Epidemiologia da tuberculose. Pulmão RJ, 21(1), pp.4-9.

Pires, J., Rosilene, R., Gadelha, M., Herzer, T.L., Peres, D.A., Jesus, M., Leitão, S., Façanha, M.C., Holanda, C.N., Girão, E.S. \& Oliveira, M.C.N. 2012. Características clínico-epidemiológicas de pacientes com coinfecção HIV / tuberculose acompanhados nos serviços de referência para HIV / AIDS em Fortaleza, Ceará , entre 2004 e 2008. Cad Saúde Colet. 20(2): 244-9.

Pozniak, A.L., Ormerod, L.P. \& Miller, R., 1999. Reply: Treatment of tuberculosis in HIV-infected patients. AIDS (London, England), 13(11), pp.1431-1432.

Rieder, H.L., 1999. Epidemiologic basis of tuberculosis Control. Paris: International Union Against Tuberculosis and Lung Disease, 73(1st Edition), pp.17-62.

Sá, L.D., Mendes, K., Souza, J.D., Nunes, G., Palha, P.F., Almei, J. 2007. Tratamento Da Tuberculose Em Unidades De Saúde Da Família: Histórias De Abandono. Texto Contexto Enferm , 16(4), pp.712-718.

Sant'Anna, C.C. 2002. Tuberculose na Infância e Adolescência. Editora Atheneu. $227 p$

Sant'Anna, C.C., 1998. Tuberculose na criança. Jornal de Pediatria, pp.69-75.

Sant'Anna, C.C. et al, 2006. Evaluation of a proposed diagnostic scoring system for pulmonary tuberculosis in Brazilian children. . International Journal of Tuberculosis and Lung Disease, Paris, v. 10, n. 4, p. 463-465.

Santos, S. \& Beck, S.T., 2009. A coinfecção tuberculose e HIV : um importante desafio - Artigo de revisão. Revista brasileira de análises clínicas, 41(3), pp.209-215.

Saraceni, V., King, B.S., Cavalcante, S.C., Golub, J.E., Lauria, L.M., Moulton, L.H., Chaisson, R.E., Durovni, B., 2008. Tuberculosis as primary cause of death among AIDS cases in Rio de Janeiro, Brazil. The international journal of tuberculosis and lung disease: the official journal of the International Union against Tuberculosis and Lung Disease, 12(7), pp.769-772. 
Schmaltz, C.A.S., Sant'Anna, F.M., Neves, S.C., Velasque, L.S., Lourenço, M.C., Morgado, M.G.et al. 2009. Influence of HIV infection on mortality in a cohort of patients treated for tuberculosis in the context of wide access to HAART, in Rio de Janeiro, Brazil. Journal of acquired immune deficiency syndromes (1999), 52(5), pp.623-628.

Sharma, S.K., Mohan, A. \& Kadhiravan, T., 2005. HIV-TB co-infection: epidemiology, diagnosis \& management. The Indian journal of medical research, 121(4), pp.550-67.

Santos, S. \& Beck, S.T., 2009. A coinfecção tuberculose e HIV : um importante desafio - Artigo de revisão. Revista brasileira de análises clínicas, 41(3), pp.209-215.

Stephen D. Lawn, 2009. Epidemiology of HIV-associated tuberculosis Running Head: Epidemiology of TB / HIV. Europe PMC Funders Group, 4(4), pp.325333.

Straetemans M., Glaziou P., Bierrenbach A.L., Sismanidis C., Van Der Werf, M.J., 2011. Assessing Tuberculosis Case Fatality Ratio: A Meta-Analysis. PLoS ONE 6(6): e20755.

Tabarsi, P., Chitsaz, E., Moradi, A., Baghaei, P., Farnia, P., Marjani, M., Shamai, M., Amiri, M., Nikaein, S., Mansouri, D., 2012. Treatment outcome, mortality and their predictors among HIV-associated tuberculosis patients. International journal of STD \& AIDS, 23(9), pp.e1-e4.

Thorn, P., 2008. La tuberculosis: información y consejos para vencer la enfermedad. StopTB Partnership. Disponível em: http://www.stoptb.org/assets/documents/resources/publications/acsm/TB\%20TI PS\%20SPN\%20WEB.pdf (Acesso em 05 de julho de 2015).

Toman, K., 2004. Toman's Tuberculosis: case detection, treatment, and monitoring: questions and answers. World Health Organizaion. Segunda edição. 350p

Udani, P.M., Parekh, U.C. \& Dastur, D.K., 2015. Neurological and related syndromes in CNS tuberculosis Clinical features and pathogenesis. Journal of the Neurological Sciences, 14(3), pp.341-357.

Velasco M., Castilla V, Sanz J, Gaspar G, Condes E, Barros C, Cervero M, Torres R, Guijarro, C 2009. Effect of simultaneous use of highly active antiretroviral therapy on survival of hiv patients with tuberculosis. J Acquir Immune Defic Syndr, v. 50, n. 2, p. 148-142. 
Vijay, S., Kumar, P., Chauhan, L.S., Narayan R.S.V., Vaidyanathan, P. 2011. Treatment Outcome and Mortality at One and Half Year Follow-Up of HIV Infected TB Patients Under TB Control Programme in a District of South India. PloS one, 6(7), p.e21008.

WHO. World Health Organization. 2013a. Consolidated guidelines on the use of antiretroviral drugs for treating and preventing HIV infection. Recomendations for a Public Health Approach. Genebra: World Health Organization.

WHO. World Health Organization. 2013b. Definitions and reporting framework for tuberculosis- 2013 revision. Genebra: World Health Organization. 46p. Disponível em:<www.who.int/tb/publications $>$ (Acesso em 17 de março de 2015).

WHO. World Health Organization. 2008. Global tuberculosis control: surveillance, planning, financing. report 2008. Genebra: World Health Organization.Disponível em:< http://www.citeulike.org/group/8437/article/3973238Inpapers2://publication/uuid/ 2DC5A009-6703-46F0-8E7A-386DAC7A598B.> (Acessado em 17 de março de 2015).

WHO. World Health Organization 2012a. Global tuberculosis report 2012, Genebra: World Health Organization. Disponível em:<http://www.who.int/tb/publications/global_report/gtbr12_main.pdf.> (Acessado em 17 de março de 2015).

WHO. World Health Organization. 2014. Global tuberculosis report 2014 Genebra: World Health Organization.

WHO. World Health Organization. 2011b. Guidelines for intensified tuberculosis case-finding and isoniazid preventive therapy for people living with HIV in resourceconstrained settings. Department of HIV/Aids, Stop TB Department. Geneva: World Health Organization.

WHO. World Health Organization. 2011c. Policy statement: automated real-time nucleic acid amplification technology for rapid and simultaneous detection of tuberculosis and rifampicin resistance: Xpert MTB/RIF. Policy statement. Geneva, Switzerland: World Health Organization.36p

WHO. World Health Organization. 2012b. WHO policy on collaborative TB / HIV activities Guidelines for national programmes and other stakeholders. Geneva, Switzerland: World Health Organization. 36p 
WHO. World Health Organization. 2013c. Xpert MTB/RIF assay for the diagnosis of pulmonary ans extrapulmonary TB in adults and children. Nature Cell Biology. Geneva, Switzerland: World Health Organization. 79p.

WHO. World Health Organization. 2011a. Collaborative framework for care and control of Tuberculosis and Diabetes. World Health Organization, pp.4-53. Disponível em: < http://www.ncbi.nlm.nih.gov/pubmed/17158327.> (Acessado em 17 de março de 2015)

WHO. World Health Organization. Stop TB, 2004. Interim Policy on Collaborative TB/HIV Activities. Geneva, World Health Organization,18p.

Yang, Z. et al., 2004. Identification of Risk Factors for Extrapulmonary Tuberculosis. Clinical Infectious Diseases , 38 (2 ), pp.199-205.

Yee, D., Valiquette, C., Pelletier, M., Parisien, I., Rocher, I., Menzies, D., 2003. Incidence of Serious Side Effects from First-Line Antituberculosis Drugs among Patients Treated for Active Tuberculosis. American Journal of Respiratory and Critical Care Medicine, 167(11), pp.1472-1477. 


\section{ANEXOS}

\section{ANEXO I- Ficha de Notificação e Investigação da Tuberculose}

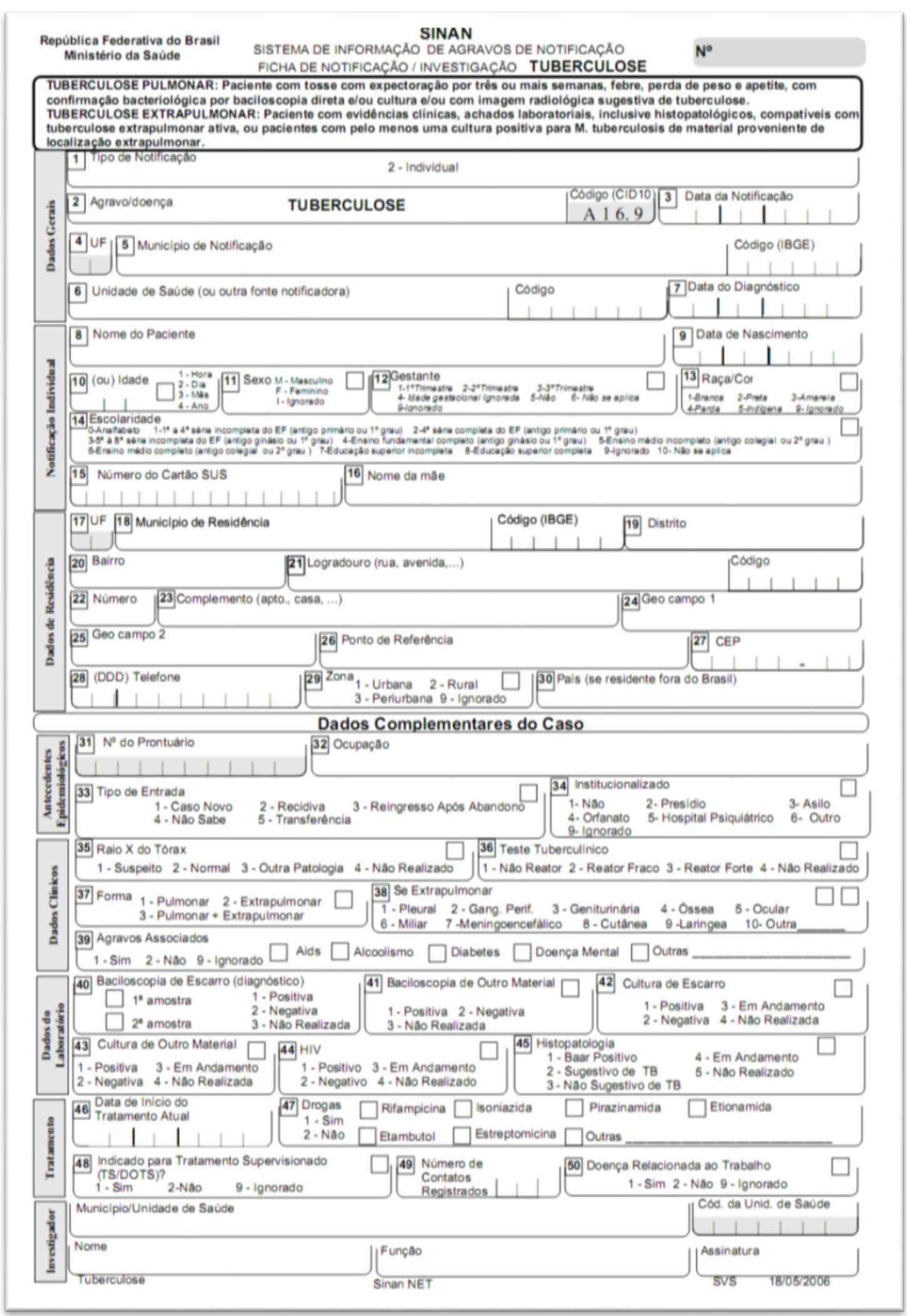


ANEXO II- Boletim de Acompanhamento da Tuberculose

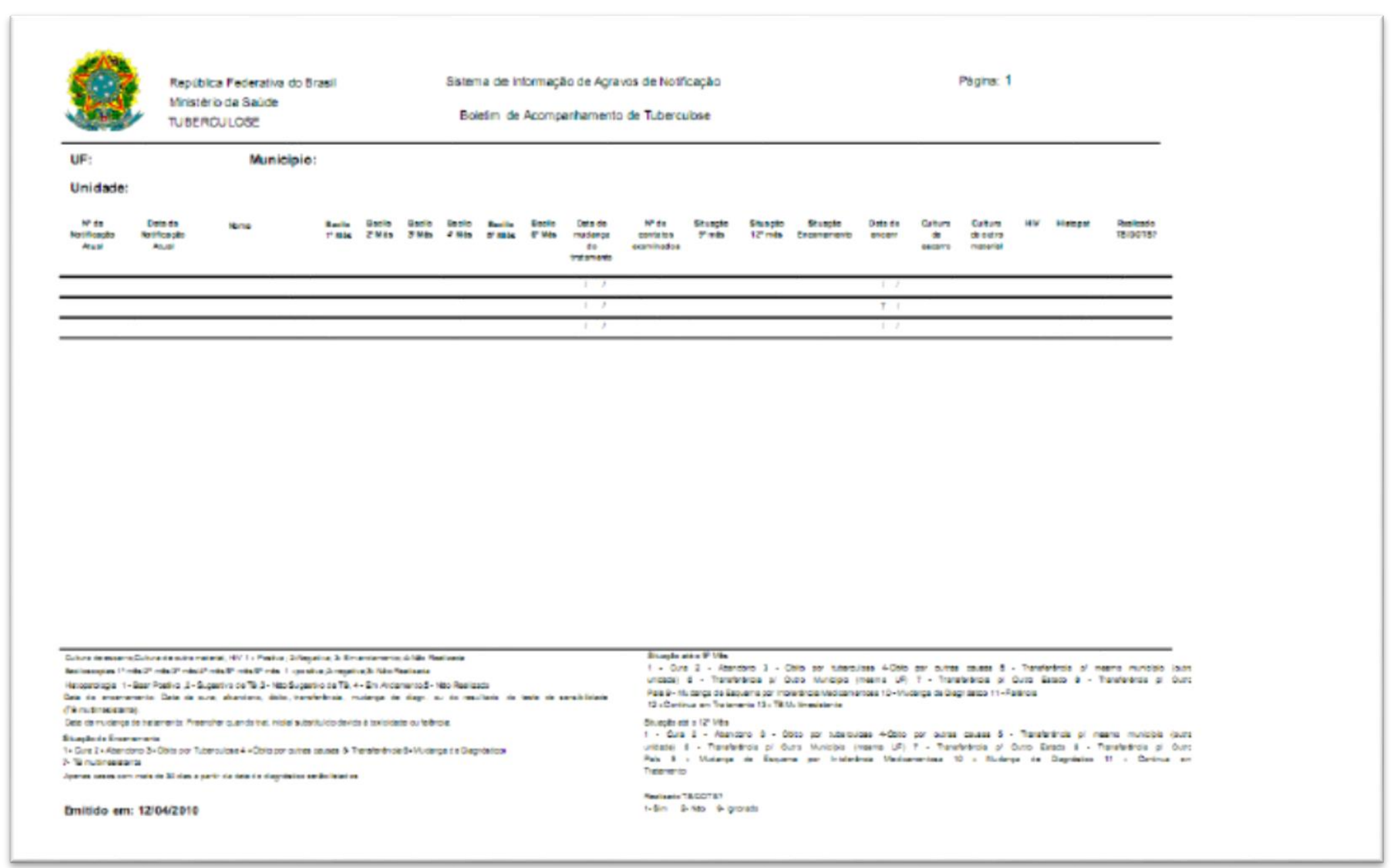


Anexo III- Nova Ficha de Notificação e Investigação da Tuberculose (a partir de 2015)

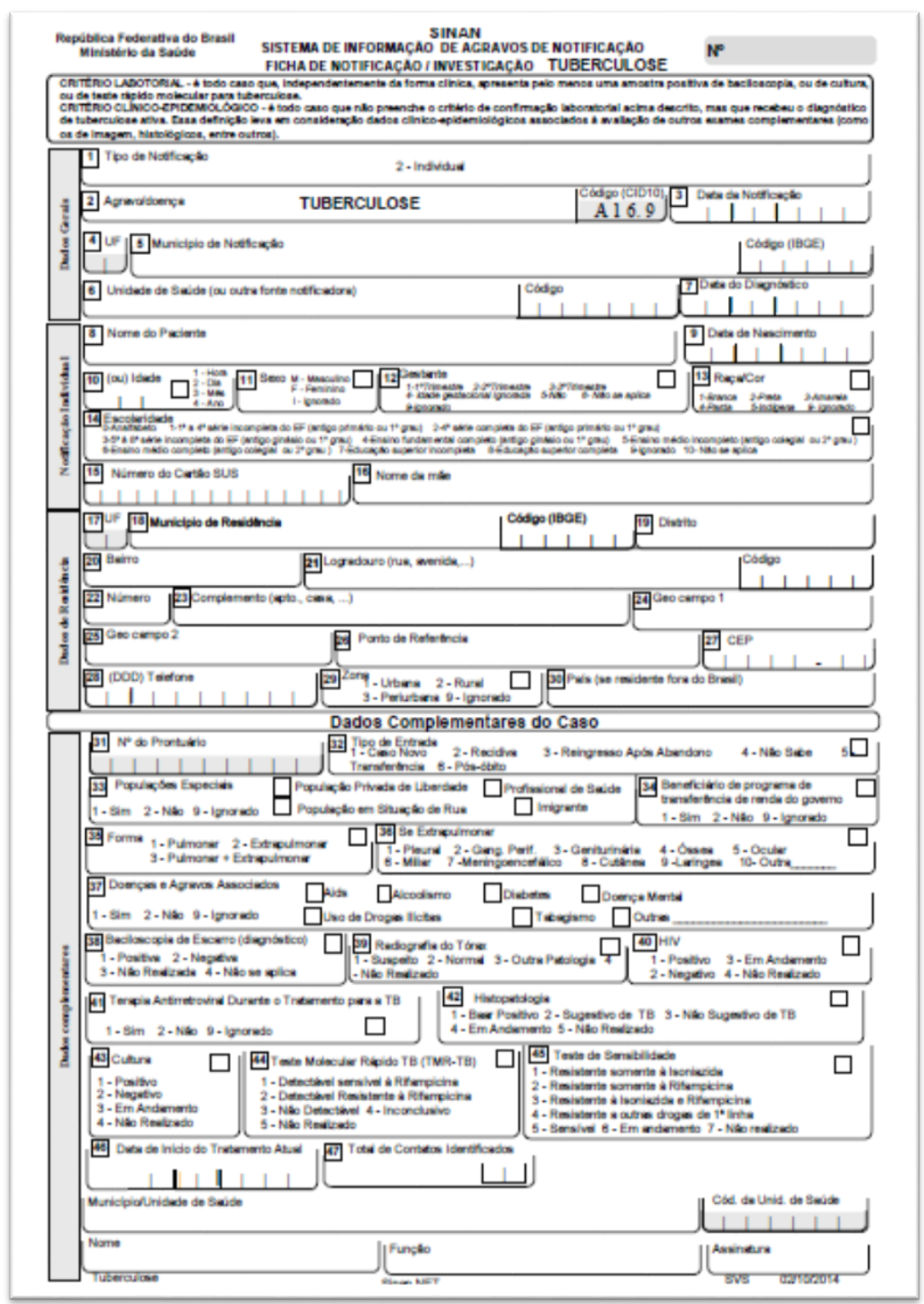


ANEXO IV- Boletim de Acompanhamento da Tuberculose (versão 2015)

\section{TELA DE ACOMPANHAMENTO DE TUBERCULOSE}

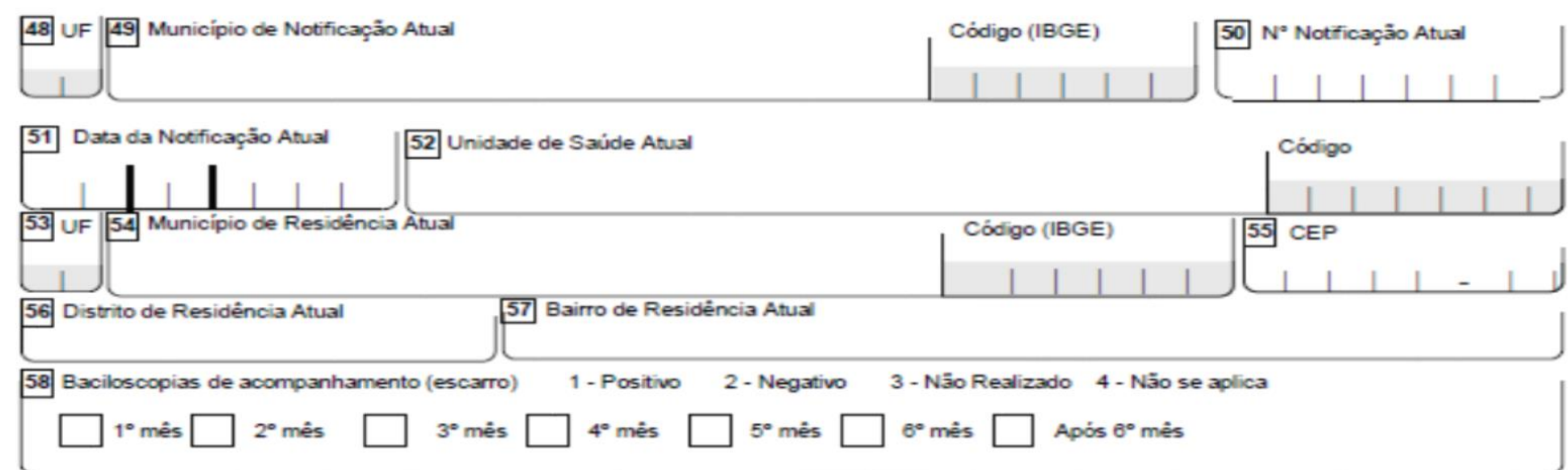

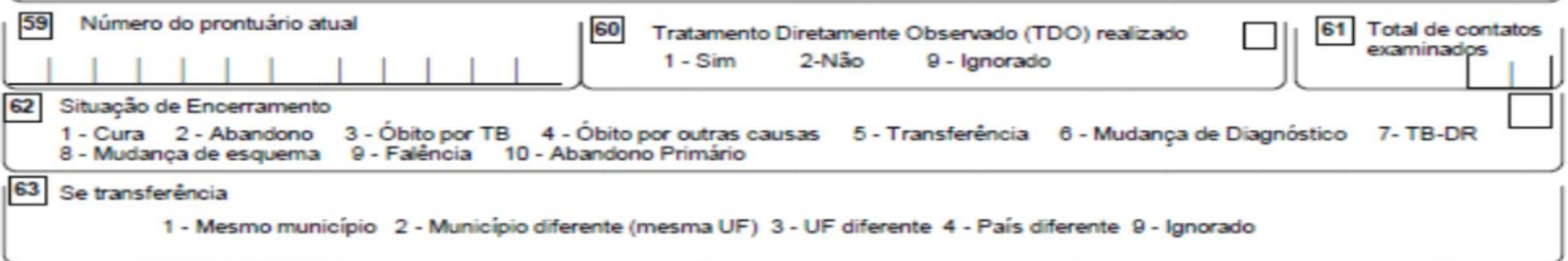

\begin{tabular}{|l||l|l|l|l|l|l|}
66 & Data de Encerramento \\
\hline
\end{tabular}


Anexo V- Tabela com as Atividades colaborativas TB-HIV por objetivo.

\section{OMS 2012}

\begin{tabular}{|l|}
\hline \multicolumn{1}{|c|}{ Atividades colaborativas TB-HIV } \\
\hline A. Estabelecer e fortalecer mecanismos para a oferta integrada de \\
serviços de TB e HIV \\
1. Estabelecer e fortalecer um mecanismo de coordenação para \\
atividades colaborativas em TB/HIV, funcionais em todos os \\
níveis; \\
2. Estabelecer a prevalência do HIV entre os pacientes com TB e \\
da TB entre PVHA; \\
3. Efetuar planejamento conjunto para integrar a prestação de \\
serviços de TB e HIV; \\
4. Monitorar e avaliar as atividades colaborativas TB/HIV.
\end{tabular}

B. Reduzir a carga de TB entre PVHA e iniciar precocemente o tratamento antirretroviral (os 3 l's)

1. Intensificar a busca de casos de TB e garantir tratamento anti-TB de alta qualidade;

2. Iniciar a prevenção da TB (tratamento da ILTB com Isoniazida) e o tratamento antirretroviral precoce;

3. Garantir o controle da infecção por TB nos estabelecimentos de saúde e em outros locais de aglomeração (por ex. prisões, quartéis, abrigos, etc.)

C. Reduzir a carga de HIV entre os pacientes com diagnóstico confirmado ou presuntivo de TB

1. Disponibilizar aconselhamento e testagem para HIV para os pacientes com diagnóstico confirmado ou presuntivo de TB Fornecer aconselhamento e testagem para HIV;

2. Disponibilizar intervenções de prevenção em HIV para pacientes com diagnóstico confirmado ou presuntivo de TB;

3. Disponibilizar a terapia preventiva com sulfametoxazol/trimetoprim para pacientes vivendo com HIV;

4. Garantir intervenções de prevenção em HIV, tratamento a cuidados para TB a PVHA;

5. Disponibilizar terapia antirretroviral para pacientes com TB vivendo com HIV.

Fonte: Adaptado do Interim Policy on Collaborative TB/HIV Activities, WHO 2004. 


\title{
Anexo VI - Ficha de notificação e investigação da AIDS
}

\author{
República Federativa do Bras| \\ Ministério da Saúde SISTEMA DE INFORMAÇAO DE AGRAVOS \\ FICHA DENOTIFICAÇAOIIVESTIGACÃO AIDS
}

Definição de caso: Para fins de notificaçăo entende-se por caso de aids o indivíduo que se enquadra nas definições adotadas pelo Ministério da Saúde. Os critérios para caracterização de casos de aids estão descritos em publlcaçäo específica do Ministério da Saúde (www.aids.gov.br).

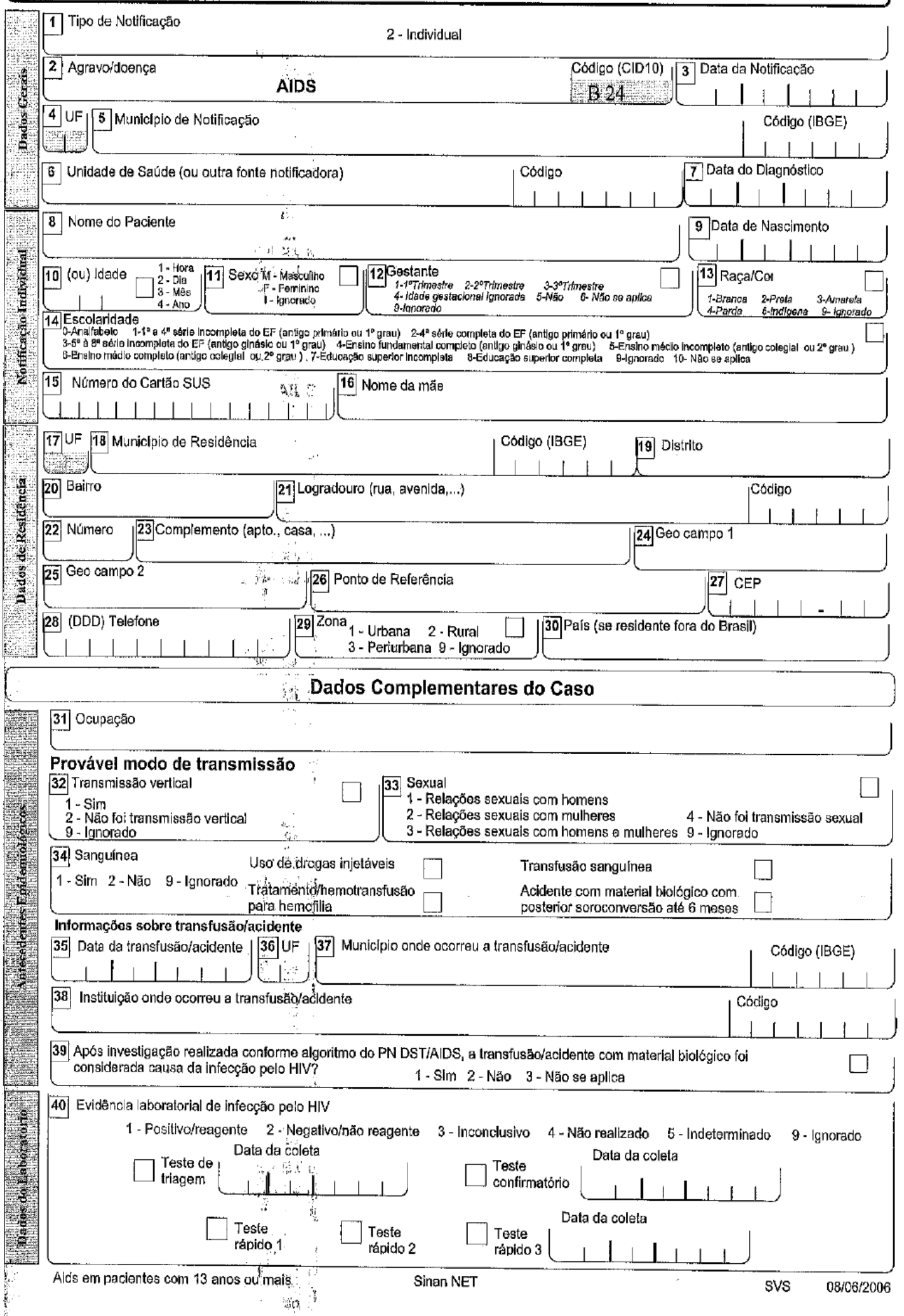




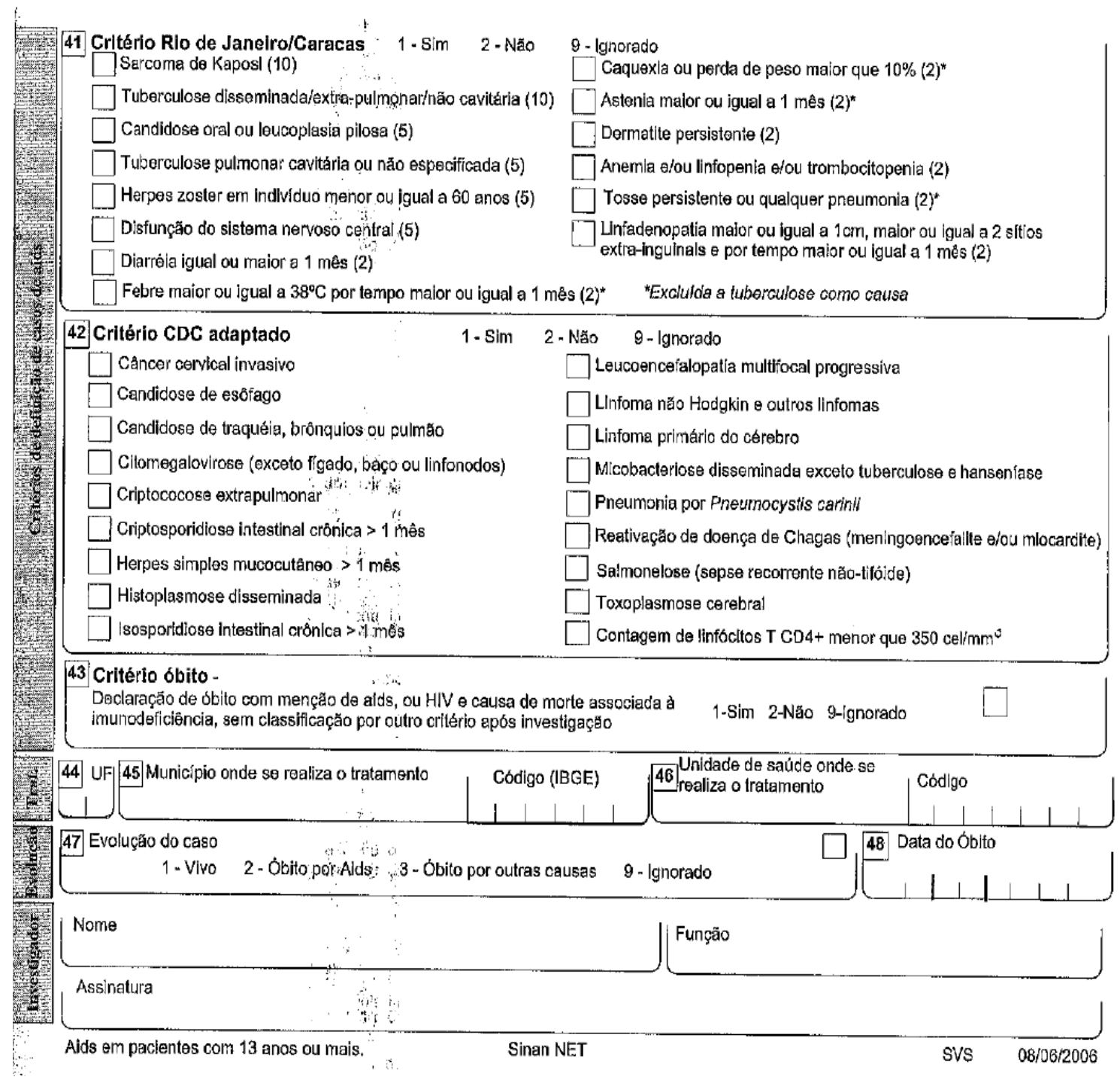




\section{Anexo VII - Fichas de solicitação de exames do SISCEL}

\section{1) Laudo Médico para emissão de BPA- Quantificação de Ácido Nucleio - Carga Viral}

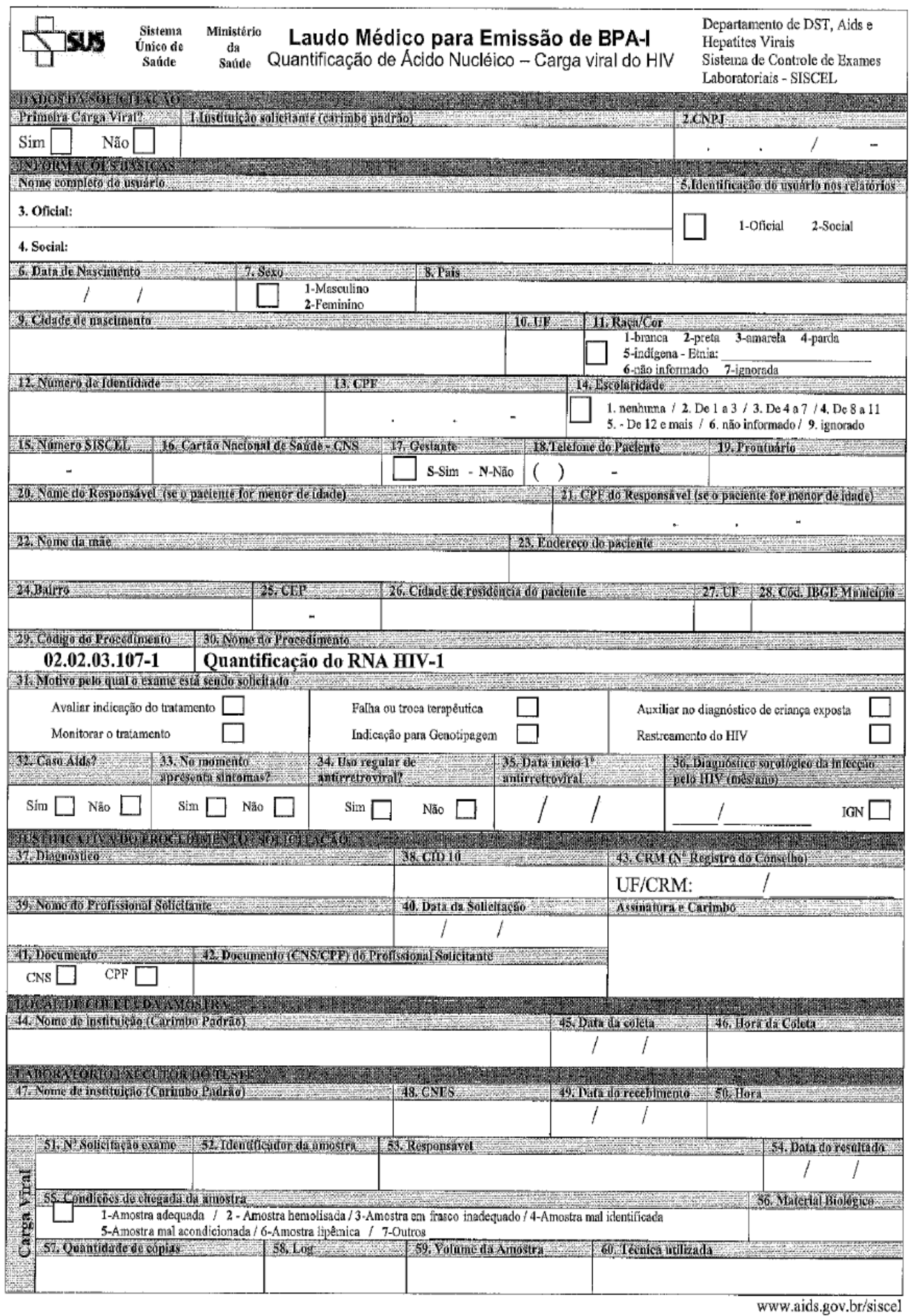




\section{2) Laudo Médico para emissão de BPA- Contagem de Linfócitos T CD4+/CD8+}

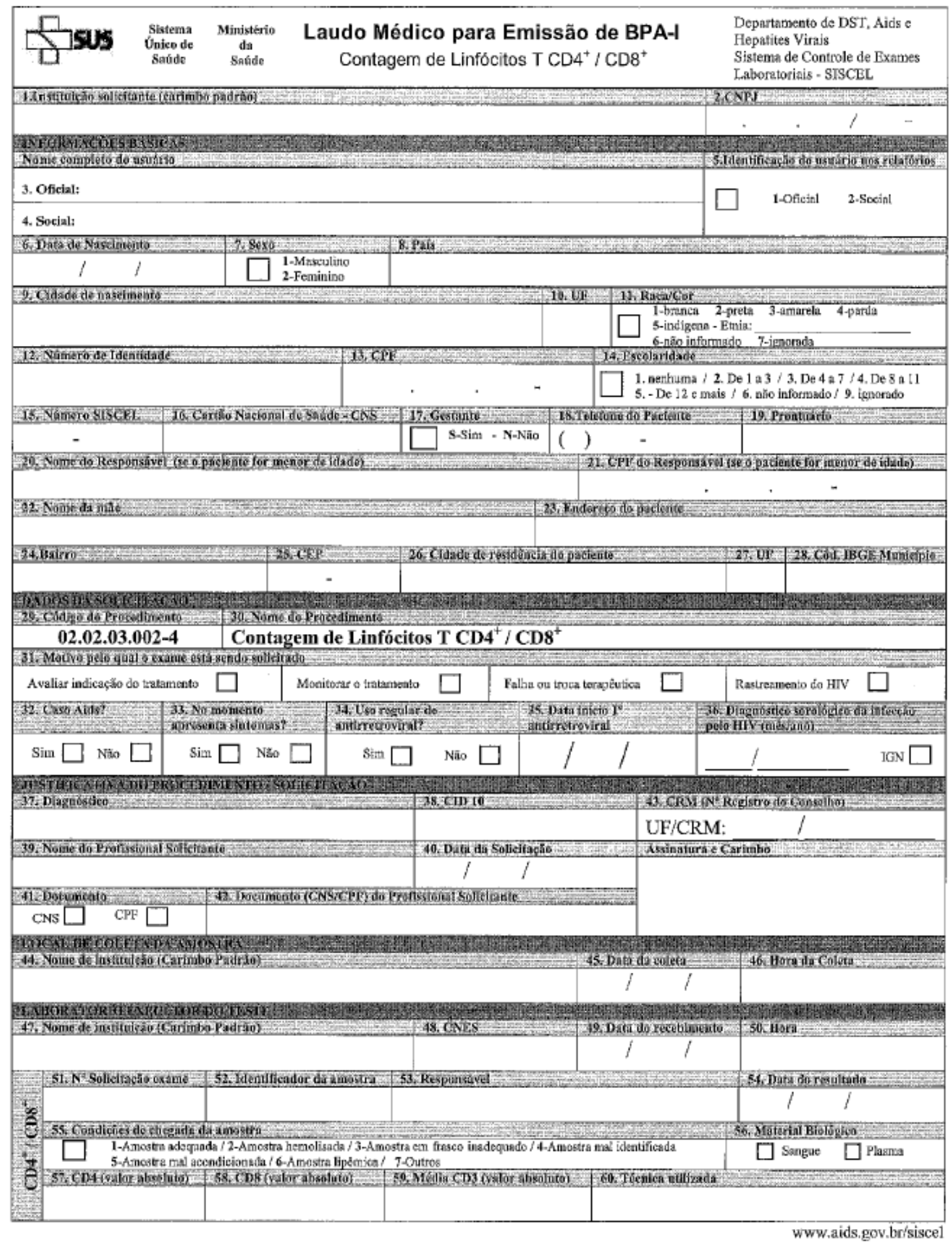




\section{Anexo VIII - Formulário de Solicitação de Medicamentos- SICLOM}

(modelo utilizado em 2011)

Formulário de Solicitação de Medicamentos

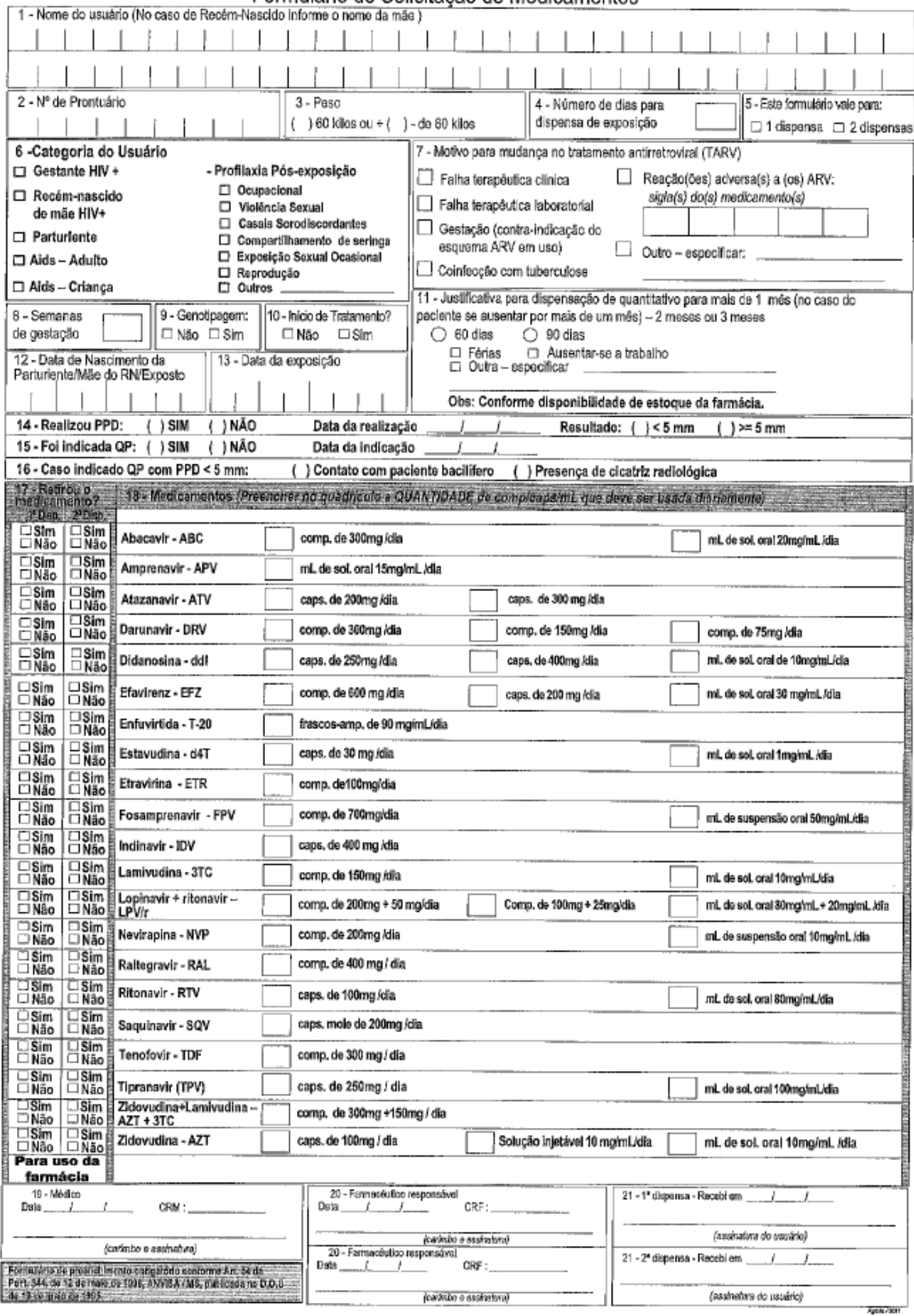


- Prosncher o formulário a caneta azul e em latra de forma legivel, dentro do espaco das lacunas. Formulário de preenchimento obrigatório conforme Art 54 da Port. 344, de 12 de maio de 1898, ANVISA/MS, publicada no D.0.U de 19 de máo de 1998.

2. A prascriçắo de medicamentos a base de substâncias antíretrovirais (lista 'C4"), só poderá ser feita por médico e será aviada ou dispensada nas farmáclas do Sistema Unico de Saúde, em formulário próprio estabelecido pelo Departamento de DST/ADS, onde a recoita ficará retída. A0 paciente, deverá ser entregue um receituário médico com informę̧oes scbre seu tratamento.

ATENĊ̃O: Cada usuário pode cadastrar-se em apenas uma unidade de saúde. Escollha a que for mais conveniente para você. "O

CADASTRAMENTO EM MAIS DE UMA UNIDADE SERA DETECTADO PELO SISTEMA E PODERA RESULTAR NA INTERRUPCCAO DO FORNECIMENTO DE MEDICAMENTOS".

Versảo março-2011

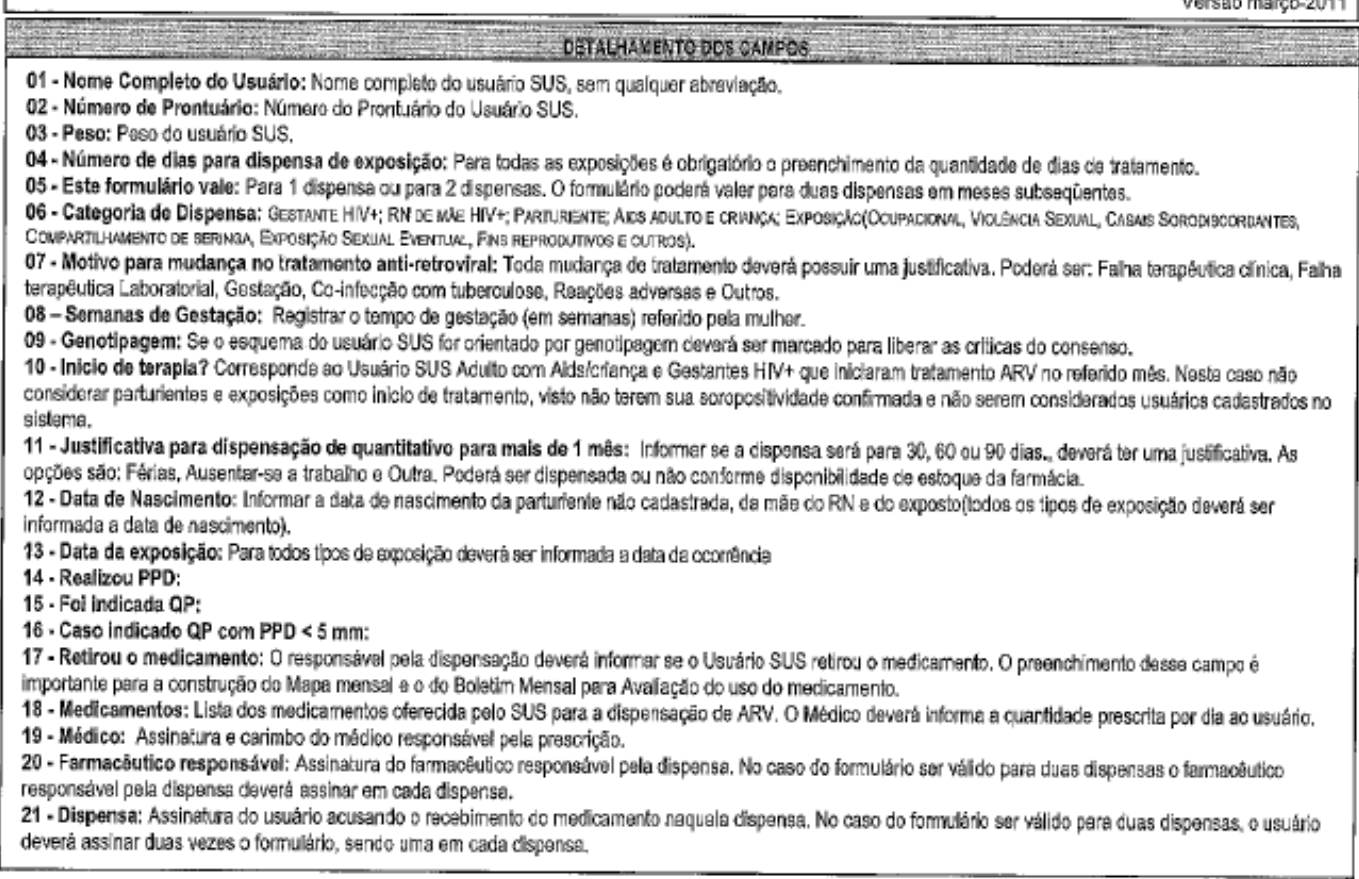




\section{Anexo IX -Declaração de Óbito}

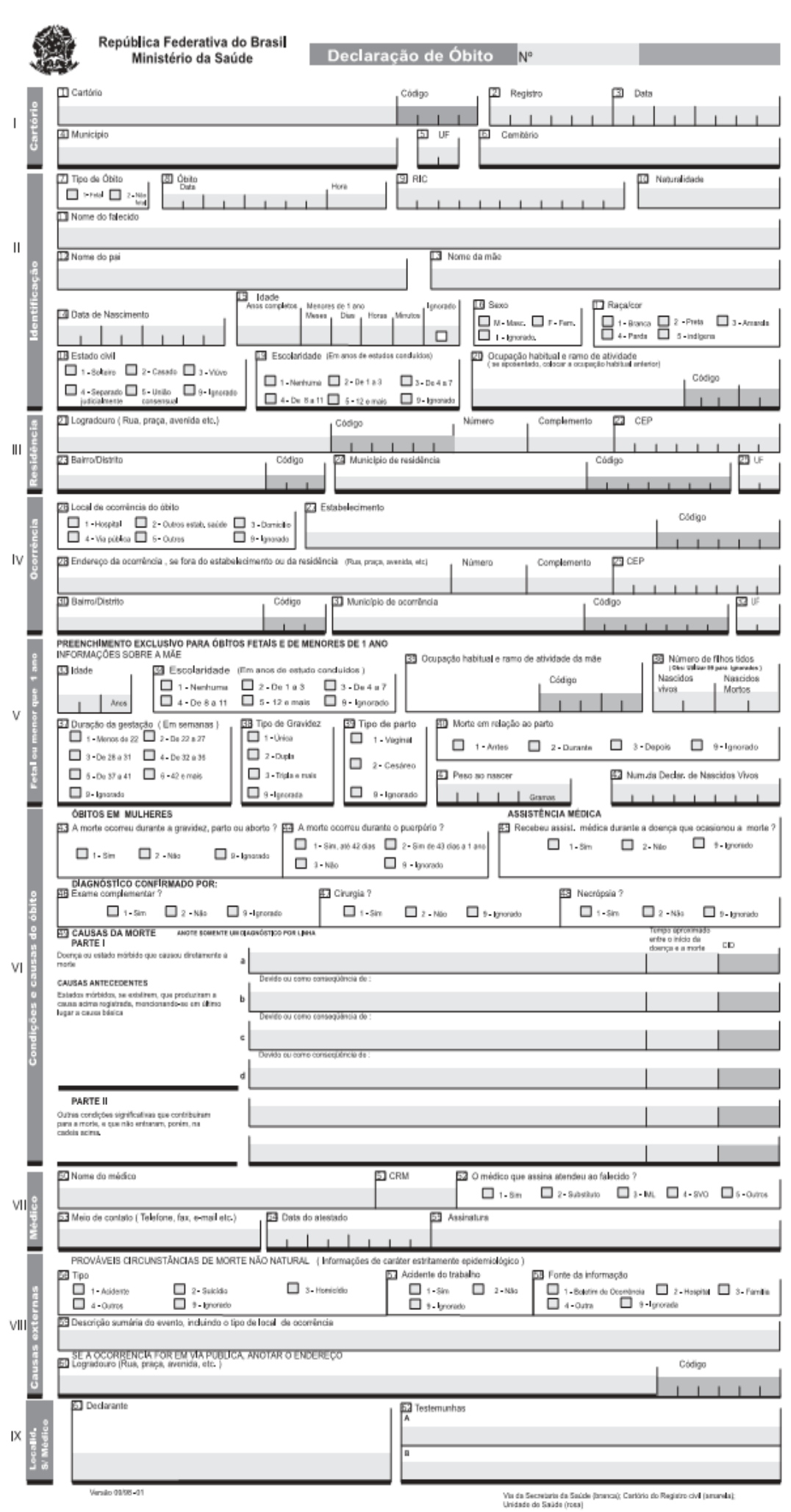


Anexo X- Liberação de base de dados da Secretaria de Vigilância em

Saúde.

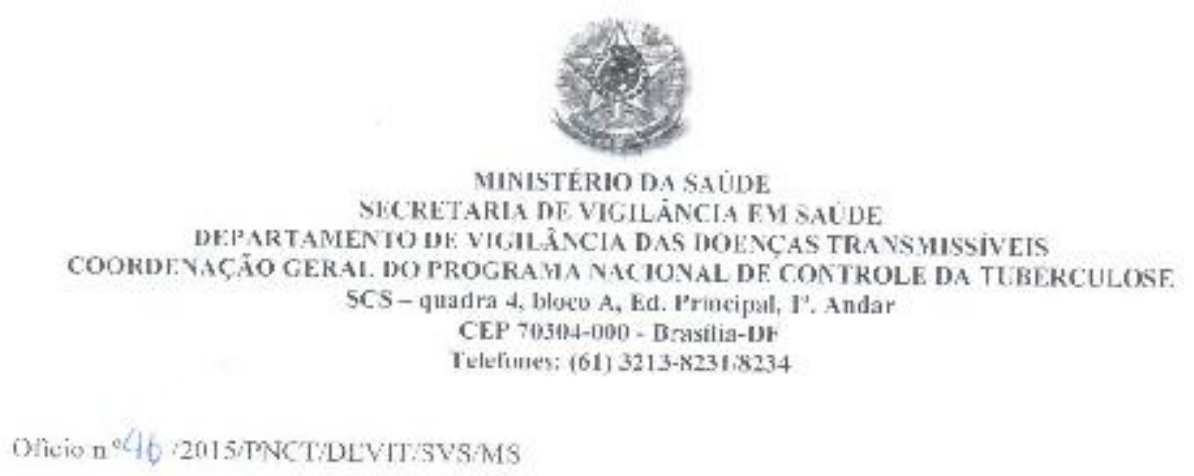

Brastis, de maic de 2015 .

A Scniture

TLR \ANDA DOCKIIORN COSTA JOLANSEN

Pexquisalora c Mestranda da Universidade de Brasilia

SMHN 2 - Cuatra 501, bloco A-FEl'ECS - Asa Norte

70710-904 Brasilia - DF

Assunto: Requerimento de hase de dados numinais da CGPNCT/DLVIT/SVS

Pruzada Senhora,

1. Eu dentimento ao ofiecio de solicitaçín de base de dados nominais para realizaçăo de pesquisa de uteresse em suúde públice na área da tuberculose. c ainda após avaltaçāo dos documentos encaminkados pura solicitaçào de acesso as bases e sigilo das informaçes pexsoais. informo que os Jados solicitados cr âo disponibilizados oport unamente. A equipe fécnica entrará em contato para informar os procedimentos.

2. O tema de sua pesquisa ć de grante intercsse para esta coordenaçăo. Favor divulgar os acsultaders para os programas de tuberculose.

Atenciosamentc,

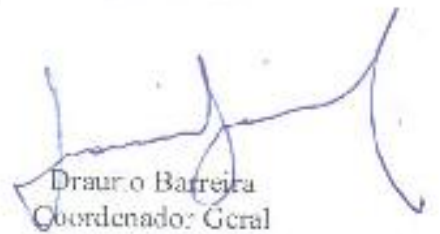

Coordenaçâo Geral do Programa Nacional de Controie da Tubcrculose 


\title{
Anexo XI- Termo de Responsabilidade e Compromisso do Pesquisador
}

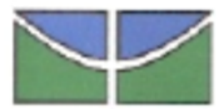 \\ Universidade de Brasilia \\ Núcleo de Medicina Tropical \\ Programa de Pós-Graduação om Medicina Tropica I

\section{TERMO DE RESPONSABILIDADE E COMPROMISSO DO PESQUISADOR}

EL, pesquisadora Fernanda Dockhorn Costa Johanaen, anb CPF no $079.799 .227-86$, mestranda da Universidade de Brasilia, residente na CLN 308, Bloco E, apt 204 da Asa Norte, Brasilia-DF. CEP 70.747-550. telefone: 6181463203 e pesquisadora responsável pelo projeto de pesquísa intitulado "FATORES ASSOCIADOS AO OBITO POR TUBERCULOSE E HIV NO BRASIL", me comprometo e me responsabilizo na conduçăo do projeto supracitado aoguindo os pressupcstos éticos previstos na resoluçăo 466 de 12 de dezembro de 2012 do Conselho Nacional de Saude. Desta forma. informo que os dados a aerem obtidos serăo preservados sob sigilo absoluto. assim como será mantido o principio da não malefickncia aos sujeitos de pesquisa, $\theta$ a manutençäo da equidade a todos 08 estudados. Como o estudo utilizará dádos eecundarios, coletados polos sistemas de vigiläncia das dcenças o compilados nas bases oficiais do Ministério da Saude, dispensa-se a utilizaçâo de Termo de Consentimento Livre EsclarecidoTCLE. No entanto, será assegurado aos sujeitos da pesquisa 0 aigilo absoluto dos dados e sob nonhuma hipotese 08 dados que identifiquem os paciontes serð̃o divulgados. Outrossim, espera-se que este estudo possa contribuir como passivel instrumento de gestao para ser utilizado na tomada de decisão. Possibilita-se ascim, o investimento futuro em programas nacionais e regicnais para a alocaçáo prioritária do recursos.

Atenciosamente,

Brasilia, 27, 11,2014

funander Socklienv Corta foharan

Fernanda Dockhorn Costa Johansen

Pesquisedora responsável pelo protocolo de pesquisa 


\section{Anexo XII- Aprovação do Comitê de Ética em Pesquisa}

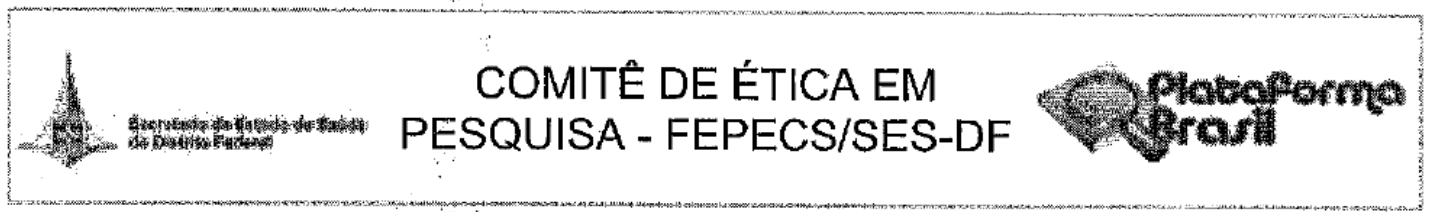

PARECER CONSUBSTANCIADO DO CEP

\section{DADOS DO PROJETO DE PESQUISA}

Título da Pesquisa: Fatores assọciados ao óbito por tuberculose e HIV no Brasil

Pesquisador: Fernanda Dockhorn Costa Johansen

Área Temática:

Versão: 1

CAAE: 39872114.2 .0000 .5553

Instituição Proponente: Secretaria de Estado de Saúde do Distrito Federal / FEPECS/ SES/ DF

Patrocinador Principal: Financiamento Próprio

\section{DADOS DO PARECER}

Número do Parecer: 943.158

Data da Relatoria: $01 / 02 / 2015$ *tot:

\section{Apresentação do Projeto:}

A tuberculose (TB) permanece como um grave problema de saúde pública de relevância mundial e obedece a todos os critérios de priorização de um agravo em saúde pública, ou seja, de grande magnitude, transcendência e vulnerabilidade.

É freqüente a descoberta da soropositividade para HIV durante o diagnóstico de TB. Estima-se no Brasil que, embora a oferta de testagem seja de aproximadamente $70 \%$, apenas cerca de $60 \%$ das pessoas com tuberculose têm acesso ao seu resultado em momento oportuno, com uma prevalência de positividade de $10 \%$.

Alguns avanços têm sido alcançădos no Brasil, porém os desfechos dos casos de coinfecção TB-HIV ainda é desafiador. A meta das atividades colaborativas em TB-HIV é reduzir a carga da TB e do HIV entre as pessoas com maior risco de adoecerem com por ambas as enfermidades ou já afetadas por estas, o que leva, na maioria das vezes, a interrupção de todo o esquema. Outros aspectos podem impactar na mortalidade na coinfecçáo, como a precocidade no diagnóstico da tuberculose e do HIV, o acesso aos serviços de saúde e exames labóoratoriais além das próprias condições de vida da população.

$\begin{array}{lll}\text { Objetivo da Pesquisa: } & \\ \text { Geral: } & & \end{array}$

Endereço: SMHN 2 Qd 501 BLOCO A - FEPECS

Bairro: ASA NORTE

UF: DF Município: BRASILIA

Telefone: (61)3325-4955 Fax; (33)3325-4955 E-mail: comitedeetica.secretaria@gmail.com 


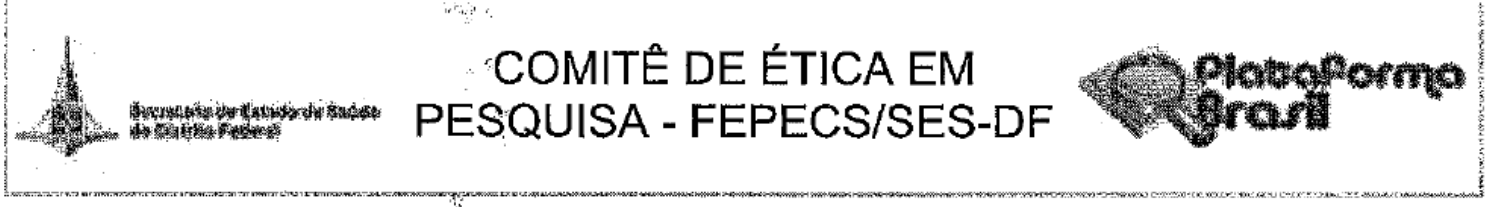

Continuaçăo do Parecer: 943.158

- Identificar fatores associados ao óbito na coinfecção TB-HIV no Brasil em

2011.

Especificos:

- Descrever o perfil clínico-epidemiológico da coinfecção TB-HIV por Unidade

Federada.

$\therefore$ is

- Descrever os óbitos por coinfecçãó TB-HIV por Unidade Federada.

- Calcular a mortalidade por TB-HIV no Brasil em 2011.

$$
\text { it }
$$

Avaliação dos Riscos e Beneflclos:

Os sujeitos foram adequadamente identificados. Os benefícios e os riscos da pesquisa foram apresentados, onde se espera um investimento futuro em programas nacionais e regionais para a alocação prioritárias de recursos, sem nenhuma maleficência aos sujeitos de pesquisa. Os antecedentes científicos que justificam a pesquisa foram apresentados.

\section{Comentários e Considerações sobre a Pesquisa:}

Trata-se de um estudo descritivo em que será demonstrado o perfil clínico epidemiológico dos pacientes e óbitos por TB-HIV no Brasil em 2011. Além disso, será conduzido um estudo caso-controle para estudar fatores de associados ao óbito por TB-HIVIAIDS, sendo esperados por volta de 2500 casos.

A população alvo e população do estudo serão pessoas que vivem com HIV, adultos e adolescentes ( 15 anos), registrados no Sinan, Siscél, Siclom ou SIM que apresentaram diagnóstico de tuberculose no ano de 2011.

Os dados serão coletados dos sistemas de informação do Departamento de DST, Aids e Hepatites Virais e da Coordenação Geral do Ṕrbogramía Nacional de Controle da Tuberculose da Secretaria de Vigilância em Saúde/Ministério da Saúde: SINAN (Sistema de Informações de Agravos de Notificação de AIDS e Tuberculose), SISCEL (Sistema de Controle de Exames Laboratoriais), SICLOM (Sistema de Controle Logístico de Medicamentos) e SiM(Sistema de Informações de Mortalidade).

Será realizada uma análise exploratória, descritiva e analítica com Intervalo de confiança de 95\% e erro de $5 \%$. Será realizada análise por núultinível. Programa de análise o SPSS versão 2.0 .

Esse trabalho foi submetido paraípublicação na revista Journal of American Society of Tropical Medicine and Higyene.

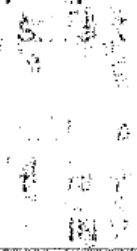

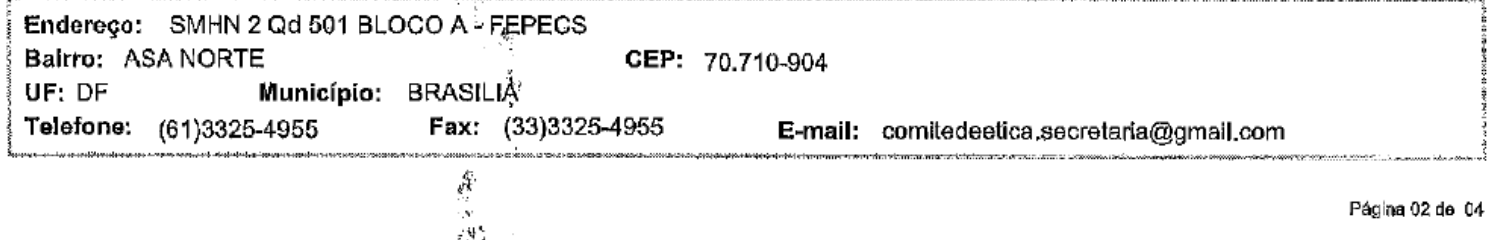




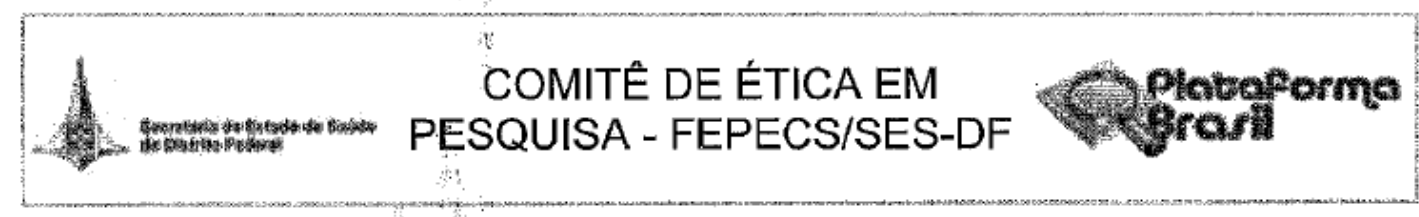

Continuaçắo do Parecer: 943.158

Consideraçōes sobre os Termos de apresentação obrigatória:

Folha de rosto: Apresentada. Documento assinada pela professora da FEPECS/SES/DF.

Termo de Concordância: Apresentado. Documento assinado pelo Coordenador do Programa Nacional de Controle da Tuberculose da Secretaria de Vigilância em Saúde/Ministério da Saúde.

Curriculum Vitae do(s) pesquisador(es): Apresentados.

Cronograma da Pesquisa: Apresentado.

Planilha de orçamento: Apresentấda.

Dispensa TCLE: Apresentado.

Critérios de Inclusẵa e Exclusão: Définidos.

\section{Recomendações:}

O pesquisador assume o comṕrbmisso de garantir o sigilo que assegure o anonimato e a privacidade dos sujeitos da pesquisa e a confidehciąlidade dos dados coletados. Os dados obtidos na pesquisa deverão ser utilizados exclusivamente para a finạlidade prevista no seu protocolo, que só poderá iniciar após aprovação pelo CEP/FEPECS/SES/DF.

O pesquisador deverá encaminhar relatório final ao término da pesquisa.

政.

Conclusões ou Pendências e Lișta de Inadequações:

- Projeto Aprovado.

Situação do Parecer:

Aprovado

(i)

Neçessita Apreciação da CONEP:

Não

Considerações Finais a critério do CEP:

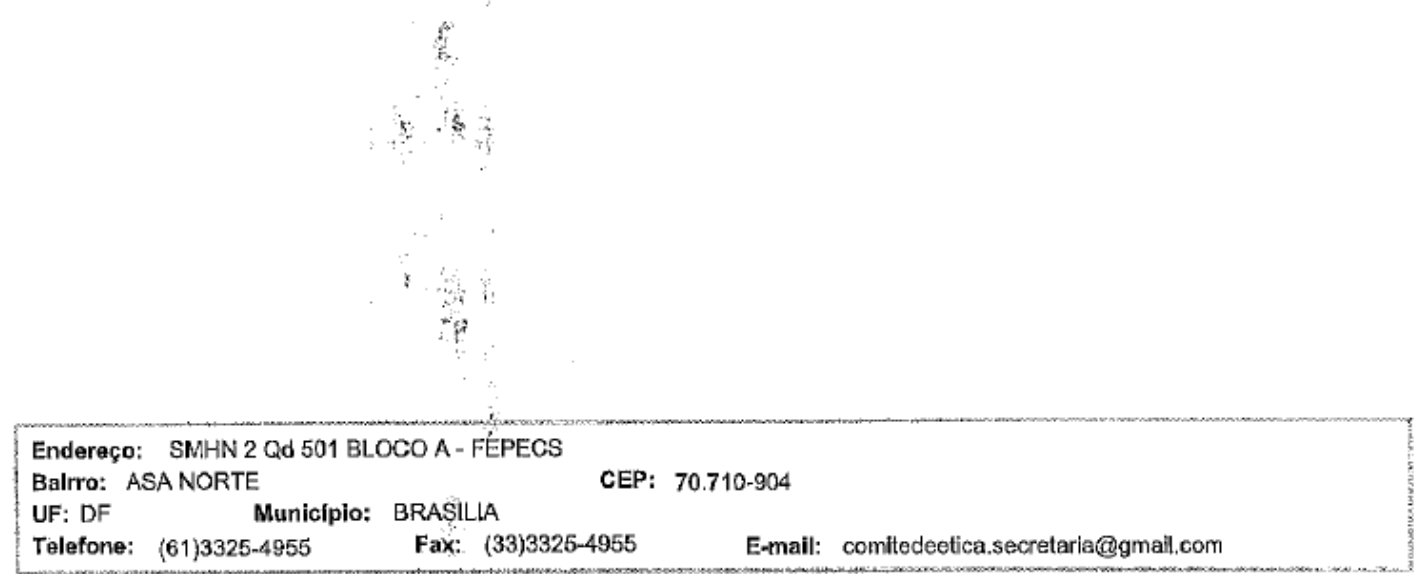




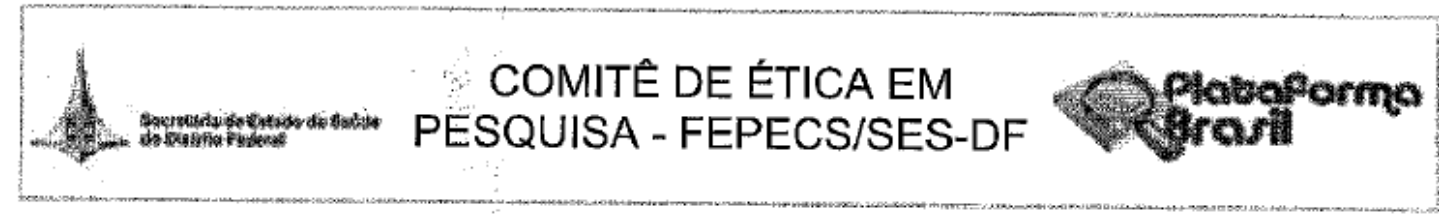

Continuaçăc do Parecer; 943.158

BRASILIA, 02 de Fevereiro de 2015

Assinado por:

Helio Bergo

(Coordenador)

Endereço: SMHN 2 Qd 601 BLOCO A - FEPECS

Bairro: ASA NORTE

UF: DF

CEP: $70.710-904$

Telofone: (61)3325-4955

Fax: (33)3325-4955

E-mail: comitedeetica.secretaria@gmall.com

Pagina 04 de 04 